XXV.

Aus der chirurg. Universitätsklinik zu Kiel (Prof. Helferich).

\title{
Ein Beitrag zur Pathologie und Therapie des inneren Darmverschlusses.
}

Von

Dr. Rudolf Göbell,

Oberarzt und Privatdocent.

(Mit 6 Abbildungen.)

Nicht die von Tag zu Tag sich mehrenden Berichte über einzelne mit Glück operierte Fälle von innerem Darmverschlnß sind imstande, ein richtiges Bild von seiner Heilungsmöglichkeit zu geben, sondern nur die lückenlose Darstellung aller Fälle, bei welchen wegen Ileus in einer Klinik oder einem Krankenhause operativ vorgegangen ist.

Es erscheint uns deshalb nicht wertlos, über sämtliche Fälle von Darmverschluß, welche seit dem April 1899, d. h. seitdem Herr Geheimrat Helferich die Leitung der chirurgischen Klinik zu Kiel übernommen hat, von uns beobachtet sind, hier Bericht zu erstatten. Dabei wird sich Gelegenheit bieten, mancherlei Interessantes zur Ätiologie ‘des Darmverschlusses zu bringen, auf die diagnostischen Schwierigkeiten in gewissen Fällen hinzuweisen und zu zeigen, welche Gesichtspunkte die Behandlung des Ileus in der hiesigen Klinik leiten.

Nur vom mechanischen Ileus soll hier die Rede sein, der dynamische wird nur insofern berücksichtigt werden, als er sekundär zum mechanischen hinzutritt, und soweit er nicht durch Peritonitis bedingt war. Vom 1. IV. 1899 bis zum 1. IV. 1906 wurde in der hiesigen Klinik bei 58 Patienten wegen mechanischen Darmverschlusses ein chirurgischer Eingriff vorgenommen, bei 5 weiteren wegen eines dynamischen, nicht auf Peritonitis beruhenden Ileus. 
Eiu Beitrag zur Pathologie und Therapie des inneren Darmverschlusses. 417

Von den 58 Patienten mit mechanischem Darmverschluß wurden 54 deswegen aufgenommen, bei 4 Patienten war er die unmittelbare Folge von in der Klinik vorgenommenen Operationen.

Von den 54 wurden 26 (48,1 Proz.), von den 58 wurden 29 (50 Proz.) geheilt.

Um akuten Darmverschluß handelte es sich bei 47 Patienten (44,6 Proz. Heilung), um chronischen Ileus bei 11 Patienten (90,9 Proz. Heilung).

Von 34 rechtzeitig Operierten wurden 26 (76,4 Proz.) von 24 zu spät Operierten 3 (12,5 Proz.) geheilt.

Unter den 58 Fällen von mechanichem Ileus lag vor:

21 mal eine Strangulation (14,2 Proz. Heilung)

6 mal eine Invagination ( $33 \frac{1}{3}$ Proz. Heilung)

31 mal eine Obturation (74,1 Proz. Heilung).

Darüber, wie oft die verschiedenen Mechanismen den Verschluß verursacht hatten, gibt die 'Tabelle auf S. 419 Auskunft.

Welche ätiologischen Momente in Betracht kamen, zeigt folgende Aufzählıng:

Kongenitale Veränderungen

I. Diverticulum Meckelii

II. Kongenitale Lageveränderungen des Darms

a) abnorme Beweglichkeit des Cöcum u. Col. ascendens 1

b) retroperitonealer Verlanf des unteren Ileumendes . 1

c) abnorm lange Flexura sigmoidea . . . . . . . . 4

Mesenterialschlitze

Nach Brucheinklemmung:

Ringbildung des Bruchlarms . . . . . . . . . 1

Netz-Adhäsion nach Herniotomie . . . . . . . . 1

Nach Appendicitis:

a) Veränderungen der Appendix . . . . . . . . . 2

1 mal Kommunikation derselben mit dem Ileum

1 mal Fixierung der Appendixspitze

b) Adhäsionen . . . . . . . . . . . . . . . . ๖

c) Mesenteriitis . . . . . . . . . . . . . . . . 1

Frühere Laparotomien . . . . . . . . . . . . . . . . 6

Adhäsionen: 4 chirurg., 2 gynäkol. Operationen.

Uterus und Adnexerkrankungen . . . . . . . . . . . . 1

Auf Tuberkulose beruhende Veränderungen des Darms, der Serosa und des Peritoneum 
Geschwülste: 5 mal Darmgeschwülste, 1 Peritonealsarkom 1 Ovarialkystom.

Fremakörper

Gallenstein . . . . . . . . . . . . . . 1

Ascaris . . . . . . . . . . . . . . . . . . . . 1

Murphyknopf . . . . . . . . . . . . . . . . . . 1

Adhäsionen unbekannter Herkunft. . . . . . . . . . . . 3

Unaufgeklärt . . . . . . . . . . . . . . . . . . . . 2

Allein durch die Peristaltik entstanden. . . . . . . . . 7

Trauma . . . . . . . . . . . . . . 1

Leichtenstern $\left.{ }^{1}\right)$, Meinhard Schmidt ${ }^{2}$ ), Hilgenreiner ${ }^{3}$ ) und viele andere haben so ausführliche Abhandlungen über den durch das Diverticulum Meckelii bewirkten Darmverschlnß gebracht, daß man es sich nunmehr versagen kann, bei jedem neuen derartigen Fall alle Möglichkeiten der Entstehung des Darmverschlusses durch ein Meckelsches Divertikel zu erörtern.

Daß auch unser Fall seine Besonderheiten hat, wird sich aus der späteren Besprechung ergeben.

Nach Eppinger ${ }^{4}$ ) und Küttner ${ }^{5}$ ) soll der retroperitoneale Verlauf des unteren Ileumendes eine Prädisposition für Achsendrehung des Dünndarms schaffen. Diese Anomalie ist als eine kongenitale und als eine gewisse Seltenheit anzusehen. So fand Wandel ${ }^{6}$ ) bei 640 Sektionen ein bewegliches Cöcum und Colon ascendens $66 \mathrm{mal}$, den retroperitonealen Verlauf des unteren Ileumendes nur 4 mal. In diesen 4 Fällen hatte die Radix Mesenterii einen steileren Verlauf, sie endigte lateral nicht am Cöcum, eine handbreite Partie des Ileum war an der hinteren Bauchwand angelötet.

Nenerdings hat Philipowicz ${ }^{7}$ ) sich durch seine bei der Ope-

1) Leichtenstern, Ziemssens Handb. d. spez. Pathol. Bd. VII, H. 2, S. 443.

2) Meinhard Schmidt, Meckelsches Divertikel und Ileus. Deutsche Zeitschr. f. Chir. Bd. 54, S. 144.

3) Hilgenreiner, Darmverschluß durch das Meckelsche Divertikel. Beiträge z. klin. Chir. Bd. 33, S. 702. Ausführliche Literatur: Zentralblatt f. d. Grenzgebiete der Chir. und Med. Bd. 8, Nr. 11-15; A. DreifuB, Das Diverticulum Meckelii.

4) Prager Vierteljahrsschrift für Heilkunde 1873.

5) Virchows Archiv, Bd. 43.

6) Mitteilungen aus den Grenzgebieten der Chirurgie und Medizin, Bd.11, S. 39.

7) Langenbecks Arch., Bd. 76, S. 443. 
Ein Beitrag zur Pathologie und Therapie des inneren Darmverschlusses. 419

\begin{tabular}{|c|c|c|c|c|c|c|c|c|c|}
\hline \multirow{2}{*}{$\begin{array}{l}\text { Verschluß ist } \\
\text { zustande gekom- } \\
\text { men durch }\end{array}$} & \multirow{2}{*}{ 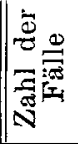 } & \multirow{2}{*}{$\begin{array}{l}\stackrel{2}{\overrightarrow{9}} \\
\stackrel{9}{9} \\
50\end{array}$} & \multirow{2}{*}{ 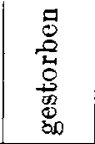 } & \multicolumn{2}{|c|}{$\left|\begin{array}{c}\text { rechtzeitig } \\
\text { operiert }\end{array}\right|$} & \multicolumn{2}{|c|}{$\begin{array}{l}\text { zu spät } \\
\text { operiert }\end{array}$} & \multirow{2}{*}{ 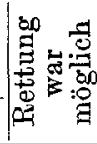 } & \multirow{2}{*}{ 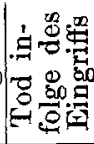 } \\
\hline & & & & geh. & gest. & geh. & gest. & & \\
\hline Volvulus . . . & 14 & 2 & 12 & 1 & 5 & 1 & 7 & 4 & 3 \\
\hline $\begin{array}{l}\text { Innere Einklem- } \\
\text { mung . . . . }\end{array}$ & 8 & 3 & $\overline{5}$ & 3 & 2 & - & 3 & 2 & 1 \\
\hline Invagination . . & 6 & 2 & 4 & 2 & - & - & 4 & 4 & 1 \\
\hline Torsion u. Knickg. & 13 & 9 & 4 & 8 & - & 1 & 4 & 2 & - \\
\hline $\begin{array}{c}\text { Umschnürung des } \\
\text { Darms. . . . }\end{array}$ & 2 & - & 2 & - & - & - & 2 & 2 & - \\
\hline $\begin{array}{l}\text { Äußere narbige } \\
\text { Stenose. . . . }\end{array}$ & 1 & 1 & 一 & 1 & - & - & - & 一 & - \\
\hline $\begin{array}{l}\text { Innere narbige } \\
\text { Stenose. } \cdot \cdot \cdot\end{array}$ & 2 & 1 & 1 & 1 & - & - & 1 & 1 & - \\
\hline $\begin{array}{l}\text { Carcinomatöse } \\
\text { Striktur . . . }\end{array}$ & 4 & 4 & 一 & 4 & - & - & - & - & - \\
\hline Fremdkörper . . & 3 & 3 & - & 2 & - & 1 & - & 一 & - \\
\hline Nicht sichergestellt & 1 & 1 & - & 1 & - & - & - & - & - \\
\hline Summe: & 54 & 26 & 28 & 23 & 7 & 3 & 21 & 15 & $\overline{5}$ \\
\hline $\begin{array}{c}\text { Postoperativer } \\
\text { mech. Ileus . . }\end{array}$ & 4 & $48,1 \%$ & $51,9 \%$ & $76,6 \%$ & $23,4 \%$ & $12,5 \%$ & $87,5 \%$ & $60 \%$ & - \\
\hline Summe: & 58 & 29 & 29 & 26 & 8 & - & - & 一 & - \\
\hline Dynamiseher Ileus: & & $50 \%$ & $50 \%$ & $76,4 \%$ & $23,6 \%$ & - & - & 一 & - \\
\hline ohne Peritonitis & 4 & 1 & 3 & 1 & 1 & - & 2 & - & - \\
\hline durch Pankreatitis & 1 & 1 & - & 一 & - & 一 & - & 一 & - \\
\hline Gesamtsumme: & 63 & $\begin{array}{c}31 \\
\pm 9,2 \%\end{array}$ & $\left|\begin{array}{c}32 \\
50,8 \%\end{array}\right|$ & $\begin{array}{c}27 \\
75 \%\end{array}$ & $\begin{array}{c}9 \\
25 \%\end{array}$ & $\begin{array}{c}3 \\
11,5 \%\end{array}$ & $\begin{array}{c}23 \\
88,5 \%\end{array}$ & - & - \\
\hline
\end{tabular}

ration von Dünndarmvolvuli erhobenen Befunde zu der Annahme veranlaßt gesehen, daß die Entstehung der Dünndarmvolvuli begünstigt werde durch eine Schrumpfung und Verkürzung des Mesenterium des untersten Ileum. Diese Veränderung des Mesen- 
terium sieht er an als die Folge einer Mesenteriitis ähnlicher Art, wie sie Virchow im Mesosigmoideum beschrieben hat. In unserem Fall 34 wurden starke, nur wenig narbig aussehende, im Mesenterium des untersten Ileum liegende Stränge konstatiert, welche das Mesenterium stark verkürzten und vom Mesocöcum in radiärer Ordnung in das Mesenterium hineinzogen. Die Mesenterialblätter waren entfaltet. Das Ileum lag sozusagen retroperitoneal. Die Stränge hatten durch verschieden starken Zug eine Drehung des Darms um seine Längsachse bewirkt, außerdem war eine Verengerung des Darms vorhanden. Die Appendix war normal, es waren keine Zeichen einer Mesenteriitis sichtbar. Das Peritoneum war überall glatt. Wir glaubten nach diesem Befund eine Mesenteriitis ausschließen zu können. Daß eine solche in der Kindheit sich hier abgespielt hat und der jetzige Befund das Endresultat derselben darstellt, ist möglich.

Jedenfalls unterschied sich dieses Bild sehr wesentlich von den anderen, welche sich uns bei unzweifelhaft vorhandener Mesenteriitis darboten.

Nur beim Pat. K. J. (J.-N. 21, 1904) ist die Mesenteriitis auf eine chronische Appendicitis mit Wahrscheinlichkeit zurückzuführen. Wenigstens war die Appendix in Adhäsionen eingebettet und enthielt einen Kotstein. In dem Peritoneum des Mesenterium verliefen viele nach dem Darm hin ausstrahlende Narbenzüge, das Mesenterium war verkïrzt und enthielt bis erbsengroße harte Drüsen. An 4 Stellen umgriffen die strahligen Narbenzüge den Darm und hatten an jeder dieser Stellen eine Stenose herbeigeführt, die Darmschleimhaut war normal.

In den übrigen Fällen (8. 16. 19. 38. 39. 40. 42). war die Ursache der Mensenteriitis stets Tuberkulose.

3 mal war der Dünndarm in Mesenteriallücken, die dicht am Darm gelegen waren, stranguliert. Daß Mesenteriitis zur Bildung von Lücken im Mesenterium führen sollte, ist schwer zu begreifen. Die Hypothese, daß sich zwischen zwei narbigen Strängen eine Art Tasche gebildet hätte und der Darm beim Hineingepreßtwerden diese Tasche sprengte, würde schon eher Beifall finden. Daß es kongenitale Mesenteriallücken gibt, ist bis jetzt nicht bekannt. Zwei von den Lücken bildeten in sonst normalen Mesenterien, eine in einem tuberkulösen, Schlupflöcher für den Darm.

Von einer Appendicitis leiteten sich die Veränderungen, welche den Darmverschluß herbeiführten, 8 mal her. Selbstverständlich fanden die Fälle, in denen akute Appendicitis mit Darmverschluß 
Ein Beitrag zur Pathologie und Therapie des inneren Darmverschlusses. 421

kombiniert war, oder in denen unmittelbar nach Beseitigung einer Peritonitis bei normaler Temperatur und normalem Puls die Erscheinungen des Ilens zur Enterostomie Veranlassung gaben, hier keine Berücksichtigung.

Fall 43, Umschnürung des untersten Ileum durch die Appendix reiht sich an die Fälle von Wikerhausen ${ }^{1}$ ), E. von Meyer ${ }^{2}$, Mac Leaur ${ }^{3}$, Paffard ${ }^{4}$ ), Mortier) ${ }^{5}$ und Pughe ${ }^{6}$ ) an.

Fall 44: Stenose des Ileum an der Stelle der Perforation der Appendix in dasselbe ist meines Wissens bis dahin ohne Analogon.

Über Darmverschluß durch Adhäsionen nach Appendicitis und nach Exstirpation der Appendix ist wiederholt berichtet worden, (Marion ${ }^{7}$ ), Loevinsohn $\left.{ }^{6}\right)$ ). Der Fall 29 rezidivierte mit seinen Ileuserscheinungen nach $4 \frac{1}{2}$ Jahren und wurde erst durch eine Darmausschaltung (Ileocolostomie) geheilt.

Die Adhäsionen, welche den Darmverschluß in Erscheinung treten ließen, waren 4 mal die Folge von chirurgischen Laparotomien, 1 mal von einer Exstirpation des Proc. vermiformis, 1 mal von einer Resektion eines Flexurcarcinoms, 2 mal lagen Rezidive von Ilens vor und zwar, abgesehen von der oben schon erwähnten Patientin, war es der Pat. Fall 34, bei welchem wir uns genötigt sahen, 3 mal wegen Darmverschlusses zu operieren.

Entsprechend der Häufigkeit der Darmtuberkulose in Schleswig-Holstein führten 9 mal tuberkulöse Veränderungen des Darms, des Peritoneum und des Mesenterium die Störung der Darmpassage herbei. Dabei waren der Adhäsionen, flächenhaften Verwachsungen, Mesenterialschrumpfungen oft so viele, daß es sehr schwierig war, das Gebilde zu finden, welches den völligen Verschluß verschuldet hatte. Wie unsere Fälle lehren, verhindern die tuberkulösen Prozesse uicht nur durch Knickung die Fortbewegung des Darminhalts, sondern sie unterstützen auch das Zustandekommen anderer Verschlußarten, z. B. Volvulus fast des ganzen Dünndarms (Fall 8), innere Einklemmung in einer Mesenteriallïcke (Fall 16), Strangu-

1) Zentralblatt f. Chir. $1897, \mathrm{Nr} .3$.

2) Beiträge z. klin. Chir., Bd. 34, s. 85.

3) Journ. Americ. medic. Assoc. 1898, p. 780.

4) New York med. Record 1898, p. 229.

5) Diction. de la science médicale. Paris 1819.

6) Brit. med. Journal 1886; zitiert nach Loevinsohn, Mitteilungen a. d. Grenzgebieten d. Chir. u. Med. Bd. 14. S. 620.

7) Gazette des hôpitaux. 1900, Nr. 134. 
lation einer Jejunumschlinge durch eine Bride (Fall 19), Umschnürung des Darms durch eine Adhäsion (Fall 42) und innere narbige Stenose (Fall 45). Daß alle Intestina so durch tuberkulöses Gewebe zusammengebacken sein können, daß eine Orientierung nicht möglich ist, ist bekannt, wird auch durch Fall 54 wieder einmal bewiesen.

Als durch die Symptome, den Verlauf und die Prognose sehr wesentlich verschieden haben $v$. Wahl und seine Schüler zwei Arten des Darmverschlusses voneinander sondern gelehrt: den Strangulations-Ileus und den Obturations-Ileus.

Bei der Strangulation handelt es sich um die Umschnürung, Einklemmung oder Achsendrehung einer Darmschlinge mit dem zllgehörigen Mesenterium. Die Drehung des Darms um seine Längsachse wird wohl besser als Torsion (W. Braun $\left.{ }^{1}\right)$ ) bezeichnet, die Umschnürung des Darms als Konstriktion. Torsion und Konstriktion sind keine Strangulation. Ist eine Darmschlinge an ihrer Kuppe fixiert und erfolgt dann eine Achsendrehung der zu- und abführenden Darmschlinge um die Achse des Mesenterium, so darf man diesen Zustand nur dann Strangulation nennen, wenn die Blutzirkulation behindert oder anfgehoben wird. Eine nicht sehr erhebliche Achsendrehung bewirkt dann nur ebenso wie die Torsion eine Obturation.

Für gewöhnlich führt ein Volvulus eine auf die Vitalität der Darmschlinge ungünstig wirkende Veränderung der Blutzufuhr herbei, Daß aber ein Volvulus nicht immer mit wesentlicher Beeinträchtigung der Blutzirkulation einher zu gehen braucht, haben die Erfahrungen der Operateure, welche viele Volvuli flexurae sigmoideae gesehen haben, zur Genüge dargetan. Auch in unserem Fall 14 war die Schädigung der Darmwand des S romanum fast nur durch die kolossale Dehnung bedingt. Daß auch Dünndarmvolvuli nicht stets von Gangrän gefolgt sind, zeigt der Sektionsbefund bei der Patientin Sch. (Fall 4).

Ebenso ist nicht jede innere Einklemmung eine Strangulation. Anch im Abdomen kann es, wenn auch selten, zu einer Incarceratio stercoracea kommen, wie unser Fall 18 in anschaulichster Weise demonstriert, die Dekubitusrinnen waren nahe dem Durchbruch, aber Mesenterium und die Schlinge selbst waren unversehrt.

Auch irreponible bruchartige Zustände ohne Ileus-Erscheinungen im Abdomen können vorkommen. Ein Beleg dafür ist die Kranken-

1) Beitr. z. klin. Chir., Bd. 41, S, 760 . 
Ein Beitrag zur Pathologie und Therapie des inneren Darmverschlusses.

geschichte des 30 jährigen Landarbeiters Th. L. aus W., J.-N. 583, 1904.

L. hatte seit Januar 1904 allmählich stärker werdendes Kollern und Spannung sowie ziehende Schmerzen im Leib, dabei häufig Stuhlverstopfung, aber niemals Erscheinungen von Darmverschluß. Mitte Juni 191)4 wurde bei ihm in der hiesigen medizinischen Klinik ein Tumor im Leib konstatiert, den wir für ein Paket tuberkulöser Mesenteriallymphdrüsen ansahen. Am 4. VII. 1904 konstatierte Herr Geheimrat Helferich bei der Operation einen doppelt fast großen Tumor an dem untersten Ileumteil, welcher wahrscheinlich durch invaginierten Darm gebildet wird. Am zugehörigen Mesenterium sah man narbige Züge und starke Verdickung der Serosa, sowie zahlreiche größere Drüsen. Der zuführende Darm war sehr erweitert und hatte eine stark hypertrophische Wand. Die ganze Darmpartie wurde reseziert, das Ileum end to side mit dem Colon ascendens vereinigt und der Patient geheilt. Als die Geschwulst aufgeschnitten wurde, zeigte es sich, daß es sich nicht um eine Invagination handelte, sondern um mehrere dicht nebeneinander liegende Dünndarmschlingen, die von einer gemeinsamen Hülle überzogen waren. Diese Hïlle war zum kleinsten Teil eine aus Adhäsionen geformte Platte, zum größten Teil wurde sie vom Mesenterium gebildet. Die Entstehung dieses höchst eigenartigen Befundes kann man sich so denken, daß zunächst durch Verklebung zweier Darmschlingen eine vom Mesenterium ausgekleidete Nische präpariert war, in welche sich der zuführende Darm allmählich hineinschob.

Die Strangulation war bedingt:

12 mal durch Volvulus,

$7 \mathrm{mal}$ durch bruchähnliche innere Einklemmung;

2 mal durch bruchähnliche innere Einklemmung kombiniert mit Volvulus.

Der Darm war eingeklemmt:

3 mal in Mesenteriallücken,

1 mal zwischen der die beiden Schenkel eines eingeklemmt gewesenen Bruchdarms verbindenden Adhäsionsbrücke und dem Mesenterium derselben Schlinge,

1 mal zwischen ein am. Fnde fixiertes Meckelsches Divertikel und dem Mesenterium,

1 mal zwischen eine Netzadhäsion und dasMesocolon ascendens, 
2 mal hinter Nischen überspannende Adhäsionsstränge,

2 mal war eine Darmschlinge von einer Bride umschnürt.

Als klassischer Symptomenkomplex der Strangulation des Darms wird nunmehr angesehen:

1. Beginn mit heftigem Leibschmerz. Derselbe soll nicht selten scharf lokalisiert sein. Von unseren 21 Patienten mit Strangulation lokalisierten den Schmerz nur 3 an der Stelle der Strangulation, die übrigen gaben nur heftigen diffusen Leibschmerz an.

2. Initiales Erbrechen, dasselbe wurde nur 5 mal vermilst (Fall $4,6,10,15,16)$.

3. Der Shok war in den Fällen, welche wir frühzeitig genug zll sehen Gelegenheit hatten, stets vorhanden.

4. Stuhl- und Windverhaltung.

Der Stuhldrang ist früher von einigen Autoren auch als ein charakteristisches Zeichen angesehen worden. Er hat sich auch ohne Zweifel oft genug bemerkbar gemacht (in unseren Fällen ist er 6 mal notiert), aber er ist nicht pathognomonisch. So sehr er beim Vorhandensein anderer ausschlaggebender Symptome zur Vervollständigung des Krankheitsbildes beiträgt, so wenig darf man auf ihn hauptsächlich die Diagnose stützen. Denn Frauen mit Tubenabort, Patienten mit im kleinen Becken lokalisierter frischer Appendizitis haben unmittelbar nach dem primären Schmerz Stuhldrang.

5. Sekundäres Erbrechen, es tritt früher oder später auf, je nach dem Sitz, dem Grad und der Ausdehnung der Strangulation.

6. Das v. Wahlsche Zeichen: Die resistente unbewegliche Schlinge haben wir naturgemäß nur selten zu Gesicht bekommen, weil die Patienten meistens zu spät in die Klinik eingeliefert wurden. In den einzelnen Fällen $(15,19,21)$ aber war die Schlinge sehr deutlich zu fühlen.

Wenn man durch große Klistiere und durch reichliche Magenspülung (10 Liter) dafür sorgt, daß die übrigen Därme möglichst leer werden, so tritt die Schlinge besonders deutlich hervor. Wird man zu einem soeben unter den Erscheinungen des inneren Darmverschlusses erkrankten Patienten gerufen, so wird man wohl immer versuchen, durch hohe Einläufe die Wegsamkeit des Darms wieder herbeizuführen. Kommen dabei Stuhl und Winde, so darf man sich dadurch nicht zu der Ansicht verleiten lassen, die Passage sei wiederhergestellt, dann wird man unangenehme Erfahrungen machen. Man muß vielmehr nach der v. Wahlschen resistenten, 
unbeweglichen Schlinge suchen. Dabei leistet nach Rehn ${ }^{1}$ ), Heidenhain ${ }^{2}$ ), Zeidler ${ }^{3}$, Braun ${ }^{4}$ ) die Untersuchnng per vaginam und rectum oft gute Dienste. Es scheint mir indessen zweifelhaft, ob die geblähten Schlingen, welche man vom Rektum oder Vagina aus gefülllt hat, wirklich die strangulierten Schlingen gewesen sind. Nach unseren Erfahrungen gehörten diese vom Mastdarm oder der Scheide aus palpierten resistenten Schlingen meist dem zuführenden Darm an. Doch soll die Möglichkeit, in geeigneten Fällen die resistente Darmschlinge im kleinen Becken zu fühlen, nicht bestritten werden. In unseren 21 Fällen lag die strangulierte Schlinge nur 2 mal so, daß sie vom Rektum aus gefühlt werden konrite.

Das v. Wahl sche Zeichen fehlt, wenn kleine Schlingen umschnürt sind, wenn die Tage derart ist, daß eine Palpation derselben nicht möglich ist, endlich wenn sehr große Darmpartien stranguliert sind.

7. Der freie Erguß (Gangolphe ${ }^{5}$ ) wurde von uns 11 mal festgestellt. Man fahndete vergeblich nach ihm in den Fällen von Volvulus der Fexura sigmoidea und dann, wenn noch keine stärkere Schädigung der zugehörigen Mesenterialgefäße erfolgt war.

Im Fall 43 ließ ich mich durch den Schallwechsel bei Lagewechsel verleiten, einen tuberkulösen freien Erguß anzunehmen. Da die Erscheinungen des Darmverschlusses bei tuberkulösem freien Erguß nach der Entleerung nicht selten verschwinden, so empfahl ich die Punktion, welche aber Dünndarminhalt statt freien Exsudats brachte, mit der sofortigen Operation wurde nicht gezögert.

Von besonderer Wichtigkeit ist die Frage gewesen, ob man bei der Strangulation vermehrte Peristaltik sieht oder nicht. Das ist durchans vom Grade der Strangulation und von der Größe der strangulierten Darmpartie abhängig. Ist letztere sehr lang, so liegt so viel gelähmter Darm der Bauchwand an, daß der nicht betroffene Darm ganz nach hinten verdrängt wird, also nicht sichtbar sein kann. Ist die Strangulation sehr hochgradig, so tritt Gangrän und Peritonitis so rasch auf, daß der zuführende Darm durch Peritonitis gelähmt wird, ehe vermehrte Peristaltik sich geltend machen kann. Wenn die Peristaltik im übrigen Darm reflektorisch durch die Strangulation anfgehoben würde, so dürfte man

1) Arch. f. klin. Chir., Bd. 43.

2) Langenbecks Archiv, Bd. 55 .

3) Mitteil. a. d. Grenzgebieten d. Chir. u. Med, Bd. 5.

4) l. c.

5) Revue de Chir. 1893, Bd. 13. 
nicht stets den abführenden Darm leer finden. Einen Unterschied zwischen zu- und abfïhrendem Darm zu machen, liegt kein Grund vor. Ist die Strangulation weniger stark, kommt etwa eine Infarcierung des Darms mit nachfolgender Gangrän zur Ausbildung, daß sich Verklebungen bilden können und die Peritonitis lokalisiert bleiben kann, dann wird der übrige Darm vermehrte Peristaltik zeigen.

Beispiele: Im Fall 15 waren $80 \mathrm{~cm}$ Dünndarm zwischen einer Netzadhäsion und dem Colon ascendens so stark eingeklemmt, daß nach der Lösung der Darm infarciert blieb und bei der Autopsie gangränös war, dabei war im linken Abdomen vor der Operation vermehrte Peristaltik deutlich sichtbar.

Im Fall 20 bäumten sich die Därme stark auf, man nahm deshalb einen Obturations-Ileus an und war überrascht, bei der Operation eine Strangulation zu finden.

Bei der Patientin B. (Fall 2) sprachen alle Symptome: „heftige Kolik, initiales Erbrechen, anhaltender Schmerz, kein Stuhlgang, keine Winde, sekundäres Erbrechen 6-7 Stunden nach dem Beginn der Erkrankung, freier Erguß im Abdomen, Ruhe und Resistenz im rechten Hypogastrium" für eine Strangulation, obwohl im übrigen Abdomen mächtig verstärkte Peristaltik und Darmsteifung beobachtet wurde. Die Operation ergab schwerste Strangulation (Achsendrehung) von 1,10 m Ilenm! Solche Fälle bilden eine Stütze für Schlangesi) Anschauung über das Verhalten des zuführenden Darms beim Strangulations-Ileus.

Deshalb ist es gefährlich, zu lehren, wo vermehrte Peristaltik da Obturation, solange es noch Ärzte gibt, welche der Meinung sind, bei einer Obturation die Operation hinansschieben zu dürfen.

Der Puls ist im Stadium des Shoks klein und weich und stark beschleunigt. Gewöhnlich bessert sich der Puls nach dem Shok wieder, namentlich wenn Exzitantien gegeben werden. Ein kräftiger Mann, z. B. Patient B. (Fall 17). kann einen kräftigen regeImäßigen Puls von 80 Schlägen in der Minute haben und dennoch eine innere Einklemmung. Die Shokwirkung kann bestehen bleiben. Frau K. (Fall 12) mit Volvulus flex. sigm. hatte z. B. subnormale Temperatur $35,5^{0}$, Puls 96, kaum fühlbar 24 Stunden nach dem Einsetzen der ersten Symptome, obwohl die Strangulation nicht so hochgradig war. Im allgemeinen wird man nicht fehl gehen, wenn man aus dem Bestehenbleiben der schlechten Pulsqualität anf

1) Schlange, Handbuch der prakt. Chir., Bd. III, S. 408. 
schwere und ausgedehnte Darmwandschädigung schließt. Dabei nehmen die sehr schwierig zu beurteilenden Fälle eine Sonderstellung ein, in welchen schwere Veränderungen am Herzen (Fall 2 und 37) schon an und für sich einen schlechten Puls zeitigen. In den Stadien, in welchen wir die Patienten zu Gesicht bekamen, war der Puls meist schon sehr beschleunigt (120-160), klein und weich. Wichtig aber ist, daß die Temperatur dieser erhöhten Pulszahl nur dann entsprach, wenn sich bereits eine diffuse Peritonitis entwickelt hatte.

Während sich bei der Strangulation ein fast typisches Symptomenbild abrollt, sind bei der Obturation die Erscheinungen nicht immer so typisch. Das hängt damit zusammen, daß eine Obturation auf die verschiedenste Weise zustande kommen kann, durch Verstopfung durch einen Fremdkörper, durch einen Tumor, durch innere und äußere narbige Stenose, durch Torsion und Knickung, durch Umschnürung und Kompression. Die Obturation kann rasch und langsam erfolgen, komplett und inkomplett sein, namentlich können Gase noch oft entweichen. Je tiefer das Hindernis, desto größer der Meteorismus, desto später das Erbrechen, um so sicherer das schließliche Koterbrechen!

Das initiale Erbrechen ist selten. Wenn der Verschluß plötzlich auftritt, der Darm z. B. plötzlich geknickt oder um seine Längsachse gedreht wird, so wird initiales Erbrechen beobachtet, aber nicht ausnahmslos. So begann z. B. der Darmverschluß bei einem Flexurcarcinom (Fall 50) mit initialem Erbrechen nnd lokalisiertem heftigem Schmerz im kleinen Becken - das Carcinom war bei einer Körperanstrengung hinter den retroflektierten Uterus getrieben und dadurch die Flexur geknickt. Mit initialem Erbrechen und heftigem Schmerz im l. Hypogastrium fing die Krankheit der Frau N. (Fall 41) an, - die Kuppe der Flexura signmoidea war durch eine Adhäsion am Tubenwinkel fixiert, die Flexur plötzlich geknickt.

Das Erbrechen kann sich oft wiederholen, bis das Erbrochene kotig wird, selbst wenn z. B. das Colon ascendens (Fall 31) durch eine Netzadhäsion geknickt wird. Oder aber es tritt sekundär erst später anf nach ein oder mehreren Tagen, je nach dem höheren oder tieferen Sitz des Passagehindernisses. Ein anderes Mal sistiert es wieder, wenn die Durchgängigkeit für Darmgase sich wiederherstellt, um wieder einzusetzen, falls die mechanischen Verhältnisse einen kompletten Verschluß bedingen.

Stets ist vermehrte Peristaltik nachweisbar, eventuell kann 
man Darmgeräusche bis zu einem bestimmten Punkt hin verfolgen $\left(\right.$ Rehn ${ }^{1}$ ). Wichtig ist, daß mit der Peristaltik fast immer ein kolikartiger, also tourenweise auftretender Schmerz verbunden ist. Wenn auch Peristaltik im allgemeinen gegen Peritonitis spricht, so haben wir doch zwei Fälle von Appendizitis-Peritonitis beobachtet, bei denen vermehrte Peristaltik deutlich sichtbar war, obwohl der Dünndarm von Eiter umspült war. Hier fehlte aber der tourenweise auftretende Schmerz, der Schmerz war ständig und steigerte sich beim Druck aufs Abdomen.

In unseren sämtlichen Fällen von Obturations-Ileus fehlte der deutlich nachweisbare freie Erguß mit 3 Ausnahmen: er war in geringer Menge vorhanden in 2 Fällen von Darmcarcinom, in mäßiger Menge bei dem Patienten F. (Fall 34), in welchem es sich um eine Torsion des untersten Ileum um dessen Längsachse ohne Schädigung des Mesenterium handelte.

Die Invaginationen sollen $z$ wischen Strangulation und Obturation rangieren. In nuseren 6 Fällen wurde angegeben heftiger initialer Leibschmerz, 3 mal genau lokalisiert, kein initiales Erbrechen, nur 2 mal Stuhldrang, 2 mal blutige Beimengungen im Stuhl, stets tourenweise auftretender Schmerz. Immer war synchrone vermehrte Peristaltik nachweisbar. Die Invagination war $5 \mathrm{mal}$ äußerlich als elastische Resistenz fühlbar. Einmal konnte man im Douglas eine elastische Vorwölbung fühlen, sie entsprach der zuführenden Darmschlinge, nicht der invaginierten Partie.

Niemals war ein freier Erguß vorhanden.

\section{Achsendrehung und Verknotung.}

14 Fälle: 12 gestorben, 2 geheilt.

Im Vergleich zu anderen aus den östlichen Provinzen, aus RußIand oder Österreich stammenden Statistiken, hat die unsrige nur eine kleine Zahl (14) Volvuli anfzuweisen. Einige von ihnen haben aber besonderes Interesse.

Vorweg sei beachtet, daß nur die Hälfte allein durch die Peristaltik entstanden sind. Unter diesen 7 sind 4 Volvuli der Flexura sigmoidea und ein Volvulus des Cöcum und Col. ascendens, nur durch kongenitale Anomalien möglich geworden. Für die Achsendrehung des ganzen Dünndarms war im Fall 8 eine tuberkulöse Mesenteriitis verantwortlich zll machen. Das Mesenterium barg

1) l. c. 
viele tuberkulöse Drüsen in der Radix, es war stary durch chronische Entzündungsprozesse und enthielt in der Mesenterialserosa des unteren Ileum viele nach dem Darm hin ausstrahlende Narbenzüge.

Ein relativ starres Mesenterium wird durch die peristaltische Bewegung des Darms leichter um seine Achse gedreht, als ein weiches schmiegsames, welches sich den Bewegungen des Darms gut anpassen kann.

Besonders geeignet zur totalen Achsendrehung scheint das Mesenterium, welches in seinem unteren Ileumabschnitt an Schmiegsamkeit eingebüßt hat. Eine solche Mesenterialpartie bildet gewissermaßen eine sektorartige Scheibe mit dem Zentrum an der Radix mesenterii. Vermehrte Peristaltik wird diesen etwas starren Sektor vorwärtsbewegen, ist er nicht am Cöcum gefesselt oder dadurch fixiert, daß anch der unterste Mesenterialteil unbeweglich geworden ist, so wird er um die Radix als Mittelpunkt geschleudert. Der übrige Darm mit seinem Mesenterium folgt, soweit es die Beweglichkeit seines Gekröses gestattet. Bei den totalen Achsendrehungen des Dünndarms, welche ich gesehen habe, war das Mesenterium stets im Sinne des Uhrzeigers gedreht, das unterste Ileum war aufs stärkste gespannt, lag im Fall 8 sogar in einer tiefen Sclnürrinne des Mesenterium und weiterhin am dichtesten dem Mesenterium an, so daß man unmöglich den Eindruck haben konnte, es sei durch die peristaltische Aktion zuletzt nachgezogen worden. Im Fall 8, P. P., war vermutlich die Reposition des prolabierten Dünndarms gleich so erfolgt, daß die Achsendrehnng damit schon eingeleitet war.

Die anderen 7 Volvuli wurden in ihrer Entstehung dadurch begünstigt, daß eine Dünndarmschlinge irgendwo befestigt war. Diese Fixierung ging in 2 Fällen der Volvulusbildung unmittelbar vorher, dadurch daß die Dünndarmschlinge in einem Mesenterialschlitz eingeklemmt wurde. Im gleichen Moment fand im Fall 6 eine komplizierte Verknotung and Achsendrehung zwischen der eingeklemmten und der nächsthöheren Schlinge, im Fall 7 eine Achsendrehung der dicht oberhalb gelegenen Darmschlinge statt.

Beachtung scheinen die Befunde in den Fällen 3 und 4 zu verdienen. In jedem war der Dünndarm an der Bauchwand fixiert. Die Passage wurde durch Knickung des Darms an dem befestigten Punkt gestört. Doch entstand kein Volvulus des zuführenden, anfangs in gesteigerter Peristaltik befindlichen Darms, sondern in dem ab- 
führenden unteren Ileum. Solche Autopsien beweisen, wie lebhaft der abführende Darm arbeitet. Abb. 1 und 2.

Die Erfahrungen bei irreponiblen Brüchen oder Brucheinklemmung des Dünndarms haben uns gelehrt, daß es oberhalb der

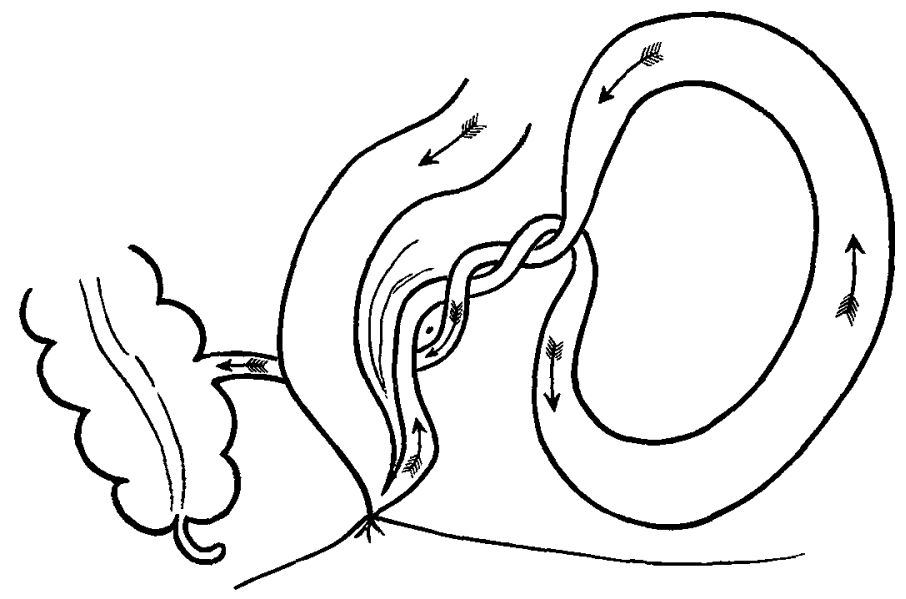

Fig. 1.

Fall 2. Achsendrehung des unteren Ileum unterhalb der den Darmversehluß bedingenden Knickung dureh Adhäsion.

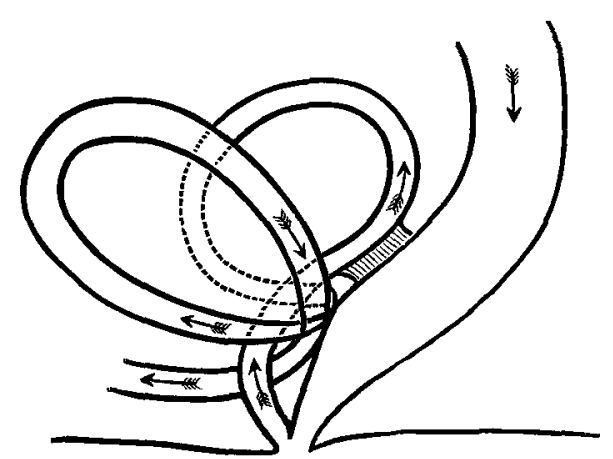

Fig. 2.

Fall 4. Volvalus des unteren Ileum nnterhalb der den Darmverschluß verursachendeu Knickung nach früherer Enterostomie.

im Bruchsack fixierten Schlinge fast niemals zur Bildung eines Volvulus kommt. Nur der von Kaiser ${ }^{1}$ ) beschriebene Fall: Volvulus coeci mit Incarceration in einer Leistenhernie und gleichzeitige

1) Deutsche Zeitschr. f. Chir., Bd. 55, S. 443. 
Einklemmung eines Ileumabschnittes mit intraabdominellem Volvulus der zu diesem zuführenden Darmschlinge bildet eine höchst seltene Ansnahme. (Nur eine Achsendrehung eines Darmkonvoluts in einem großen Skrotalbruch haben wir beobachtet.) Dabei sollte man annehmen dürfen, daß die Bedingungen für Entstehung einer Achsendrehung besonders günstig sind, wenn eine Dünndarmschlinge in einem rechtsseitigen Leisten- oder Schenkelbruch festsitzt und noch dazu gesteigerte Peristaltik vorhanden ist.

Die Tatsache, daß man eine Achsendrehung oder Strangulation des zu einer im Bruchsack festsitzenden Ileumschlinge führenden Darms höchst selten sieht, - so selten, daß man bei der Herniotomie gar nicht mit diesem Faktor zu rechnen gelehrt wird, - wird damit erklärt, daß man annimmt: es wird stets die Schlinge mit den längsten Mesenterium eingeklemmt und die Länge des Mesenterium des zuführenden Darms reicht zur Volvulusbildung nicht aus. Doch kann das nicht der einzige Grund sein. Gerade die Fälle 6 und 7 zeigen, daß bei Einklemmung einer tiefen Dünndarmschlinge in einem Mesenterialschlitz der zuführende Darm noch zur Achsendrehung, ja zur Knotenbillung befähigt sein kann. Es muß also gerade die Fesselung der tiefen Schlinge in einer Lücke der Bauchwand und der dadurch am Mesenterium nach dieser Stelle hin ausgeübte Zng mechanisch oder reflektorisch so wirken, daß eine Aclisendrehung oder eine innere Einklemmung des zuführenden Darms unmöglich ist. Es läßt sich hinzufügen, daß es meist die regellose vermehrte Peristaltik ist, die zu Achsendrehungen des Düundarms führt, daß dagegen die zwar gesteigerten, aber durchaus regelmäßig sich abspielende Peristaltik oberhalb eines Hindernisses gewiß nur selten zu einer Achsendrehung Veranlassung gibt.

Anch aus den anderen Fällen von Strangulation des Dünndarms geht hervor, daß mit ganz seltenen Ausnahmen der unterste Teil des Ileum betroffen ist. Wenn größere Partien eingeklemmt waren, so reicht die incarcerierte Partie meist bis nahe an die Valvula ileo-coecalis. Um diese bekannte Tatsache zu erklären, hat Wilms ${ }^{1}$ ) angenommen, daß zunächst die Peristaltik in der eingeklemmten Schlinge erhalten bleibt und der abführende Teil durch die Pforte nachgezogen wird. Es ist ohne weiteres zuzugeben, daß diese Auffassung für die Fälle berechtigt ist, in welchem eine relativ weite Lücke vorhanden war. Wenn aber der Darm durch einen ganz engen Schlitz geprelst ist, so wird stets sofort oder wenigstens

1) Langenbecks Archiv, Bd. 69.

Deutsche Zeitschrift f. Ohirnrgie. LXXXII. Bd. 
sehr schnell der Darm gelähmt. Wenn man an Tieren enge elastische Einklemmungen des Dünndarms macht und durch Seidennähte die Stellen der Schnürung markiert, so findet man nach 3-4 Stunden entweder zu- und abführendes Ende gleichweit um $1 \frac{1}{2}-2 \mathrm{~cm}$ nachgezogen oder das abführende Ende um $2 \mathrm{~cm}$, das zuführende Ende um 1-1 1/2. Diese geringen Unterschiede beruhen darauf, daß der leere abführende Teil leichter nachgezogen werden kann, als der gefüllte zuführende. Davon, daß die Peristaltik bei der Strangulation in engen Ringen zunächst erhalten bliebe und das abführende Ende sogar bis an das Cöcum nachgezogen würde, habe ich mich nicht überzeugen können, wie es ja auch mit den Resultaten der bekannten Experimente von Schweninger ${ }^{1}$, Reiche $\mathbf{l}^{2}$ ), Tietze ${ }^{3}$ ) und Buchbinder ${ }^{4}$ ) nicht in Einklang zu bringen ist. Nimmt man aber einen weiten Ring und zieht eine Dünndarmschlinge hindurch, so findet man am folgenden Tage stets den abführenden Darm nachgezogen und den Ring am Cöcum.

Der Fall 6 und 7 unserer Statistik sind für die Lehre des Mechanismus der Strangulation und Verknotung von prinzipieller Bedeutung und sollen deshalb genaner besprochen werden. (Abb. 3 u. 4.)

Beim Pat. Schr., Fall 6, war die unterste Ileumschlinge in einem sehr engen Mesenterialschlitz eingeklemmt und mit dieser Schlinge die zuführende Dünndarınschlinge absolut fest verknotet und außerdem waren beide Schlingen noch 2 mal umeinander gedreht.

Eine solche Verknotung auf eine der von Wilms beschriebenen Arten entstanden sich vorzustellen, hält schwer. Nach Wilms müßte man folgendes annehmen: Eine kleine Dünndarmschlinge ist durch eine enge Mesenteriallücke hindurchgepreßt, ihre erhalten gebliebenene, ja sogar gesteigerte Peristaltik hat den Darm so lange nachgezogen, bis das Mesenterium kein weiteres Durchlassen mehr gestattet. Die durchgezogene Schlinge spielt nun dieselbe Rolle, wie die Flexura bei der Knotenbildung zwischen Flexur und Dünndarm. Der zuführende Darm befindet sich in stark peristaltischer Bewegung, dabei legen sich die Schlingen so zueinander, daß sich ihre Mesenterialachsen kreuzen. Der oberste Teil der zuführenden Schlinge tritt durch die von den beiden sich kreuzenden Schlingen gebildete Lücke, wird stranguliert und zieht

1) Arch. f. Heilkunde. 1873, Bd. 14.

2) Die Lehre von der Brucheinklemmung. Stuttgart 1886.

3) Arch. f. klin. Chir. 1895, Bd. 49.

4) Deutsche Zeitschr. f. Chir., Bd. 55. 
Ein Beitrag zur Pathologie und Therapie des inneren Darmverschlusses.

den abführenden Teil derselben Schlinge nach und befindet sich sodann noch in vermehrter peristaltischer Tätigkeit, deren Resultat eine $2 \%$ malige Achsendrehung mit der eingeklemmten Darmschlinge ist.

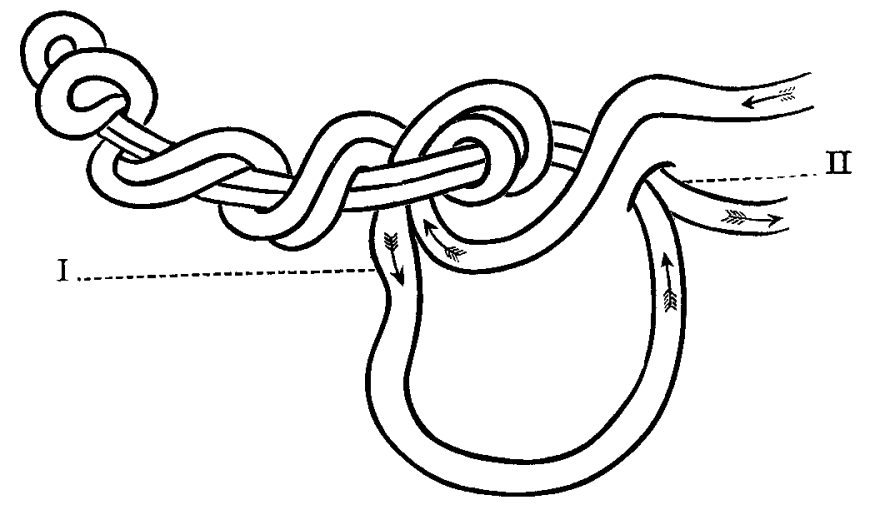

Fig. 3.

Fall 6. Innere Einklemmang und Verknotung der zufihrenden Schlinge (I! mit der eingeklemmten (II).

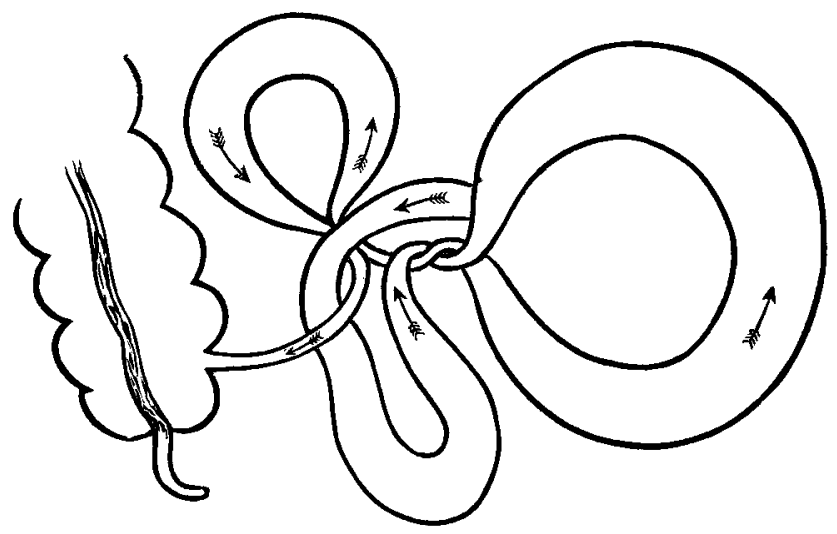

Fig. 4.

Fall 7. Innere Einklemmung. Achsendrehung der zuführenden Darmschlinge.

Es würde sich demmach nicht um ein in einem Moment sich vollziehendes Geschehnis, sondern um eine Episode handeln.

Bei der Patientin Sch. (Fall 7) endigte die $20 \mathrm{~cm}$ lange in eiver Mesenteriallücke einer benachbarten Schlinge eingeklemmte Darmschlinge $15 \mathrm{~cm}$ oberhalb der Valvula ileo-coecalis und die 
$75 \mathrm{~cm}$ lange zuführende Schlinge hatte eine Achsendrehung um die Mesenterialachse erfahren. Nach Wilms würde zunächst wiederum eine kleine Schlinge durch die sehr enge Mesenteriallücke gepreßt sein, deren erhaltene Peristaltik den abführenden Schenkel nachgezogen hätte, soweit es der Umfang des Mesenterium erlaubte, also in diesem Fall $20 \mathrm{~cm}$. Sodann würden sich die Schenkel der nächsthöheren Schlinge wiederum durch die Tätigkeit der Peristaltik gekreuzt haben, und schließlich die Achsendrehung dieser Schlinge um ihre Mesenterialachse erfolgt sein.

Wenn man sich die Entstehung dieser beiden Volvuli in der soeben geschilderten Weise vorstellt, so muß man konsequenterweise zugeben, daß beide Patienten einen zweimaligen Strangulationsschmerz ev. auch Shok erlebt haben müßten. Nur die Patientin Sch. (Fall 7) konnte darüber Auskunft geben, daß sie nur einen heftigen Schmerz empfunden hatte. Denn der Pat. Schr. (Fall 6) war im Schlaf von dem unangenehmen Ereignis überrascht worden. Die 'Tatsache, daß es im Schlaf zur inneren Einklemmung kam, stellt auch eine wesentliche Mitwirkung der Bauchpresse in Frage.

Auch die Pat. Sch. hat versichert, daß sie an dem Morgen ihrer Erkrankung nichts getan habe, was ihre Bauchpresse besonders in Anspruch genommen hätte. Wenn der Darm in einer Bauchfelltasche oder in einer von einer Adhäsion überspannten Nische, oder hinter dem retroflektierten Uterus eingeklemmt gefunden wird, so kann man sich leicht vorstellen, daß er durch den gesteigerten intraabdeminellen Druck dort hineingepreßt worden ist. Wenn sich aber in einem stark beweglichen die peristaltischen Bewegungen seines zugehörigen Darms mitmachenden Mesenterium eine ganz kleine Lücke befindet, so eng, daß man es nicht begreifen kann, wie eine $20 \mathrm{~cm}$ lange Dünndarmschlinge hat hindurchtreten können, so fällt es einem sehr schwer, der Anschauung beizupflichten, der Darm sei durch diese kleine Lücke unter dem Einfluß einer nicht einmal gesteigerten Bauchpresse hindurchgetrieben worden, es sei denn, daß das die Lücke enthaltende Mesenterium durch irgendwelche Momente fixiert worden wäre.

Zur Erklärung dieser Art Fälle genügen deshalb die Bauchpresse und die Peristaltik allein nicht, und mir scheint, daß Wilms unter zu starker Betonung der Wichtigkeit der Peristaltik für die Entstehung solcher Zustände das mechanische Moment etwas vernachlässigt hat.

Solche Art Strangulationen und Verknotungen oder Achsendrehungen, wie wir sie in den Fällen 6 und 7 vor Augen gehabt 
haben, können nur durch einen momentanen Vorgang erklärt werden. Eingeleitet wird derselbe durch eine sehr stark vermehrte heftige Peristaltik des Dünndarms. Dabei wird plötzlich, ob mit oder ohne Mitwirkung der Bauchpresse bleibt unentschieden, eine kleine Partie durch die Lücke im Mesenterium getrieben. Die Lücke wird dadurch erweitert. Solange diese Erweiterung danert, läuft die peristaltische Welle im durchgeschlüpften Darm weiter und zieht eventuell den abführenden Schenkel nach, bis die erweiterte Lücke sich wieder verengert. Dann hört jedes Nachziehen auf, weil die Lücke so eng ist, daß es auch dem stärksten Zug mit der Hand nicht gelingt, mehr Darm durch die Lücke hindurchzuziehen (s. o.). Durch das Eintreten der Darmschlinge in die Lücke ist der Darm plötzlich fixiert und geschlossen, die Wirkung der peristaltischen Welle ist plötzlich unmöglich geworden. Die Masse im Darm ist aber noch in starker Vorwärtsbewegung. Sie stellt eine mächtig wirkende lebendige Kraft dar.

In diesem Moment, scheint mir, ist es nicht mehr die Peristaltik, welche die Situation beherrscht, sondern es handelt sich jetzt lediglich darum, durch welche Momente jene Kraft beeinflußt wird. Denn was sie schafft, hängt von mechanischen Momenten ab. Ist der Darm an einem Mesenterium fixiert, welches ihm keine großen Exkursionen gestattet, so wird lediglich eine Dilatation des Darms erfolgen. Ist das Mesenterium lang und gut beweglich, so wird der Effekt ein ganz anderer sein. Der in einer bestimmten Richtung in Bewegung befindlichen Flüssigkeitsmasse wird nicht allein plötzlich ein Riegel vorgeschoben, sondern sie befindet sich im gleichen Augenblick in einem Rolır mit momentan veränderter Richtung die Folge davon ist, daß alle Flüssigkeitsteilchen sich mit einem Mal in exzentrischer Bewegung befinden, noch dazu in einem elastischen beweglichen und dehnbaren Schlauch.

So war im Falle 6 (Schr.) plötzlich folgende Lage geschaffen: Eine Schlinge durch die Einklemmung fixiert - an demselben Punkt gefesselt und mit einenı langen beweglichen Mesenterium versehen eine zweite Schlinge, welche von ihrem augenblicklich in seiner Vorwärtsbewegung aufgehaltenen und in eine andere Richtung geschleuderten flüssigen Inhalt fortgerissen wird. Diejenige Stelle des Darms, an welcher die exzentrisch geschleuderte Flüssigkeitsmasse die stärkste Kraft entfaltet wird zur Schlingenkuppe; die so geformte Schlinge schlägt sich um die daneben liegende fixierte Schlinge herum und bildet so mit ihr Verknotungen, welche durch peristaltische Vorgänge zu erklären äußerst schwerfallen würde. 
Am Darm der Pat. Sch. (Fall 7) lagen andere mechanische Verhältnisse vor, das Mesenterium war kürzer und die Fixierung der strangulierten Schlinge erfolgte so, daß die Kraft der vorwärtsgetriebenen aus ihrer Richtung gebrachten Flüssigkeitssäule eine Achsendrehung der zuführenden Schlinge zustande brachte.

Im Fall (8 F. K.) Achsendrehung fast des ganzen Dünndarms handelte es sich um die Entscheidung, ob man die Operation unèrledigt lassen sollte oder so wie es geschehen ist, den Darm, welcher wegen der Strangulation des Mesenterium sich nicht erholen konnte, radikal entfernen. $\mathrm{Zu}$ letzterem wurden wir hanptsächlich durch die Peritonitis bewogen. Wir hofften, daß nach Beseitigung des gangränosen Darms das Peritoneum leichter mit der Infektion fertig werden würde. In dieser Hoffnung sahen wir uns getäuscht. Ein anderer Weg wäre der gewesen, den strangulierten Darm durch Jejuno-cöcostomie auszuschalten und zu versuchen durch Tamponade und Enterostomien der Peritonitis Herr zu werden, dann sekundär erst die gangränösen Partien zu resezieren. So hat Nigrisoli einen Patienten mit Enteroanastomose und sekundärer Resektion von $520 \mathrm{~cm}$ Dünndarm geheilt. - Ob es möglich gewesen wäre, so einen besseren Erfolg zu erzielen, ist natürlich sehr zweifelhaft. Yan muß aber beachten, đaß man bei der Resektion so ausgedehnter Darmpartien dem Patienten sehr viel Blut und damit auch viel Schutzmittel gegen die Infektion nimmt.

Über die Berechtigung einer ausgedehnten Darmresektion entscheidet, wie kürzlich Schlatter ${ }^{1}$ ) erst wieder dargetan hat, der Erfolg. Man kann nicht bestimmen, ob der Patient mit dem gekürzten Darm leben kann oder nicht. Nigrisolis Patient hat breiige oder flüssige Stühle, ist aber sonst gesund.

$\mathrm{Ob}$ unser Patient imstande gewesen wäre, mit 1,30 m Dünndarm zu existieren, diese Frage zu erörtern, erscheint mir müßig.

Der Krankheitsverlauf des zweiten Falles von Achsendehnung des ganzen Dünndarms ist in vielen Punkten unaufgeklärt geblieben:

J.-N. 1163/1905. 22jälıriger Schlachter P. P. aus A. Am 24. XII. 1904 paranephritischer AbszeB. Incision, Heilung, gute Rekonvaleszenz. Anfang Oktober 1905 von neuem kontinuierliches Fieber, nach Blutantersuchung im hygienischen Institut kein Typhus. Wegen Verdachts aufs Appendizitis: Exstirpation der Appendix. Aufplatzen der anscheinend per

1) Beitr. z. klin. Chir, Bd. 49 . 
primam geheilten Wunde am 11. Tage post operationem. Vorfall einer großen Dünndarmpartie. Reposition derselben und Tamponade. Kollaps. Patient erholt sich wieder. Winde gehen und Stuhlentleerung normal. Temperatur hält sich um $38^{\circ}$. - 10 Tage nach dem Vorfall: Temperatur normal, Puls 92, regelmäBig, mittelvoll, aber zum erstenmal mehrfach Erbrechen. Leib etwas aufgetrieben, überall recht druckempfindlich. Das Erbrechen hält an, ist nach weiteren zwei Tagen kotig: In der Absicht, eine Enterostomie zu machen, wird das Abdomen median unterhalb des Nabels eröffnet. Es quillt reichliches dunkelrotes Blut hervor, zwischen den Dünndarmschlingen Bluthoagula, die Quelle der Blutung wird nicht gefunden. Diagnose: PfortaderverschluB? 19 Tage nach dem Prolapsus intestini Exitus. Autopsie ergiebt: Totale Achsendrehung des Dünndarms an der Radix mesenterii. Freies Blut und Gerinnsel in der Bauchhöhle, hämorrhagische Infarcierung des Dünndarms. Peritonitis. An der Stelle des paranephritischen Abszesses schwieliges Gewebe. Keine Veränderungen, welche die Febris continua im Oktober und Anfang November 1905 erklären würden.

Wenn auch die Grundkrankheit nicht ergründet ist und dadurch der Fall sehr unbefriedigend ist, so hat er für uns doch ein holes Interesse.

Es ist wahrscheinlich, daß bei der Reposition des Darmprolapses dieAchsendrehung bereits eingeleitet worden ist, denn es ist inı späteren Verlauf kein plötzlicher heftiger Schmerz oder Shok zu verzeichnen. Man muß vielmehr sich vorstellen, daß die Achsendrehung langsam komplett geworden ist. Daß der Vorgang ein allmählicher gewesen ist, dafür spricht auch der eigentümliche Befund bei der Eröffnung des Abdomens: Man fand Blut, aber keinen infarcierten Darm, durch einen infarcierten Darm würde man veranlaßt gewesen sein, nach der Radix Mesenterii zu fühlen. jedenfalls haben wir ans dieser Erfahrung die Lehre gezogen, bei nicht aufgeklärter Blutung in abdomine auch an eine inkomplette Achsendrehung des Dünndarms zu denken.

\section{Volvulus flexurae sigmoideae.}

Die Annäherung der Fußpunkte der Flexura sigmoidea (Curschmann) und eine abnorme Länge des Mesosigmoideum konnte in jedem Fall konstatiert werden. Es waren aber keine Verwachsungen zwischen den Schenkeln der Flexur vorhanden, welche nach Riedel1), 0. Brehm²) u. a. zur Achsendrehung disponieren. Zweimal war man berechtigt, von einem Megacolon zu sprechen. S. 153.

1) Mitteil. a. d. Grenzgeb., Bd. II, S. 529. - Langenbecks Arch., Bd. 47,

2) Langenbecks Arch., Bd. 70. 
Im Fall L. (Nr. 11) reichte die entwickelte Flexur bis zur Mitte des Oberschenkels nnd die Autopsie bewies, daß es sich um kongenitale Veränderungen handelte.

Ferner im Falle W. Nr. 14, dessen Krankheitsbild deshalb Beachtung verdient, weil man ihn wohl der Hirschsprungschen Krankheit zurechnen muß. Es handelte sich um einen 14jährigen Knaben, bei welchem die Mutter in seiner frühsten Kindheit stets nur mit Klistieren Stuhlgang bewirken konnte, und welcher in seinem Knabenalter sehr oft an Stuhlverstopfung litt. Dann war der Leib immer stark aufgetrieben.

Am 20. XI. 1905 erkrankte der Knabe plötzlich an kolikartigen Schmerzen, und Erbrechen mit den Zeichen des tiefsitzenden Dickdarmverschlusses, welcher vom 24. XI. bis zum 3. XII. durch Klysmata überwunden werden konnte. Am 4. XII. 1905 trat aber eine Verschlimmerung ein, Klysmata waren erfolglos und so wurde der Junge am 7. XII. 1905 in die Klinik eingeliefert.

Bei der Operation wurde die 11/2 mal um ihre Mesenterialachse gedrehte, fast $60 \mathrm{~cm}$ lange, mannsoberschenkeldicke Flexur detorquiert und reseziert. Zu der Annahme, daß es sich hier um eine Art Hirschsprungsche Krankheit handelte, hielten wir uns berechtigt aus folgenden Gründen:

1. Man fühlte im Rektum etwa $5 \mathrm{~cm}$ oberhalb des mit starken Hämorrhoidalknoten besetzten Anus 3 enge, übereinander gelegene, stark kontrahierte Muskelringe.

2. Bei der Operation konnte festgestellt werden, daß die Erweiterung des Darms nicht nur die durch die Achsendrehung gedehnte Flexur und das Colon descendens betraf, sondern anch das Rektum unterhalb der Achsendrehung.

3. Die Muskelringe verschlossen das Rektum so fest, daß auch nach der Resektion der Flexura sigmoidea Stuhlentleerung nur dann erfolgen konnte, wenn die Ringe durch 2 eingeführte Finger gedehnt und auseinandergehalten wurden. Es war deshalb nicht zu verwundern, daß eine Kotfistel an der Resektionsstelle auftrat. Die Fistel schloß sich rasch, als am 25. Tage nach der Operation die Muskelringe in Narkose sehr stark gedehnt worden waren und ein dickes Darmrohr eingeschoben worden war.

Demzufolge wird man wohl zugeben müssen, daß in diesem Falle der Muskelspasmus gewisser Ringmuskelpartien des Rektum nicht ohne Bedeutung für die Entstehung des Megacolon gewesen sein kann, wohlverstanden nur für das Megacolon; denn für die 
Ein Beitrag zur Pathologie und Therapie des inneren Darmverschlusses. 439

Achsendrehung der Flexur ist neben der abnormen Länge auch die Annäherung der Fußpunkte (ätiologisch) wichtig gewesen.

Soltan Fenwick hatte in seinem Fall einen Spasmus des Sphincter ani gefühlt und in ihm die Ursache der Dickdarmdilatation erblickt. Perthes ${ }^{1}$ ) hat nicht anerkannt, daß Muskelspasmen des Rektum bei der Ausbildung der sog. kongenitalen Dickdarmerweiterung mitwirken können.

Die übrigen Fälle boten keine Besonderheiten. Nur war Fall 13 dadurch bemerkenswert, daß eine Magenblutung auftrat und der Pat. schließlich an einer Perforation des Magengeschwürs in die freie Bauchhöhle zugrunde ging.

Von 14 Patienten mit Achsendrehung wurden nur 2 geheilt, obwohl 4 innerhalb der ersten 48 Stunden in Behandlung kamen. Von den 4 rechtzeitig Operierten starben 2 Franen kurz nach der Operation an Herzschwäche, die Autopsie ergab Myokarditis.

Von den sogen. rechtzeitig Operierten wurde nur Fall 6 durch Resektion von $3 \mathrm{~m}$ Dünndanm geheilt.

Die Befunde, welche wir in den zweiten 24 Stunden nach Beginn der Erkrankung bei Dünndarmvolvulus erhoben haben, haben uns zu der Überzengung gebracht, daß man von einer rechtzeitigen Operation nur in den ersten 24 Stunden sprechen kann.

\section{Innere Einklemmung.}

7 Fälle: 4 gestorben, 3 geheilt.

In keinem unserer Fälle handelt es sich um eine Einklemmung in einer inneren Bauchfelltasche, sondern nur um bruchartige Einklemmung des Darms. Dieselbe kann mit und ohne Strangulation einhergehen. So zeigte z. B. bei Frau W. die zwischen Adhäsionen und Peritoneum parietale incarcerirte Schlinge tiefe Dekubitusrinnen, aber das Mesenterium war ganz unbeschädigt. Es lag hier eine Art Incarceratio stercoracea vor; in den übrigen Fällen dagegen mehr oder weniger hochgradige Strangulation.

Nur zwei Fälle verdienen besonderer Erwähnung.

1. Demonstriert der Pat. B., wie eine nach einer Brucheinklemmung durch Adhäsionen zwischen den Schnürringen entstandene Ringbildung des Bruchdarms dem Träger dadurclı verhängnisvoll

1) G. Perthes, Pathologie und Therapie der Hirschsprungschen Krankheit. Verhandlungen des 34. Chirurgenkongr. II, S. 1. 
werden kann, daß eine andere Dünndarmpartie sich zwischen die 2 Darmschenkel, die Adhäsion und das Mesenterium einzwängt.

2. Die durch das Meckelsche Divertikel bedingte Einklemmung; das Ende des Meckelschen Divertikels war am Mesenterium der nächsthöheren Darmschlinge fixiert. Der oberhalb dieser Adhäsion gelegene Dünndarm war zwischen Divertikel und Mesenterium hindurch geschlüpft und hatte dabei das Divertikel um seine Längsachse gedreht, wie der Treibriemen die Rolle. Das Resultat war eine an beiden Polen an spiralig gewundenen Fäden

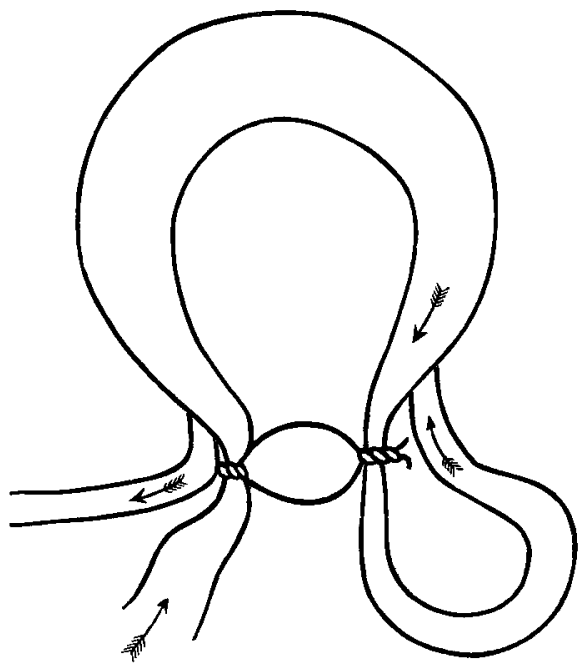

Fig. 2.

Fall 22. Innero Einklemmung einer Ileumschlinge zwischen Meckelsches Divertikel und Mesenterinm. Torsion und Gangrän des Meckelschen Divertikels.

aufgehängte gangränöse Cyste. Das gangränöse Divertikel hatte eine diffuse Peritonitis bedingt, während die eingeklemmte Schlinge zwar etwas stranguliert, aber noch völlig lebensfähig war. (Abb. 5)

Der Mechanismus der Entstehung der gangränösen Cyste aus dem Meckelschen Divertikel in unserem Falle könnte auch auf andere Fälle Licht verbreiten, in denen man aus einem Meckelschen Divertikel hervorgegangene Cysten beobachtet hatte, ohne über den Entstehungsmechanis mus klar geworden zu sein.

Leider ist aber in dem von Rebentisch ${ }^{1}$ ) beschriebenen Fall von Entzündung eines Meckelschen Divertikeis und Ileus das

1) Langenbecks Archiv, Bd. 70. 
Vorhandensein zweier zwischen den Schenkeln einer Dünndarmschlinge ausgespannter hohler Divertikelreste erst fast 3 Monate nach dem Auftreten der ersten Ileuserscheinungen konstatiert worden. Deshalb läßt sich nicht entscheiden, ob ähnliche Verhältnisse dort vorgelegen haben, wie in unserem Falle oder nicht. Die Krankeugeschichte und die Zeichnung sprechen dafür.

In Fällen wie B. ist es unmöglich, eine richtige Diagnose vor der Operation zu stellen. Alle Versuche, ein diagnostizierbares Krankheitsbild zu konstruieren, sind gekünstelt, weil es sich um die Kombination der inneren Einklemmung mit der durch die Gangrän des Diverticulum Meckelii verursachten rapiden Peritonitis handelt.

Die Operationsresultate waren schlecht, zweimal war der Exitus die direkte Folge fehlerhaften Operierens, im Fall Sch. (Nr. 15) wurde dor ans der Einklemmung befreite Darm für lebensfähig gehalten, er wurde aber gangränös. Im Fall B. (Nr. 17) führte eine Blutung aus dem Mesenterialstumpf den tödlichen Ansgang herbei, während in 2 anderen Fällen anderweitige tuberkulöse Prozesse das günstige Resnltat der operation vereitelten.

\section{Invaginationen.}

6 Fille: 2 geheilt, 4 gestorben.

Invaginationen sind bei uns zulande selten. Im ganzen haben wir in 7 Jahren 8 Invaginationen gesehen. Ein Kind (Kl. f. I. N. 792/1901) wurde moribund in die Klinik gebracht, es hatte eine Invagination des Colon ascendens and transversum in das Colon descendens und die Flexura sigmoidea, und wurde nicht operiert. Ein Patient $(\mathbf{K}$.) ließ sich wegen Mastdarmvorfalls aufnehmen. Es stellte sich heraus, daß es sich um einen Prolapsus flexurae sigmoideae invaginatae handelte. Die Reposition gelang in tiefer Narkose und in stärkster Beckenhochlagerung. Bei der Nachbehandlung mit Massage wurde ein Tumor in dem S Romanum gefühlt und deshalb die den Tumor, ein submuköses Lipom, enthaltende Flexurpartie mit vollem Erfolg reseziert. Dieser Fall wird in der Statistik nicht mitgezählt, weil klinisch die Erscheinungen des Prolapsus und nicht die des Darmverschlusses im Vordergrund standen. Die Invagination war ebenfalls durch eine Neubildung hervorgerufen bei einer 42 jährigen Frau, deren Ileum an der Stelle invaginiert war, an welcher ein submuköses Myom seinen Sitz hatte. 
Bei dem Knaben Gl. (Fall 26) wurde der Beginn der Erkrankung auf einen Fußtritt in die rechte Unterbauchgegend, in welcher sich nachher die Invagination das Ileum fand, zurückgeführt. Nach der Beobachtung von Braun ist das auch durchans möglich.

Ein 18 jähriger Patient schuldigte als Ursache für seine Invaginatio ilei den Genuß von Stachelbeeren und Bier an.

5 Darmeinschiebungen betrafen Kinder, von denen nur 2 im ersten Lebensjahre, 3 dagegen im Alter von 7-8 Jahren waren.

Das Ileum war bei den Kindern 3 mal invaginiert, davon $1 \mathrm{mal}$ ins Cöcum (Fall 27 Sch.), zweimal das Colon bei den Kindern im ersten Lebensjahr.

Von letzteren ist der Operationsbefund bei dem Kind F. (Fall 28) besonders interessant, weil eine retrograde oder aufsteigende Invagination zweifellos sichergestellt werden konnte.

Fälle von aufsteigender oder retrograder Invagination sind von d'Arcy Power, Broca, Braun, Rydygier und Riedel ${ }^{1}$ ) beschrieben worden. Wie in allen übrigen Fällen war auch in dem von Herrn Geheimrat Helferich operierten Fall das Colon vollkommen beweglich. Flexur und Colon descendens waren nicht zu unterscheiden. Im unteren Teil des Colon schimmerte blutiger Darm durch, es fand sich daselbst eine Invagination und zwar war der untere Darmteil in den oberen eingeschoben - etwa $15 \mathrm{~cm}$ weit. Durch Streichen von oben nach unten gelang es verhältnismäßig leicht, den invaginierten Teil zu entwickeln.

In einem anderen Falle (B. Nr. 45) war eine beginnende aufsteigende Invagination des Ileum vorhanden. Unterhalb einer Stenose des Ileum war der Darm eng kontrahiert, oberhalb erweitert. Der dilatierte zuführende Darm hatte sich nur wenige $\mathrm{cm}$ über die Stenose und den abführenden Darm gestülpt, aber doch so deutlich, daß Herr Geheimrat Helferich an diesem Bild demonstrierte, wie sich eine aufsteigende Invagination entwickeln kann.

Die Behandlung bestand in 5 Fällen in Resektion der beteiligten Darmpartie, im Falle F. wurde ein Anus praetern. a. d. S. Romanum angelegt.

Die gestorbenen Pat. wurden sehr spät (5, 7, 9, 10 'Tage, nach dem Beginn der Krankheit) operiert. Ein Mädchen (27) hatte eine Aspirationspneumonie, der Knabe Gl. (26) starb an einer durch den Murphyknopf veranlaßten Perforationsperitonitis.

1) Mitteilungen aus den Grenzgebieten, Bd. 14, S. 218. 


\section{Torsion und Knickung.}

13 Fialle: 4 gestorben, 9 geheilt.

Die Passagestörung war in fast allen Fällen durch Adhäsionen - strangförmige oder flächenhafte - hervorgerufen.

Die Adhäsionen stammten her von Appendizitis, von Adnexerkrankungen, von früheren Laparotomien, 3 mal spielte die Tuberkulose eine wichtige Rolle.

Im Fall 34, Fr. I., gab zu dem Darmverschluß der zuerst von Küttner beschriebene retroperitoneale Verlauf des unteren Ileumendes Veranlassung dadurch, daß der zu der fixierten Partie führende Darm um seine Längsachse torquiert war. Daneben bestand aber noch eine mäßige Enge des in etwa 5-6 cm Ausdehnung retroperitoneal gelagerten Ileum. Denn als durch Peritonealplastik dieser Teil mobilisiert war, schien er doch nicht weit genug. Deshalb wurde diese Partie durch Ileocolostomie ausgeschaltet. Derselbe Pat. mußte 2 Monate später wegen Darmverschlusses, hervorgerufen durch flächenhafte und bandartige Adhäsionen, zum zweitenmal und 1 Jahr später wegen Einklemmung einer Darmschlinge zwischen ligamentösen Adhäsionen zum drittenmal operiert werden. Nach der 3. Operation erlag er einer Pneumonie.

Auf Adhäsionsknickung beruhende Verschlüsse der Flexura sigmoidea dürften zu den Seltenheiten gehören. Wir lıaben sie zweimal gesehen.

Der Pat. Kr. (Fall 40) kam mit der Diagnose: chronischer Ileus bei hochsitzendem Rektum carcinom und die Erscheinungen waren auch derart. Proktoskopisch waren allerdings nur einzelne flache Geschwüre am Übergang vom Rektum in die Flexur zu sehen, in die Flexur vorzudringen gelang nicht. Die Probelaparotomie ergab eine Sigmoiditis. Danach gelang es durch hohe Einläufe Stuhl und Winde zu erzielen, bald aber traten von neuem die Erscheinungen des Darmverschlusses auf. Die Flexura sigmoidea wurde eingestellt und eine Fistel angelegt. Als man nach einiger Zeit versuchte, die Wegsamkeit der Flexur und des Rektum wieder herzustellen, gelang dies nicht. Es wurde deshalb abermals eine Laparotomie gemacht und num zeigte sich am unteren Ileum geringe tuberkulöse Peritonitis, die Flexur war mit dem Mesenterium dieser Ileumpartie, durch alte Adhäsionen verwachsen, nach rechts hinübergezogen, geknickt und unpassierbar geworden. Durch eine Peritonealplastik erhielt die Flexur wieder ein freies Mesosigmoideum, das 
Ileum ein bewegliches Mesenterium. Die Fistel in der Flexura sigmoidea heilte und der Patient nahm 40 Pfund an Gewicht zul. Diese Erfahrung hat uns gelehrt, wie vorsichtig man mit der Diagnose Sigmoiditis sein muß.

Im Fall N. (Nr. 41) war die Kuppe des S Romanum durch einen bleistiftdicken Strang an dem linken Tubenwinkel fixiert, bei der Patientin war 5 Jahre vorher ein intraligamentäres Myom exstirpiert worden.

Auch Fall 32 bedarf noch besonderer Erwähnung, weil bei ihu ein doppeltes Passagehindernis bestand. Das eine war ein strikturierendes Carcinom des Colon descendens, das andere eine adhäsive Peritonitis des Dünndarms, welche denselben zu zwei Konvoluten zusammen gebacken hatte.

Interessant ist nun, daß der Patient zunächst die Beschwerden eines Appendizitiskranken hatte: 4 tägige Stuhlverstopfung, auch nach reichlicher Stuhlentleerung, Schmerzen in der Ileocoecalgegend, schmerzhafte Resistenz daselbst, sodaß das Cöcum freigelegt und die Appendix exstirpiert wurde. Dabei fiel die eigenartig knetbare Konsistenz der Cöcumwand auf, sodaß man glaubte, es handelte sich hier einmal um eine wirkliche Typhlitis stercoralis ohne Beteiligung der Appendix. Nach 3 Monaten kam Pat. wieder, diesmal mit Ileuserscheinungen. Die Laparotomie zeigte die beiden Dünndarmkonvolute, das Ileum unterhalb des 2. war leer, oberhalb weit und gebläht, das Cöcum von gleicher Beschaffenheit, wie damals. Die Wirkung einer Enteroanastomose zwischen geblähtem und leerem. Ileum konnte nicht mehr konstatiert werden, da unmittelbar nach der Operation der Exitus eintrat. Die Autopsie ergab: kleines stenosierendes Krebsgeschwür des Colon descendens und tiefer rechtsseitiger Leistenbruchsack mit stark schwieliger Verdickung des Bruchsackperitoneums. Sch lußfolgerung: Der eigenartige Zustand des Cöcum war der Folgezustand der vorher vorhanden gewesenen Überdehnung des Cöcum, auch eine Pseudoappendizitis! Krenter ${ }^{1}$ ) und Weiß ${ }^{2}$ ) haben sogar eine Dehnungsgangrän des Cöcum bei tiefsitzendem Dickdarmverschluß beobachtet. Die Dünndarmkonvolute waren wahrscheinlich frülıer einmal Bruchdarm gewesen.

1) Kreuter, Langenbecks Archiv, Bd. 70, S. 518.

2) Weiß, Langenbecks Archiv, Bd. 73, S. 839 . 


\section{Umschnïrung des Darms, äußere und innere narbige Stenose.}

5 Fälle: 2 geheilt, 3 gestorben.

Die Umschnürung des Darms, die äußere und innere narbige Stenose, könnte man zusammen abhandeln, da der mechanische Endeffekt die Verengerung des Darmlumens bis zur Undurchgängigkeit bei allen der gleiche ist.

Indessen sind die pathologischen Bilder so mannigfaltig, daß es nicht angängig erscheint, sie in Bausch und Bogen zu besprechen.

Sehr verschieden sind z. B. die beiden Fälle von Umschnürung: Im Falle 42 tuberkulöse Mesenterialdrüsen, Mesenterium geschrumpft und verkürzt. Der Dünndarm mehrfach von runden Ligamenten, wie von einem Bindfaden, umschnürt. Diese Bänder liegen anf der Darmserosa, sie gehen aber nicht auf das Mesenterium über.

Bei der Patientin H. J. (Nr. 43) reitet der Proc. vermiformis anf dem Ilem, seine Spitze ist an der oberen Mesenterialfläche fixiert und obwohl er den Darm nicht völlig umschnürt, hat er doch einen gangränösen Schnürring erzengt, welcher eine kirkumskripte Peritonitis hervorgerufen hat.

Noch bemerkenswerter ist der Fall 44, dessen Ileum an 4 Stellen durch chronische Mesenteriitis von außen dadurch verengert ist, daß die narbigen Züge vom Mesenterium auf die Darmserosa übergreifen und gewissermaßen wie Fangarme den Darm zusammengeprebt haben. An der tiefsten Enge sind auch Adhäsionen und Knickungen, und es ergibt sich aus dem Befund an der Appendix, daß es sich mit großer Wahrscheinlichkeit um die Folgen einer Appendizitis handelt. 3 Enteroplastiken und eine Ileocolostomie sind nötig, um dem Darminhalt freie Bahn zu verschaffen. Dabei hat man die Möglichkeit, sich von dem Unversehrtsein der Darmschleimhaut in den Stenosen zu überzeugen.

Endlich die eigenartige Krankengeschichte des 11jährigen Mädchens E. M. (46). Nicht die vermutete tuberkulöse Peritonitis, nur tuberkulöse Mesenterialdrüsen - nicht die erwarteten zahlreichen Adhäsionen, sondern freier, mächtig erweiterter Dünndarm, im unteren Ileum mit sehr stark hypertrophischer Wandung - die Ursache des Darmverschlusses: eine Stenose des untersten Ileumendes, welche dort beginnt, wo der Wurmfortsatz in den Dünndarm mündet. Die Appendix bequem durchgängig. Man erhält den Eindruck, daß Appendix und unterstes Ileum den Darminhalt aus dem. 
erweiterten zuführenden Dünndarm in das Cöcum befördert haben (Abb. 6.)

46. J.-N. 1664/1903. E. M., 12jähriges Mädchen. 15. II. bis 6. III. 1904. Dünndarmverschluß. Stenose des untersten Ileum. Perforation der Appendix in das Ileum. Darmresektion.

30. VIII. bis 31.X. 1903 in der medizinischen Klinik wegen Peritonitis tuberculosa und Ascites. Adhäsionen und Neigung zu Meteorismus blieben zurück. Gute Beeinflussung durch Bauchmassage. Stuhlregelung war möglich. Seit November 1903 zeitweise Auftreibungen des Leibes abwechselnd mit Durchfällen. Vor 14 Tagen im AnschluB an solche Auftreibung Durchfall. Täglich 10 Entleerungen. Große Ermattung. Am 13. II. 1904

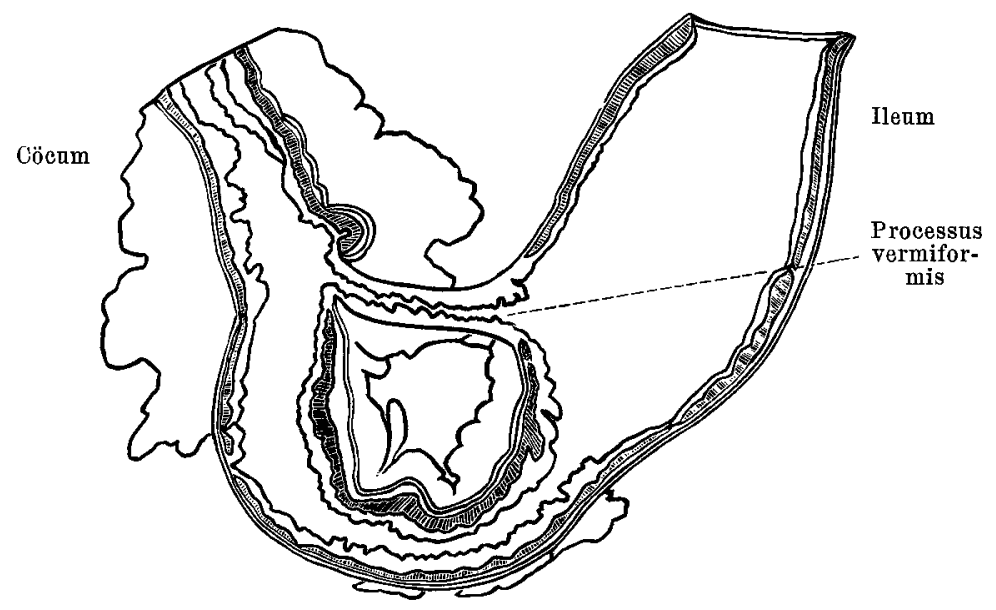

Fig. 6.

Fall 46. Perforation des Proc. vermiformis in das Ilenm. Stenose des untersten Ileum. Darmverschluß.

wieder in die medizinische Klinik aufgenommen. Kein Durchfall mehr, aber kein Stuhl, keine Winde. Kollern im Leib, vermehrte Peristaltik. Leibesumfang $68,5 \mathrm{~cm}$. Dämpfung verschieblich, aber keine deutliche Fluktuation. 14. II. 1904 Koterbrechen.

Am 15. II. in die chirurgische Klinik verlegt.

Status: Mageres graziles Mädchen, erbricht kotige Massen. Kein Stuhl, keine Winde, Puls 124, klein.

Abdomen sehr stark aufgetrieben, von Zeit za Zeit sehr starke Peristaltik des auBerordentlich erweiterten Dünndarms, beginnend am linken Rippenbogen bis ins kleine Becken sich fortsetzend. Bei Rückenlage Dämpfung in den abhängigen Partieen, bei Lagerung auf die rechte Seite, links hinten Tympanie, dann weiter vorn Dämpfung bis zum Nabel, bei Linkslagerung Dämpfung links breiter. - Da Ascites angenommen 
wurde, wurde auf Anraten des Verf. eine Punktion in der medizinischen Klinik vorgenommen. Dieselbe ergab aber Dünndarminhalt.

Deshalb sofortige Operation in der chirurgischen Klinik nach vorheriger Magenspülung. Sauerstoff-Chloroformnarkose: Mediane Laparotomie (Dr. Göbell). Kein freies Exsudat, Dünndarmschlingen kolossal erweitert. Ileum mannesarmdick mit hypertrophischer Wand. Serosa fast überall noch spiegelnd. Einzelne Netzadhäsionen durchtrennt und gelöst. Passagehindernis im untersten Ileum. Cöcum leer. Unterstes Ileum mit narbiger Serosa und verdicktem Mesenterium bildet dadurch eine Schleife, daß die zeigefingerdicke und -lange Appendix mit ihrer Spitze am Ileum festhaftet. Rings um die Appendix alte Adhäsionen. Cöcumwand verdickt. Tuberkulöse Mesenterialdrüsen. Punktion des Dünndarms. Entleerung von 5 Liter Inhalt. Resektion des untersten Ileumteils nebst Cöcum und Appendix. Beide Darmlumina geschlossen. Ileum seitlich mit Colon ascendens vereinigt. Schluß der Bauchhöhle durch Etagennaht. Verband. Kochsalzinfusionen. Kampfer.

Glatter Verlauf. 6. III. Mit Leibbinde geheilt entlassen.

Wann diese Perforation des Proz. vermiformis in den Dünndarm erfolgt ist, wer vermöchte es zu sagen! Die mikroskopische Untersuchung der Darmwand des engen Ileumteils, der Appendix und der Cöcum ergab an der Mündungsstelle der Appendix in das Ileum nur einzelne kleine Geschwüre im Ileum, aber keine tuberkulösen Veränderungen. Dagegen findet sich hinter dem Winkel zwischen Cöcum und Ileum eine Drüse mit verkreideten Massen. Dieser Befund würde daranf hinweisen, daß der vielleicht tuberkulöse Prozeß, welcher sich hier abgespielt hat, länger zurückliegt, als die Beobachtungszeit in der medizinischen Klinik währte. Ob die Perforation in frïher Kindheit durch einen akuten Prozeß oder dureh einen tuberkulösen verursacht wurde, kann man nicht bestimmen.

\section{Darmverschluß durch carcinomatöse Striktur.}

4 Fälle: 4 geheilt.

Von den Fällen, in deneu der Darmverschlnß durch eine carcinomatöse Striktur inszeniert war, sind nur die aufgeführt, bei welchen sich ein kompletter Darmverschluß mit völlig ausgeprägten Symptomen entwickelt hatte. Nur einmal konnte die Diagnose auf den Sitz und die Art des Verschlusses so sicher gestellt werden, daß gleich ein Anus praeternaturalis an der Flexura sigmoidea angelegt wurde, der nach 18 Tagen die Resektion der Flexur unterhalb des Anus praeternaturalis folgte. In den übrigen 3 Fällen mußte erst eine mediane Probelaparotomie ausgeführt werden, um die Diagnose zu 
sichern. Es wurde 1 mal die primäre Resektion und Naht, 2 mal ein Anus praeternaturalis oberhalb des Hindernisses, und sekundäre Resektion der Flexura sigmoidea, 1 mal Vorlagerung und Resektion der Flexura ausgeführt. Alle 4 Patienten wurden geheilt. Der cöcale Meteorismus war meist nicht mehr nachweisbar, weil die Valvula ileocoecalis bereits insuffizient geworden war.

\section{Fremdkörper-lleus.}

3 Fälle: 3 geheilt.

Die Erscheinungen des Darmverschlusses wurden in 3 Fällen durch einen Fremdkörper hervorgerufen, je einmal durch einen Murphyknopf, einen Gallenstein und durch einen Ascaris lumbricoides. Nur der letztere Fall (Nr. 51) beansprucht Interesse. Er lehrt, daß ein Spulwurm imstande ist, durch Erzeugen eines Enterospasmus einen regelrechten Obturationsileus hervorzurufen. Letzterer trotzt 5 Tage allen Mitteln (auch dem Atropin!) und wird endlich durch Enterotomie und Extraktion des Wurms beseitigt.

Er läßt die bisher publizierten Fälle von Darmverschluß durch Enterospasmus in einem nenen Lichte erscheinen und veranlaßt, jeden Fall von Ileus bewirkendem Enterospasmus mit besonders scharfer Kritik zu prüfen.

\section{Hinsichtlich des Mechanismus nicht sichergestellt.}

1 Fall: 1 geheilt.

Unaufgeklärt blieb der Mechanismus der Passagestörung in dem Fall 54 - wahrscheinlich wirkten Kompression und Knickung zusammen. Netz und Dünndarm bildeten einen Klumpen, zusammengebacken durch tuberkulöses Gewebe. Es war unmöglich, den Darm zu präparieren oder gar die Stelle des Hindernisses aufzusuchen. In der Erwartung, es möchte sich durch Offenhalten der Bauchhöhle die Passage wiederherstellen, wurden wir nicht getäuscht. Daß bei vorhandenem tuberkulösen Ascites und Ileuserscheinungen die Entleerung des Exsudats durch Punktion zuweilen genügt, um den Darm wieder wegsam zu machen, braucht nur erwähnt zu werden. Auch wir verfügen über eine solche Beobachtung. Da der Fall sonst keine operative Behandlung erheischte, ist er in unserer Statistik nicht aufgeführt. 


\section{Postoperativer Darmverschluß.}

4 Fälle: 3 geheilt, 1 gestorben.

Rein mechanischer Ileus unmittelbar nach Laparotomien ist selten, oft wird es sich um eine Kombination von mechanischen und dynamischen Momenten handeln; mechanische Knickung und zarte Verklebung, welche durch einen Darm mit guter Peristaltik überwunden werden würden, führen zum völligen Verschluß, wenn der zuführende Darm länger als 48 Stunden paretisch bleibt. Wenn letzterer dazu dilatiert wird, so komprimiert er, wie Wilms ${ }^{1}$ ) kürzlich gezeigt hat, den abführenden Darm, so daß wiederum eine mechanische Kraft mitwirkt.

In diese Rubrik gehört z. B. die Form des Darmverschlusses, welche man allerdings selten beobachtet: es ist gelungen einen Appendico-Periotonitis im unteren Teil des Abdomens zum Stillstand zu bringen. Der Patient ist fieberfrei, hat einen normalen kräftigen Puls, aber er bricht dauernd, und Stuhl und Winde stellen sich nicht ein, trotz aller hohen Einläufe. Daß es kein rein dynamischer Ileus ist, erkennt man daran, daß man den Dünndarm in vermehrter Peristaltik sieht. Hierdurch und durch das gute Allgemeinbefinden unterscheiden sich solche Patienten von den anderen mit dynamischem Ileus peritonitischen Ursprungs. Daß bei solchen Zuständen ein Enterostomie ein lebensrettender Eingriff sein kann, davon hat sich heutzutage jeder Chirurg überzeugt.

Um einen dynamischen Ileus ohne Peritonitis handelt es sich wohl in allen den Fällen, in welchen lange dauernde Laparatomien. vorausgegangen sind. Kliniken, in denen lange dauernde Laparotomien zu den Seltenheiten gehören, werden über den postoperativen dynamischen Ileus nach aseptischen Laparotomien geringe Erfahrungen haben. Die Ursachen für unsere Fälle von postoperativem Ileus sind 4 mal rein mechanischer Natur gewesen. 2 mal trat nach Darmresektion eine derartige Störung des Heilungsverlaufs auf. Das eine Mal war nach der end to end Vereinigung der Darmenden durch Knickung und Torsion das Darmlumen verschlossen, das andere Mal hatte nach der side to side Vereinigung eine Knickung am abführenden Ende und Verklebung der geknickten Schlingenschenkel die gleiche Wirkung.

Im dritten Falle war ein Meckelsches Divertikel, welches

1) Münchner med. Wochenschr. 1966, Nr. 4 . 
bis dahin symptomlos geblieben war, exstirpiert und an dem zugehörigen Dünndarm eine Verengerung aufgetreten. Dieselbe wurde 4 Tage nach der 1. Operation beseitigt.

Schließlich trat einmal nach einer Appendixexstirpation im Intervall ein Obturationsileus mit Koterbrechen auf, dessen Erscheinungen sofort verschwanden, als die Bauchwunde wieder eröffnet und tamponiert wurde. Der Erfolg dieser Maßnahme spricht für ein rein mechanisches Hindernis.

Nur in 2 Fällen handelte es sich um einen dynamischen Ileus, einmal nach einer Radikal-Operation eines Leistenbruches und einmal nach Durchtrennung eines an der Milz fixierten und auf dem Colon transversum reitenden Netzstranges.

Damit haben wir schon 2 unserer Fällevon dynamischem Ileus erwähnt. Es erübrigt noch mitzuteilen, daß wir einmal einen Pat. an Darmverschluß durch Koprostase sterben sahen, ferner, daß bei einem unserer Ileusfälle die Erscheinungen durch ein stielgedrehtes Ovarium, bei einem anderen durch eine Pankreatitis ihre Erklärung fanden. Beide Patientinnen wurden durch Operation geheilt.

Bei der operativen Behandlung desinneren Darmverschlusses wird von Herrn Geheimrat Helferich in der Kieler chirurgischen Klinik im allgemeinen nach denselben Grundsätzen wie früher in der Greifswalder Klinik verfahren, wie sie seinerzeit von Heidenhain u. a. dargelegt worden sind.

Jeder Operation wegen inneren Darmverschlusses geht eine gründliche Magenspülung voraus, nicht allein um das Erbrechen während der Operation zu vermeiden, auch um der Diagnose willen. Wir haben es erlebt, daß ein Patient mit der Diagnose Ileus eingeliefert und sofort auf den Operationstisch gebracht wurde, und, als der Bauch eröffnet war, man einen das Abdomen ausfüllenden Riesenmagen fand. Dieser mußte nun erst in Narkose ausgehebert werden, was immer Unannehmlichkeiten hat. Der Patient wurde durch eine Gastroenterostomia retrocolica posterior geheilt.

In allen Fällen wurde die allgemeine Narkose angewandt, auch im Shok. Man kann oft genug konstatieren, daß der Puls sich bessert, wenn die Spannung der Bauchdecken aufhört. Gewöhnlich wurde mit Chloroform narkotisiert, seit $3 \frac{1}{2}$ Jahren meist mit dem Sauerstoffchloroformapparat, - nicht selten wurde die Narkose mit Chloroform eingeleitet und als Äthertropfnarkose weiter geführt.

Das Hauptgewicht wurde auf die Sorge für möglichst geringe Abkühlung, deshalb vermeiden wir feuchte Kompressen, und auf 
schnelle Ausführung der Operation gelegt. Bei Dünndarmverschlüssen wurde stets der lange mediane Bauchschnitt, oder wenn die Lokalsymptome auf das untere Ileum hinwiesen, ein rechtsseitiger Schrägschnitt ausgeführt. Immer wurde danach gestrebt, durch große Schnitte die rascheste Orientierung zu ermöglichen. Die vorquellenden geblähten Darmschlingen werden in warme trockene Tücher gepackt und das Hindernis freigelegt.

Beim Strangulationsileus und bei den Invaginationen soll man mit der Entwirrung von komplizierten Knoten oder der Desinvagination, wenn sie nicht leicht vonstatten gehen, sich nur dann aufhalten, wenn die Möglichkeit, daß sich der strangulierte oder invaginierte Darm erholt, vorhanden ist. Sonst soll man unverzüglich zur Entleerung des zuführenden Darmes schreiten. Ist der Darm oberhalb des Passagehindernisses durch Überdehnnng so geschädigt, daß man ein gut Teil mitresezieren muß, so sorgt man erst für gute Entleerung des Darms durch Einnähen eines Drains und vorsichtiges Leerstreichen; am leeren Darm läßt sich dann leichter feststellen, ob sich der Darm erholt, ob man ihn zurücklassen kann oder nicht. Dabei gelten für die Ausdehnung der Resektion dieselben Regeln, wie bei der Darmresektion incarcerierter Bruchdärme. Ist der zuführende Darm in gutem Zustand, so näht man etwas weiter oberhalb das Drain ein, streicht den Darm oberhalb des Darmverschlusses nach diesem Drain hin leer und legt einen Gummischlauch unterhalb das Drain um den Darm, um den Zuflul zur Resektionsstelle zu vermeiden. Die Enterostomiestelle versorgt man mit Mull so, daß der Darm durch das lange Drain entleert werden kann, während man an dem tiefer gelegenen Darm die Resection vornimmt.

Während man mit der Exstirpation der erkrankten Darmpartie beschäftigt ist, muß man sich überlegen, ob man die Darmenden vereinigen will, oder in die Wunde fixieren will und dann sekundär die Kommunikation durch Darmklemmen oder Operation herstellen.

Das hängt von dem Allgemeinzustand $a b$, und der Operateur muß sich darüber klar sein, was er dem Patienten zumuten kann. Im allgemeinen wird jeder Chirurg bestrebt sein, die Darmpassage nach unten wieder herzustellen. Er wird dann stets die Methode wählen, welche am schnellsten die Operation beendigt. Da das unterste Ileumende bekanntlich wenig beweglich ist, so wird er öfters eine side to side Vereinigung des oberen Darmendes mit dem Cöcum, Colon ascendens oder auch Colon transversum, welches von ihnen am leichtesten zugängig, ausführen und sich nicht damit 
abmühen, den zuführenden Dünndarm mit dem unteren Ileumrest zu vernähen. Je länger der Darmverschluß besteht, je zweifelhafter es ist, daß sich die Darmfunktion rasch wiederherstellt, um so eher wird man sich zum Anus praeternaturalis entschließen, zumal dann, wenn der Puls von Minute zu Minute schlechter wird. Ein Anus raeternaturalis am Dünndarm ist kontraindiziert: bei hochsitzendem Dünndarmverschluß und wenn man große Strecken Dünndarm hat entfernen müssen, wegen Inanitionsgefahr.

Hier soll aber gleich bemerkt werden, daß wir den Murphyknopf, den wir vorher schon niemals am Dickdarm anwandten, jetzt nach zweimaligen schlechten Erfahrungen am Dünndarm ganz außer Gebrauch gesetzt haben.

War bereits schon Gangrän und Peritonitis vorhanden, so muß man die Bauchhöhle mit warmer steriler Kochsalzlösung spülen, der man mit Vorteil Wasserstoffsuperoxyd zusetzt. Dann wird drainiert, tamponiert und es werden einige Situationsnähte angelegt.

Wenn nicht vor der Operation schon eine subkutane Kochsalzinfusion gegeben war, wird nach der Operation am besten gleich eine intravenöse Infusion gegeben, aber nur bei jüngeren Individuen, deren Herz noch gesund ist, auf das Herz älterer Individuen wirkt die intravenöse Infusion direkt schädlich.

Die Hauptaufgabe der Nachbehandlung besteht in der Wiederherstellung der Darmfunktion. Man darf nicht müde werden, immer wieder Klistiere zu machen; gelingt die Herbeiführung der Darmwegsamkeit nicht, so sieht man sich genötigt, eine Dünndarmschrägfistel anzulegen. Gewöhnlich reguliert sich danach die Darmfunktion rasch und gut. Solange der Patient noch bricht, muß er natürlich mit ernährenden subkutanen Infusionen bei Kräften erhalten werden.

Wir haben die Überzengung gewonnen, daß unsere Resultate in den letzten beiden Jahren deshalb bessere geworden sind, weil wir die bei der Peritonitisbehandlung gewonnenen Erfahrungen auch den Patienten mit inneren Darmverschluß haben zugute kommen lassen.

Die durch Adhäsionen hervorgerufenen Dünndarmverschlüsse erheischen stets eine völlige Entwicklung des Darms, weil man nicht selten findet, daß neben der Knickung durch Adhäsionen noch eine Darmschlinge oder ein Darmschenkel umschnürt ist. Ist der Darm frei, dann muß man die notwendigen Eingriffe machen, eine Enteroplastik an Stenosen, eine Peritonealplastik oder eine Enteroanastomose. Aber gerade mit der Darmausschaltung sei 
man nicht zurückhaltend. So war z. B. im Fall 34 der Versuch, durch eine Peritonealplastik das untere Ileum beweglich zu machen, Zeitvergeudung, im Fall 40 dagegen war die Wiederherstellung des Mesenterium und Mesosigmoideum durch Peritonealplastik sehr nützlich. Die Resektion im Fall 36 hätte durch eine Ileokolostomie ersetzt werden müssen. Auch im Fall 44 wäre die Operation dadurch vereinfacht worden, wenn man auf die Enteroplastiken verzichtet hätte und sofort zur Ileokolostomie geschritten wäre.

Eine besondere Stellung nehmen auch hinsichtlich der Therapie die Dickdarmverschlüsse ein, mögen sie nun durch Achsendrehung oder Invagination, durch eine carcinomatöse Striktur oder durch Knickung bedingt sein. Zweimal haben wir die Resektion der Flexur (Fall 14 und 47) mit primärer Vereinigung ausgegeführt, und Heilung erzielt. Im Fall 14, Achsendrehung der Flexura sigmoidea, waren aber die ersten Tage nach der Operation so kritisch, daß wir zu der Überzeugung kamen, man hätte besser getan zweizeitig zu operieren. Bei den übrigen Patienten ist auch nach diesen Grundsätzen verfahren. Auf welche Weise man den Darm zunächst entlastet, hängt vom Befund ab. Dafür bieten ja die Krankengeschichten genügende Exempel. Einmal konnte eine seitliche Darmfistel an der Flexur angelegt werden, die sich - nach Beseitigung der Knickung der Flexur durch Peritonealplastik - von selbst wieder schloß; zweimal wurde ein regelrechter Anus praeternaturalis an der Flexura sigmoidea bei Flexurcarcinom, dreimal eine Kolostomie bei Achsendrehung der Flexur gemacht. Einmal wurde die Entlastung durch Punktion des Colon descendens, ein anderes Mal durch Entleerung des Ileum erreicht; im letzeren Falle konnte dazu das Flexurcarcinom reseziert und die zu- und abführende Schlinge in der Wunde fixiert werden.

Bei starker Füllung des Cöcum, des Colon ascendens und des unteren Ileum scheint uns die Appendicostomie ein sehr empfehlenswertes Verfahren. Sie ist bei durchgängiger Appendix rasch und reinlich zu erledigen und der Operateur kann den Darm auslaufen lassen, während er an einer tiefer gelegenen Stelle des Dickdarms weiter arbeitet.

Im Fall 41, Knickung der Flexura sigmoidea durch Adhäsionen, leistete uns die Appendicostomie gute Dienste: 1. entleerte sie das stark gefüllte Cöcum und Colon ascendens sowie den Dünndarm, 2. konnte man sehr gut Ernährungsklistiere von hier aus in den Dickdarm einführen, 3. wurde der Dickdarm von oben nach unten und umgekehrt durchgespült, sehr wichtig bei der vorhanden ge- 
wesenen Neigung der Flexur, durch Adhäsionen fixiert und geknickt zu werden.

Wir halten die Appendicostomie bei Ileus für indiziert:

1. bei strikturierendem Carcinom des Colon, falls nicht beim Flexurcarcinom ein einfacher Anus praeternaturalis an der Flexur genügt,

2. bei Volvulus des Cöcum und Colon ascendens, wenn rechtzeitig eine Detorsion möglich ist. Durch die Appendicostomie wird das bewegliche Cöcum zugleich an der Bauchwand fixiert;

3. bei Volvulus der Flexura sigmoidea, wenn sich derselbe langsam entwickelt hat, und eine starke Füllung des Dick- und Dünndarmes vorhanden ist;

4. in jenen Fällen von paralytischem Ileus, in denen der Dickdarm ad maximum gedehnt sich trotz aller hohen Einläufe nicht entleeren läßt.

Um die Verhältnisse möglichst günstig für einen raschen Verschluß der Fistel zu schaften, empfiehlt es sich, eine Invagination des bis auf 2-3 cm gekürzten Appendix auszuführen und durch den invaginierten Appendixstumpf das Drain in das Cöcum einzuführen.

Nach diesen therapeutischen Prinzipien ist die Behandlung der Fälle mit innerem Darmverschluß in der hiesigen Klinik geleitet worden.

Es wurden folgende Operationen ausgeführt (s. Tab. S. 455).

\begin{tabular}{|c|c|c|c|c|}
\hline & Zahl & geh. & gest. & \\
\hline \multirow{2}{*}{$\begin{array}{l}\text { Der Darm wurde entleert: } \\
\text { Der Darm wurde nicht } \\
\text { entleert: }\end{array}$} & 31 & 15 & 16 & 48,3 Proz. Heilung \\
\hline & 21 & 10 & 11 & 47,2 \\
\hline
\end{tabular}

Diese Gegenüberstellung hat nicht mehr die Bedeutung wie in in der Greifswalder Statistik, weil bei den schweren Fällen fast immer die Darmentleerung vorgenommen worden ist. Die 31 Fälle stellen also die schwersten dar, wenn 48,3 Proz. Heilung erzielt worden sind, so spricht das entschieden für die Entleerung.

Die Resultate sind keine glänzenden; mit den Erwartungen, welche man vor 10 Jahren gehegt hat, stimmen sie nicht überein; das hängt aber weniger mit der geringen Leistungsfähigkeit der 
Ein Beitrag zur Pathologie und Therapie des inneren Darmverschlusses. 455

\begin{tabular}{l|r|r|r|l}
\hline \multicolumn{1}{c|}{ Art der Operation } & Zahl & geh. & gest. & \\
\hline \hline Laparotomie, Tamponade & & & & \\
ohne weiteren Eingriff & 4 & 3 & 1 & \\
Darmresektionen & 25 & 15 & 10 & \\
Dünndarmresektionen & 17 & 9 & 8 & \\
Ileokökalresektionen & 2 & 1 & 1 & \\
Dickdarmresektionen & - & - & - & \\
$\quad$ primäre & 3 & 3 & - & \\
sekundäre & 3 & 2 & 1 & \\
Desinvagination & 2 & 1 & 1 & \\
Enterotomie & 3 & 3 & - & \\
Enteroplastik & 3 & 2 & 1 & Die zweite durch Ileo- \\
Peritonealplastik & 2 & 1 & - & kolostomie geheilt. \\
Darmausschaltungen & 5 & - & - & \\
$\quad$ Enteroanastomose & 2 & - & 2 & \\
Ileokolostomie & 3 & 3 & - & \\
Lösung v. Adhäsionen etc. & 17 & 9 & 8 & \\
Enterostomie & 3 & - & 3 & \\
Cöcostomie & 1 & - & 1 & \\
Appendicostomie & 1 & 1 & - & \\
Colostomie & 7 & 4 & 3 & \\
Appendixexstirpation & 3 & 1 & 2 & \\
Exstirpation eines Ovarial- & & & & \\
kystoms & 1 & 1 & - & \\
& & & & \\
& & &
\end{tabular}

chirurgischen Therapie zusammen, als vielmehr mit der Tatsache, daß die meisten Patienten zu spät der operativen Behandlung zugewiesen wurden.

Bessere Resultate werden wir erst haben, wenn die Ärte gelernt haben werden, die Diagnose auf Strangulations-Ileus rechtzeitig zu stellen und sich die interne Medizin zu der Anschauung bekehrt hat, daß sie durch ihre zuwartende Haltung beim Okklusions-Ileus die Gefahren der Operation von Tag zu Tag steigert, und daß viele Menschenleben als ein Opfer der Lehren der internen Medizin, nicht aber der chirurgischen Therapie anzusehen sind. 
Vol-

\begin{tabular}{|c|c|c|c|c|c|c|}
\hline Nr. & Name & 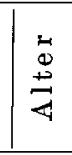 & 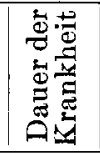 & Diagnose & Befund & $\begin{array}{l}\text { Operations- } \\
\text { verfahren }\end{array}$ \\
\hline 1 & E., Chr. & $\begin{array}{c}40 \mathrm{~J} . \\
\mathrm{m} .\end{array}$ & 6 Tage & $\begin{array}{l}\text { Dickdarmver- } \\
\text { schluß bei Tu- } \\
\text { mor im klein. } \\
\text { Becken. }\end{array}$ & $\begin{array}{l}\text { Flexur sigm. u. } \\
\text { Cöcum leer. } \\
\text { Volvulus des } \\
\text { Ileum. }\end{array}$ & Enterostomie \\
\hline 2 & $\begin{array}{l}\text { B., S. } \\
1369 / 1903\end{array}$ & $\begin{array}{c}64 \mathbf{J} . \\
\text { w. }\end{array}$ & 19 Std. & $\begin{array}{l}\text { Dünndarmver- } \\
\text { schluß (in Zu- } \\
\text { sammenhang } \\
\text { m.früherer Her- } \\
\text { niotomie). }\end{array}$ & $\begin{array}{l}\text { Volvulus des } \\
\text { Ileum. }\end{array}$ & $\begin{array}{l}\text { Resektion. Ileo- } \\
\text { kolostomie. }\end{array}$ \\
\hline 3 & $\begin{array}{l}\text { Schr., Cl. } \\
\text { 1406/1902 }\end{array}$ & $\begin{array}{c}53 \mathrm{~J} . \\
\mathrm{m.}\end{array}$ & 4 Tage & $\begin{array}{l}\text { Darmverschluß } \\
\text { nach Resectio } \\
\text { flex. sigmoideae. }\end{array}$ & $\begin{array}{l}\text { Volvulus eines } \\
\text { st. verwachsen. } \\
\text { Dünndarmkon- } \\
\text { voluts. }\end{array}$ & $\begin{array}{l}\text { Zweifache Darm- } \\
\text { resektion. }\end{array}$ \\
\hline 4 & \begin{tabular}{|l} 
Sch. \\
1397/1901
\end{tabular} & $\begin{array}{c}46 \mathrm{~J} . \\
\text { w. }\end{array}$ & 4 Tage & $\begin{array}{l}\text { Darmverschlu } \beta \\
\text { oberhalb alter } \\
\text { geheilteriDünn- } \\
\text { darmfistel. }\end{array}$ & $\begin{array}{r}\text { Bei der Autopsie } \\
\text { Volvulus unter- } \\
\text { halb der Fistel. }\end{array}$ & $\begin{array}{l}\text { Wiedereröffnung } \\
\text { der Dünndarm. } \\
\text { fistel. }\end{array}$ \\
\hline 5 & v.P. & $\begin{array}{c}47 \mathrm{~J} . \\
\text { w. }\end{array}$ & 6 Tage & $\begin{array}{l}\text { Dünndarmver- } \\
\text { schlu@. }\end{array}$ & $\begin{array}{l}\text { Volvulus des } \\
\text { untersten } \\
\text { Ileum, Netz- } \\
\text { adhäsion. }\end{array}$ & $\begin{array}{l}\text { Laparotomie. Lö- } \\
\text { sung der Adhä- } \\
\text { sion. Detorsion. }\end{array}$ \\
\hline 6 & Schr., L. & $\begin{array}{c}30 \mathrm{~J} \\
\mathrm{~m} .\end{array}$ & 28 Std. & $\begin{array}{c}\text { Diffuse Peritoni- } \\
\text { tis durch Ap- } \\
\text { pendicitis oder } \\
\text { Strangulation. }\end{array}$ & $\begin{array}{c}\text { Innere Einklem- } \\
\text { mung in einem } \\
\text { Mesenterialspalt } \\
\text { u. Verknotuug. }\end{array}$ & $\begin{array}{l}\text { Resektion von } \\
\text { 3mIleum. Ileo- } \\
\text { kolostomie. }\end{array}$ \\
\hline 7 & $\begin{array}{l}\text { Sch., E. } \\
\text { 1245/1904 }\end{array}$ & $\begin{array}{c}26 \mathrm{~J} . \\
\text { w. }\end{array}$ & 2 Tage & $\begin{array}{l}\text { Dünndarmver- } \\
\text { schluß. Gravi- } \\
\text { dität Mens. V. }\end{array}$ & $\begin{array}{l}\text { Innere Einklem- } \\
\text { mung v. Ilenm } \\
\text { in einem Me- } \\
\text { senterialschlitz. } \\
\text { Volvulus der } \\
\text { nächsthöheren } \\
\text { Schlinge. Peri- } \\
\text { tonitis. }\end{array}$ & $\begin{array}{l}\text { Resektion von } \\
1 \text { mIleum. Anus } \\
\text { praeternaturalis. }\end{array}$ \\
\hline 8 & $\underset{751 / 1905}{\mathrm{~K} . \mathrm{F}}$ & $\begin{array}{c}16 \mathrm{~J} \\
\mathrm{~m} .\end{array}$ & 42 Std. & $\begin{array}{l}\text { Diffuse Peritoni- } \\
\text { tis,ob durch Ap- } \\
\text { pendicitis oder } \\
\text { Strangulation } \\
\text { fraglich. }\end{array}$ & $\begin{array}{c}\text { Volvulus fastdes } \\
\text { ganzen Dünn- } \\
\text { darms. Perito- } \\
\text { nitis. }\end{array}$ & $\begin{array}{l}\text { Detorsion. Re- } \\
\text { sektion v. } 5,50 \mathrm{~m} \\
\text { Dünndarm. }\end{array}$ \\
\hline
\end{tabular}


Ein Beitrag zur Pathologie und Therapie des inneren Darmverschlusses.

vulus.

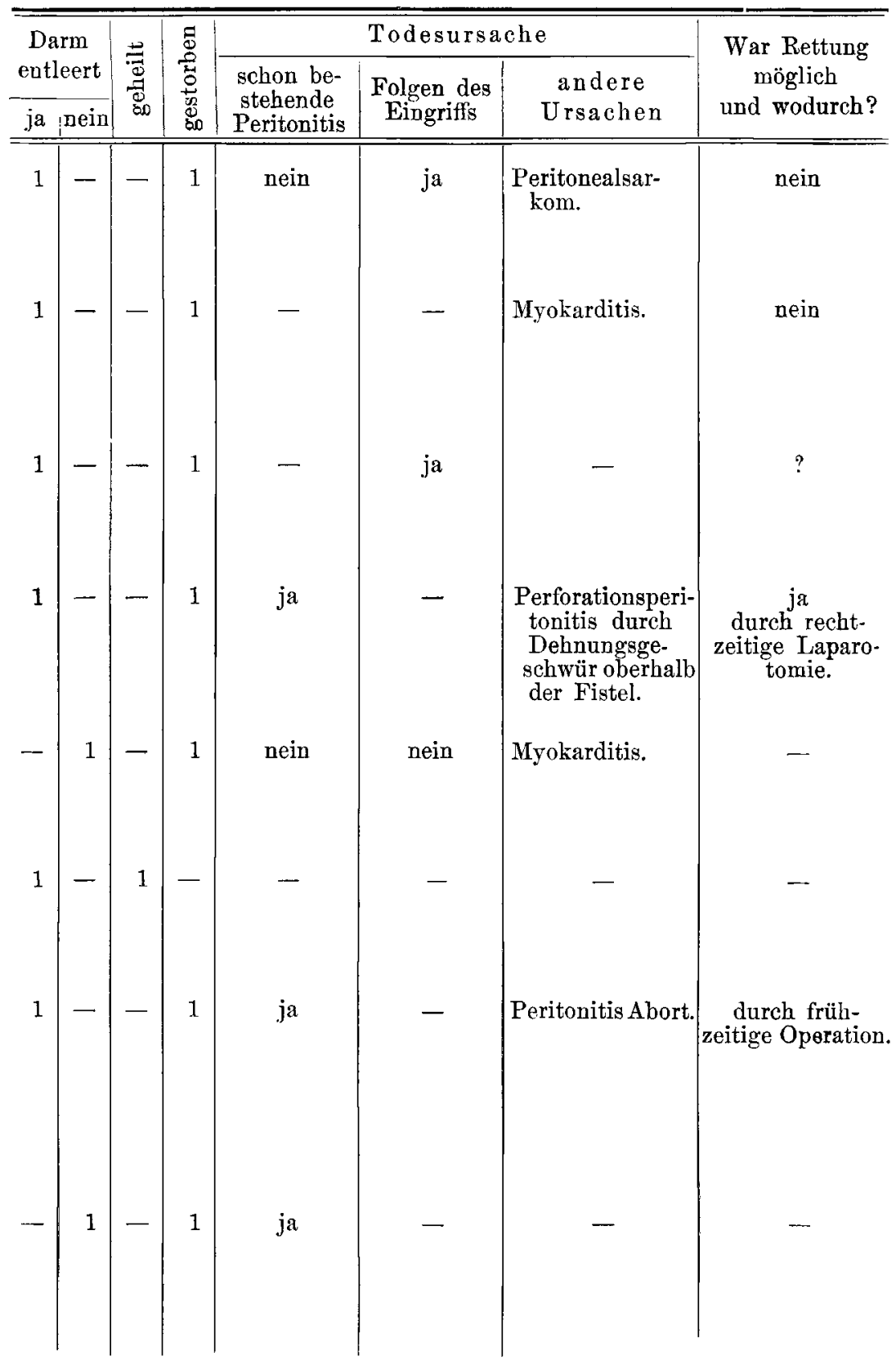




\begin{tabular}{|c|c|c|c|c|c|c|}
\hline $\mathrm{Nr}$. & Name & 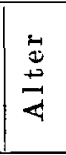 & 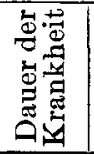 & Diagnose & Befund & $\begin{array}{l}\text { Operations - } \\
\text { verfahren }\end{array}$ \\
\hline 9 & $\begin{array}{l}\text { P. P. } \\
1163 / 1905\end{array}$ & $22 \mathrm{~J}$. & - & $\begin{array}{l}\text { Thrombose der } \\
\text { Mesenterial- } \\
\text { venen. }\end{array}$ & $\begin{array}{l}\text { Autopsie. Volvu- } \\
\text { lus des ganzen } \\
\text { Dünndarms. }\end{array}$ & $\begin{array}{l}\text { Laparotomie. } \\
\text { folvulus nicht } \\
\text { erkannt. }\end{array}$ \\
\hline 10 & W., J. & $\begin{array}{c}16 \mathrm{~J} . \\
\mathrm{m} .\end{array}$ & 7 Tage & $\begin{array}{l}\text { Peritonitis bei } \\
\text { Darmverschluß. }\end{array}$ & $\begin{array}{l}\text { Keine diffuse } \\
\text { Peritonitis. Ach- } \\
\text { sendrehung des } \\
\text { Cöcum u. Colon } \\
\text { ascendens. }\end{array}$ & $\begin{array}{l}\text { Detorsion. Vor- } \\
\text { lagerung. Cö- } \\
\text { costomie. }\end{array}$ \\
\hline 11 & $\begin{array}{l}\text { L., C. } \\
1292 / 1903\end{array}$ & $\begin{array}{l}42 \mathrm{~J} \\
\mathrm{~m} .\end{array}$ & 5 Tage & $\begin{array}{l}\text { Dickdarmaver- } \\
\text { schluß, Perito- } \\
\text { nitis. }\end{array}$ & $\begin{array}{l}\text { Volvulus derFle- } \\
\text { xura sigmoidea. }\end{array}$ & $\begin{array}{l}\text { Detorsion. } \mathrm{Co}^{-} \\
\text {lostomie. }\end{array}$ \\
\hline 12 & K. K. & $\begin{array}{c}47 \mathrm{~J} \\
\mathrm{w} .\end{array}$ & $24 \mathrm{Std}$ & Darmverschluß. & $\begin{array}{l}\text { Volvulus derFle- } \\
\text { xura sigmoidea. }\end{array}$ & $\begin{array}{l}\text { Detorsion. } \mathrm{Co}- \\
\text { lostomie. }\end{array}$ \\
\hline 13 & S., G. & $\begin{array}{c}30 \mathrm{~J} \\
\mathrm{~m} .\end{array}$ & 2 Tage & $\begin{array}{c}\text { Beckenperitonitis } \\
\text { Appendizitis? }\end{array}$ & $\begin{array}{l}\text { Volvulus derFle- } \\
\text { xura sigmoidea. }\end{array}$ & $\begin{array}{l}\text { Detorsion. Vor- } \\
\text { lagerung, sek. } \\
\text { Resektion. }\end{array}$ \\
\hline 14 & $\begin{array}{c}\text { W., G. } \\
1905\end{array}$ & $\begin{array}{l}14 \mathrm{~J} . \\
\mathrm{m} .\end{array}$ & $\begin{array}{l}3 \text { Tage } \\
(17 \text { Ta- } \\
\text { ge) }\end{array}$ & $\begin{array}{l}\text { Tiefsitzender } \\
\text { Dickdarmver- } \\
\text { schluß. }\end{array}$ & $\begin{array}{l}\text { Volvulus derFle- } \\
\text { xura sigmoidea. }\end{array}$ & $\begin{array}{l}\text { Detorsion. Re- } \\
\text { sektion des Fle- } \\
\text { xura sigmoidea. }\end{array}$ \\
\hline
\end{tabular}

1. 701/1902. E., Chr, Maurer, Kiel. 40 Jahre. Aufn. 16. VII. 1902, gestorben 17. VII. 1902. Ileus. Großer Peritonealer Tumor. Achsendrehung. des Dünndarms. Anus praeternaturalis.

Anamnese: Seit einigen Jahren Unregelmäßigkeit des Stuhlgangs, oft mehrere Tage angehalten.

Am 10. VII. 1902 morgens initiales Erbrechen von gelblich grünlichen Massen.

Am 12. VII. morgens sekundäres Erbrechen. Seit 12. VII. erbricht Pat. ungefähr jede halbe Stunde. Erbrochenes riecht seitdem übel. Winde fehlen seit dem 10 . VII.

Status: Hochgradig elend aussehender Mann. Puls sehr frequent, wenig kräftig. Dauerndes Erbrechen von gelblich fäkulent riechenden Massen. Leib aufgetrieben. In den abhängigen Teilen etwas Dämpfung, sonst überall hohe Tympanie. Kein Bruch. Rektale Untersuchung: im Douglas knollige Tumoren (von Schleimhaut bedeckt).

Operation in der Absicht, einen Anus praeternaturalis anzulegen in Narkose: Linker Schrägschnitt, Flexur leer, ebenso nach rechtem Schrägschnitt Cöcum. Dünndarmschlingen stark gebläht, eine Dünndarmschlinge vorgelagert und fixiert.

17. VII. 1902. Pat. sehr elend, heftiges Aufstoßen.

Dünndarmschlinge eröffnet. Entleerung von reichlich flüssigem Kot 
Ein Beitrag zur Pathologie und Therapie des inneren Darmverschlusses.

\begin{tabular}{|c|c|c|c|c|c|c|c|}
\hline \multirow{2}{*}{\multicolumn{2}{|c|}{$\begin{array}{c}\text { Darm } \\
\text { entleert }\end{array}$}} & \multirow{3}{*}{ 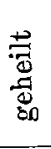 } & \multirow{3}{*}{$\begin{array}{l}9 \\
0 \\
0 \\
0 \\
0 \\
0 \\
00 \\
0 \\
0 \\
0\end{array}$} & \multicolumn{3}{|c|}{ Todesursache } & \multirow{3}{*}{$\begin{array}{l}\text { War Rettung } \\
\text { möglich } \\
\text { und wodurch? }\end{array}$} \\
\hline & & & & \multirow{2}{*}{$\begin{array}{l}\text { schon be- } \\
\text { stehende } \\
\text { Peritonitis }\end{array}$} & \multirow{2}{*}{$\begin{array}{c}\text { Folgen des } \\
\text { Eingriffs }\end{array}$} & \multirow{2}{*}{$\begin{array}{c}\text { andere } \\
\text { Ursachen }\end{array}$} & \\
\hline $\mathrm{ja}$ & nein & & & & & & \\
\hline - & - & - & 1 & - & 一 & - & $?$ \\
\hline 1 & - & - & 1 & $\begin{array}{l}\text { Zirkum- } \\
\text { skripte Peri- } \\
\text { tonitis. }\end{array}$ & nein & 一 & $\begin{array}{c}\text { frühzeitige } \\
\text { ration. }\end{array}$ \\
\hline 1 & - & - & 1 & ja & nein & - & $\begin{array}{l}\text { ja } \\
\text { frühzeitige Ope- } \\
\text { ration. }\end{array}$ \\
\hline 1 & 一 & - & 1 & - & nein & $\begin{array}{l}\text { Myokarditis. } \\
\text { Herzschwäche. }\end{array}$ & nein \\
\hline - & 1 & - & 1 & - & - & $\begin{array}{l}\text { Ulcus ventriculi } \\
\text { perforatum. }\end{array}$ & nein \\
\hline 1 & - & 1 & 一 & - & - & - & - \\
\hline 11 & 3 & 2 & 12 & & & & \\
\hline
\end{tabular}

\section{Uhr Exitus.}

Autopsie: Starke Auftreibung des Dünndarms. Kollaps des Dickdarms. Eine Ileumschlinge tief ins kleine Becken herabgezogen und hängt mit einem über faustgroßen blau gefärbten Tumor innig zusammen. Sie ist zweimal um ibre Achse gedreht. Der Tumor ist weich und liegt eng der Flexur an, die er komprimiert. Keine Peritonitis.

Kindskopfgroßes, das kleine Becken ausfüllendes Sarkom des Peritoneum. Zahlreiche, kleine, gestielte, hämorrhagische Tumoren des Douglas.

2. J.-N. 1369/1903. B. S., 64 Jahre, Arbeiterfrau aus N. Aufnahme 12. XII. 1903, gestorben 13. XII. 1903. Achsendrehung einer Dünndarmschlinge. Darmresektion.

Anamnese: Vor 13 Jahren wegen eingeklemmten Bruchs in der hiesigen Klinik behandelt. War bis gestern abend gesund. Keine Stuhlverhaltung.

Gestern abend 11 Uhr starke Leibschmerzen. Initiales Erbrechen. Um 3 Uhr wegen heftiger Schmerzen der Arzt gerufen. Heute morgen dauerudes sekundäres Erbrechen, kein Stuhlgang, keine Winde.

Status: Kleine magere, blasse, schwache Frau mit belegter Zunge. Lungen: Bronchitis. Puls klein, 120 in der Minute. Mäßige Arteriosklerose Abdomen stark aufgetrieben, stark vermehrte Peristaltik (die Därme bäumen 
sich auf) im rechten Hypogastrium weniger als im übrigen Abdomen. Leber unter den Rippenbogen verschwunden.

Freier Erguß in die Bauchhöhle. Keine Hernien, wohl aber alte Herniotomienarbe in der R. Leistenregion. Erbrechen. Beim Magenspülen reichlicher Dünndarminhalt, noch nicht kotig. Keine Winde.

$6 \mathrm{Uhr}$ nachm. Sauerstoff-Chloroform, Äthertropf-Narkose (Dr. Göbell.) Medianer Laparotomieschnitt. In der Bauchhöhle dunkle, blutig-seröse Flüssigkeit. Geblähte Dünndarmschlingen. Weiter abwärts schwarzrote Dünndarmschlingen. Volvulus: Ca. 1,10 m über der Valvula Bauhini. Adhäsion zwischen Dünndarm und R. Leistengegend. Um diesen Strang und durch diese Lücke war der unterhalb der Adhäsionen gelegene Dünndarm geschlüpft bis $5 \mathrm{~cm}$ oberhalb der Valv. Bauhini, Das ganze Konvolut hatte sich noch 2 mal um die eigene Achse gedreht. Gangrän im obersten nnd untersten Teil der Schlinge. Lösung der Adhäsion und der Achsendrehung. Entleerung des zuführenden Darms. Resektion des Darms. Zuf. und abf. Ende eingestülpt. 2 mal übernäht. Ileocolostomie an das Col. transversum. Naht des Schlitzes. Austupfen der Bauchhöhle. Spülung mit Kochsalzlösung. Col. transvers. bereits mit Dünndarminhalt gefüllt. SchluB der Bauchhöhle durch Etagennaht. Kochsalzinf. campher. Abends 10 $\frac{1}{2}$ Uhr Stuhlgang.

11/2 Uhr Puls klein, weich, aber fühlbar. Pat. schläft ruhig.

13/12. 3 Uhr morgens Exitus letalis.

Autopsie: Sehr trübes, schlaffes Herz mit myokard. schwielen Fettdurchwachsung. Beg. fibr. Peritonitis. Rechts Cruralhernie. Residuen von Peritonitis, Lungenödem und Emphysem. Trübung der Leber. Trübung der Nieren mit ganz geringer Granularatrophie.

3. J.-N. 1406/1902. Schr. Cl., 58 Jahre, Schiffer aus L. Aufnahme 12. XII. 1902, gestorben 14. XII. 1902. DünndarmverschluB durch Achsendrehung bei Adhäsionen nach Resectio Carc. flex. sigm. - Zweifache Darmresektion.

Anamnese: 10. IV. 1902 ein wallnußgroßer Tumor an der Flexura sigmoidea zugleich mit dem erkrankten Darmstück entfernt. 25. VI. 1902 entlassen. Stuhlgang regelrecht. Appetit gut. Bis zum 3. XII. 1902 gesund. Am 3. XII. 1902 Erbrechen. Nach einer Verordnung des Arztes Besserung. Am 8. XII. Unwohlsein, Erbrechen. Seit demselben Tage völlige Stuhlverhaltung und Aufstoßen. Am 11. XII. wieder Erbrechen.

Status: Älterer kräftig gebauter Mann. Herz und Lungen ohne Besonderheiten. - Leib: in der Mittellinie unterhalb des Nabels eine $20 \mathrm{~cm}$ lange, gradlinige Narbe, die auf der Unterlage nicht verschieblich ist und $2 \mathrm{~cm}$ oberhalb ihres unteren Endes eine mit Schorf bedeckte eingezogene Stelle zeigt, aus derselben läuft reichlich kotige Flüssigkeit. Leeib mäBig aufgetrieben, oberhalb des Nabels ïberall tympan. Schall. Unterhalb desselben und in den seitlichen Partien besteht Dämpfung. Bei Seitenlage sind die abhängigen Stellen gedämpft, die hohen dagegen tympanitisch. Nirgends ein Tumor zu fühlen aber freier ErguB. Im Rektum kein Tumor, aber reichlich Kotmassen.

13. XII. 1902. Chloroform-Narkose: Operation: Geh. Rat Helferich. Laparotomie in der linken Lumbalgegend: Colon descendens leer. Hindernis also 
Ein Beitrag zur Pathologie und Therapie des inneren Darmverschlusses. 461

nicht an der früheren Operationsstelle. Deshalb mediane Laparotomie rechts neben der alten Narbe, Dünndarm in breiter Ausdehnung adhärent. Beim Versuch, die Adhäsionen stumpf zu lösen, starke Blutung. Schnitt nach oben bis an den Proc. xiphoides verlängert. Es quellen übermäBig bis zum Platzen gedehnte Dünndarmschlingen heraus. Blutung aus den Adhäsionen läßt sich nicht stillen. Nun sieht man, daß 2 Dünndarmschlingen stark abgeknickt als starres Konvolut unter sich und mit dem Peritoneum verwachsen sind. Ferner ist eine Achsendrehung des Darms vorhanden. Knäuel nur schwer zu entwirren. Unterhalb des Hindernisses Darm kollabiert. Die Lösung der verschlungenen Darmabschnitte wird dadurch ermöglicht, daß die stark geblähten Schlingen eröffnet und reichlich entleert wurden. Resektion der stark verwachsenen Darmschlingen. (4 Darmenden.) Einmal side to side, einmal end to end Anastomose. Toilette der Bauchhöhle. Reposition des Darms. Partielle Naht der Bauchwunde. Jodoformtamponade, seitliche Wunde tamponiert.

Aus der Fistel entleert sich nach Verschluß der Bauchwand reichlich dünner Kot. Sublimatkompresse auf die Fistel.

13. XII. nachmittags eine Kochsalzinfusion (1 l) mit $30 \mathrm{gr}$ Kognak, ferner Portwein per os. Puls 132 klein, kein Erbrechen, kein Aufstoßen.

14. XII. Puls klein, 140. Allgemeinzustand leidlich, Pat. hat viel getrunken, nicht erbrochen. Nachmittags Kollaps. Exitus 6 Uhr 40 p. m.

Autopsie: Fibrinöse Peritonitis. Fibrinöse Belege an den Nahtstellen und dem Mesenterium, Darmnähte in gutem Zustande. Dünndarmschlingen durch frische Adhäsionen untereinander verklebt. Am Rektum kein Rezidiv, dagegen carcinomatöse Mesenterialdrüsen.

4. J.-N. 1397/1901. Sch., 46 Jahre, Stellmachersfrau aus G. Aufnahme 19. I. 1901, gestorben 21. I. 1901. DarmverschluB nach Enterostomie. Wiedereröffnung der Darmfistel. Volvulus des anteren Ileum. Peritonitis infolge Perforation eines Dehnungsgeschwürs.

Anamnese: 25. V. 1900 in der hiesigen Frauenklinik an Myomen operiert, am 30. V. 1900 Enterostomie. Am 23. IX. aus der Frauenklinik entlassen. 11 Wochen in ihrer Heimat bettlägerig. Seit 25. XII. Darmfistel geschlossen. Stuhlgang und Blähungen normal. Seit dem 17. I. 1900 kein Stuhlgang und kein Flatus. Jeden Tag sehr hä口figes Erbrechen, auch nachts jede Stunde mehrmals.

Am 19. I. Aufnahme in die chirurgische Klinik.

Status: Blasse magere Pat. mit stark belegter Zunge. Urin kein Eiweiß, kein Zucker. Abdomen mäBig aufgetrieben, aber noch weich. In der Mittellinie zwischen Nabel und Symphyse $10 \mathrm{~cm}$ lange Laparotomienarbe. In der linken Inguinalgegend dicht über dem Lig. inguinale eine $6 \mathrm{~cm}$ lange in der Mitte eingezogene Narbe. Venen in der linken Unterbauchgegend leicht erweitert.

Linke Unterbauchgegend etwas stärker prominent als die rechte. Schall über dem Abdomen überall tympanitisch. In der linken Unterbauchgegend Perkussion empfindlich. Pat. bricht wässrige, nicht übelriechende Massen. Klysma, 2 Liter, laufen bequem ein. Einzelne harte Kotballen gehen ab. Keine Winde. Man fühlt zur Narbe in der linken Inguinal- 
gegend eine prallgefällte Darmschlinge ziehen. Die Palpation in dieser Gegend ist schmerzhaft.

Puls 104 mittelkräftig, regelmäBig. Temperatur 37,4.

Per vaginum Cervixstumpf, keine resistente Darmschlinge. Behandlung: Magenspulung. Hohe Klistiere.

20. I. 1901. Keine Winde abgegangen. AufstoBen, kein Erbrechen, Temperatur 37,6, Puls 100, etwas weich. Linke Unterbauchgegend etwas stärker druckempfindlich, hoher Einlauf.

20. I. 1901. Abends noch keine Winde. 1 mal erbrochen. Pat. sieht schlechter aus. Temperatur 37,2, Puls 106.

21. I. 1901. Nachts einige Mal erbrochen. Kein Koterbrechen. Keine Winde. Temperatur 37,6, Puls 108.

Abdomen stärker aufgetrieben und fast überall empfindlich, bläulich verfärbt. Narbe (links) gerötete Prominenz. Chloroform Narkose. Operation: Geh. Rat Helferich. Inzision in die Inguinalnarbe. Es sturzt sofort diennflüssiger Kot heraus. Man fühlt innen Darmschleimhaut. Reichliche Menge Kot und Gas.

Nach der Operation sehr matt, stündlich Kampfer. Exitus.

Abends Temperatur 39,8. Sehr stark aufgetriebenes Abdomen. $7 \mathrm{Uhr}$

Autopsie: Diffuse, eitrig fibrinöse Peritonitis. Perforation im Ileum $26 \mathrm{~cm}$ oberhalb der Fistel. Kotige Flüssigkeit im Abdomen. Zwischen der Fistel, welche $1 \mathrm{~m}$ oberhalb der Ileocöcalklappe liegt, und dem Cöcum Volvulus. Ein Teil des Ileum zwischen der Darmschlinge und einer die Darmschenkel vereinigenden Adhäsion durchgeschlüpft. Dieser Ileum-Teil ist aber nicht incarceriert. Knickung und Darmverschlu $B$ durch Adhäsionen bedingt. Volvulus ist für Wasser durchgängig. Mäßiges Emphysem und zahlreiche kleine Blutungen der Lunge. Nierensteine.

\section{Frau v. P., 47 Jahre alt. Achsendrehung einer Dünndarmschlinge. Detorsion.}

Anamnese: Sommer 1903 wegen angeblichen Gallenblasenleidens in Karlsbad. Damals schon etwas am Darm nicht ganz in Ordnung. 27. XI. 1908 wechselnde Schmerzhaftigkeit und Druckempfindlichkeit im rechten Teil des Leibes unterhalb der Leber, Schmerzen nach der Blasengegend ausstrahlend. Befund: bewegliche Niere. Daneben hochgradige Trägheit des Darms. Am 2. XII. 1903 abends und in der folgenden Nacht heftige Schmerzen im Leibe und sich wiederholendes initiales Erbrechen. 3. XII. 1903 keine umschriebene Druckempfindlichkeit in dem etwas aufgetriebenen Leibe, krampfartige Schmerzen (Darmkoliken) Temperatur 37,8, Puls 62. 4.XII. 1903 nach Tinct. opii und heißen Umschlägen subjekt. Besserung. Morgens noch Erbrechen. Dann kein Erbrechen mehr, Stuhlgang und Winde noch vorhanden. Leib weich, Temperatur 37,6. - 5. XII. 1903 Winde gehen noch ab, kein Stuhlgang. 6. XII. 1903 Temperatur 37,2, Puls kräftig. Abdomen ziemlich stark aufgetrieben. Warmwasser und Ol. Ricin.-Einlauf ohne Erfolg. Abends zunehmende Schmerzen. 7.XII. 1903 hohe Einläufe. 2 Liter ohne Erfolg. Kein Stuhlgang, keine Winde. 8. XII. 1903. Temperatur 38,0 , Puls 82 . Kein Stuhl, keine Winde. Zur chirurg. Klinik 
verlegt. Abdomen aufgetrieben, einzelne geblähte Darmschlingen sichtbar. Sofortige mediane Laparotomie in Sauerstoffchloroform-Narkose: Geh. Rat Helferich. Dündarmschlingen stark geblält. Colon leer. Hindernis im unteren Ileum. Netzadhäsion am Cöcum und Adhäsionsstrang vom Netz nach dem kleinen Beckenrand. Etwa $20 \mathrm{~cm}$ lange Schlinge unter der Adhäsion durchgetreten und Achsendrehung derselben. Lösung der Adhäsionen. Detorsion. Schlinge nicht stark geschädigt, erholt sich. Reposition des Darms. Schlug der Bauchhöhle durch durchgreifende Knopfnähte. Anfangs günstiger Verlauf. Winde gehen, keine Temperatur. In der Nacht vom 10. zum 11. XII. 1903 plötzlicher Herzkollaps. Exitus. Autopsie: keine Peritonitis.

6. J.-Nr. 548/1904. S. L., 30 Jahr, Werftarbeiter. Aufnahme 25. VI. 1904, entlassen 4. 8. 191). Innere Einklemmung und Volvulus. Resektion von $3 \mathrm{~m}$ Ileum.

cf. Deutsche Zeitschr. für Chirurgie, Bd. LXXVII, S. 608.

7. J.-N. 1245/1904. Sch., Frau, 26 Jahre aus B. Aufgenommen 16. XI. 1904, gestorben 19. XI. 1904. Peritonitis acuta bei innerer Einklemmung und Volvalus, Graviditas Mensis V. Laparotomie. Darmresektion. Anus praeternaturalis. Tamponade, Drainage der Bauchhöhle.

Anamnese: Bis 14. XI. 1904 nachmittags völlig gesund. Normaler Partus vor 3 Jahren. Jetzt Gravidität im fünften Monat. Am 14. XI. 1904 plötzlich leftiger Schmerz. Von der rechten Unterbauchgegend nach links in die Magengegend hinziehend. Gleichzeitig olnmachtähnliches Schwächegefühl und initiales Erbrechen. Sehr heftige Schmerzen durch Morphin nur vorübergehend gelindert. 14. XI. 190t nachmittags noch einmal Stuhlgang, seitdem kein Stuhlgang, keine Winde. Am 15. XI. 1904 mittags sekundäres Erbrechen, Erbrochenes ohne kotigen Geruch, seitdem AufstoBen. Heftige, nicht wehenartige, stechende Sclmerzen, keine zunehmende Blässe im Gesicht, keine Blutung aus den Genitalien. Zunehmende Unruhe.

Status: Schwer liranker Gesichtsausiruck, Atmung oberfächlich beschleunigt, 48, Puls 160 klein, regelmäßig. Brustorgane olme Besonderheiten. Zunge trocken, nur wenig belegt. - Leib aufgetrieben, etwas gespannt, doch noch eindrüclibar, im allgemeinen nicht sehr druckempfindlich. Rechte Tnterbauchgegend etwas stärker druckempfindlich, Uterus genau in der Mittellinie, fast bis zum Nabel reichend, zeitweilig liontrahiert. Neben dem Uterus keine Geselnulst. Vom Rektum und von der Vagina aus nichts Besonderes, Leber in Kantenstellung. Links handbreite Dämpfung, die sich bei Lagewechsel etwas auf hellt.

Operation: Dr. Göbell. In Äthertropfnarkose, gegen Schluß fast ohne Narkose. Mediane Laparotomie, einige cem bräunlicher, leichtgetrübter Flüssigkeit stürzen vor, die geblähten Dünndarmschlingen liegen vor, Serosa getrübt gerötet, hier und da mit Fibrinfetzen belegt. Etwas oberhalb der Ileocöcalgegend in einem Konvolut von verlilebten Dünndarmschlingen eine Kuppe grünlich schwař gefürbt. Vorsichtige Lösung der Verklebungen: $20 \mathrm{~cm}$ langes Darmstück ist durch ein kleines Loch des Mesenteriums einer benachbarten Schlinge getreten. Erweiterung des Loches, Reposition der Schlinge. - AuBerdem hat die $75 \mathrm{~cm}$ lange zuführende Schlinge eine Achsendrehung um die Mesenterialachse erfahren. Auch diese Schlinge

Deutsche Zeitschrift fuir Chirurgie. LXXXII. Bil. 
gangränös. - Das distale Ende der ganzen veränderten Darmpartie $15 \mathrm{~cm}$ oberhalb der Ileocöcalklappe. - Einnähen eines Drains in das Ileum oberhalb der erkrankten Partie. Entleerung von dickflüssigem, gelbem Kot unter Ausstreichen des Dünndarms. Abspülen mit steriler Kochsalzlösung. Resektion der ganzen erkrankten Darmpartie. Unteres Ende durch Tabaksbeutelnaht geschlossen. Oberes Ende mit Drain durch eine neue Wunde in der Ileocöcalgegend herausgelagert. Da Peritonitis besteht, zwei Inzisionen in der rechten und linken Weiche, Drainage der Peritonealhöhle. Darm nach AbgieBen mit Kochsalzlösung reponiert. Bauchwunde breit tamponiert. 3 Situationsnähte, steriler Verband. Kranke auf die rechte Seite gelagert.

Während der Operation mehrfach Kampfer Einspritzungen und Kochsalzinfusion $800 \mathrm{ccm}$.

17. XI. Allgemeinbefinden leidlich, aber Puls 160 , kräftiger als vor der Operation. Temperatur 38,3. 3 Kochsalzinfusionen mit Traubenzucker und Alkohol.

Abends Temperatur 39,3, Puls 160.

In der Nacht zum 18. XI. Abort ohne nennenswerte Blutung. Aber am Tage stärker ausgesprochenes Bild der Peritonitis.

19. XI. 10 Uhr morgens Exitus.

Autopsie: Eitrig fibrinöse Peritonitis der unteren Bauchhälfte, zu beiden Seiten des gut kontrahierten Uterus.

8. J.-N. 751/1905. K., Fr., 16 Jahre, Milchjunge aus K. Aufnahme 3. VIII. 1905, gestorben 5. VIII. 1905.

Achsendrehung fast des ganzen Dünndarms. | Resektion von $5,50 \mathrm{~m}$ Peritonitis diffusa.

j Dünndarm

Anamnese: Bis zum Mai 1905 immer gesund. Im Mai und Juni 19056 Wochen krank wegen Leibschmerzen und Verstopfung, dann Diarrhoe, Damals bettlägerig. Dann gesund bis Dienstag 1. VIII. 1905 abends. Heftige Schmerzen im ganzen Leibe. Erbrechen während der ganzen Nacht. Kein Stuhldrang. Ob Winde gegangen, weiw Pat. nicht. 2. VIII. 1905 im Bett, erbrach weiter, schlaflos wegen heftiger Schmerzen. Am 3. VIII. 1905 auf Veranlassung des Arztes in die akademischen Heilanstalten.

Status: Magerer, schwer kranker Junge mit sehr stark belegter Zunge und etwas lividen Schleimhäuten.

Brustorgane ohne besonderen Befund, untere Lungen- und Herzgrenze aufwärts verschoben. Abdomen aufgetrieben. Bauchdecken sehr stark gespannt. Geringer freier ErguB im Abdomen. Leberdämpfung nur 2 Querfinger breit. Ganzes Abdomen druckempfindlich, am stärksten rechts und unten vom Nabel. Douglas vorgewölbt, druckempfindlich. Deutliche Resistenz nirgends nachzuweisen. Pat. erbricht von Zeit zu Zeit sauren grünlichen Mageninhalt. Winde sind nicht abgegangen. Temperatur 38,6 , Puls 148, weich, klein.

Diagnose: Diffuse Peritonitis, ob durch Appendizitis oder Darmverschlus, fraglich.

Behandlung: Chloroform Äther Sauerstoff Narkose. Operation: Dr. Göbell. Schrägschnitt R. eröffnet das Abdomen. Sofort dringt übel- 
riechende bräunlich-rötlich eitrige Flüssigkeit hervor. Abdomen möglichst breit eröffnet. Dünndarmschlingen herausgelagert. Dünndarm blaurote Schlingen sehr stark gebläht, zum Teil mit Fibrin belegt, zum Teil mit rauchiger Serosa. Einzelne Partien ganz schwarz. Fast der ganze Dünndarm mit Auswahme des obersten Jejunum $(1 \mathrm{~m})$ hat am Fuße des Mesenterium eine Achsendrehung um 360 rechts herum erfahren. Beiseitigung der Achsendrehung. Im Mesenterium sehr zahlreiche weißlich-gelbliche Drüsen (wahrscheinlich tuberkulös.) Das untere Ende des Ileum trägt eine vollständig gangränöse $3 \mathrm{~cm}$ breite Schnürfurche. Am oberen Ende des an der Achsendrehung beteiligten Darms ist der Dünndarm in etwa $10 \mathrm{~cm}$ Ausdehnung durch breite Adhäsionen verwachsen. Das Mesenterium ist stark infarciert, eine tiefe Schnürfurche verläuft an der Unterfläche der Radix mesenterii. Es wird zunächst abgewartet ob sich der Darm erholt. Da keine Zeichen von Zirliulation vorhanden sind, so wird der ganze Darmteil $(5,50 \mathrm{~m})$ reseziert. Der Darm wird unter der unteren Schuürfurche gequescht, geschnürt, durchtrennt. Der Stumpf durch Tabaksbeutelnaht versenkt. IJann wird in großen Zügen das Mesenterium zentral von der Schnürfurche ligiert und abgetragen. Auch am Ende des zuführenden wird ein VerschluB durch Tabaksbeutelnaht hergestellt. Spülung, Austupfen der Bauchhöhle. 2 Liter Kochsalzlösung ins Abdomen, Kopf gesenkt. Side to side Anastomose zwischen Jejunumende und Cöcum. Austupfen der Bauchhöhle, Tamponade: Verband. Intravenöse Kochsalzinfusion. Abends Temperatur $39,0^{\circ}$, Puls 132 , leidlich gut.

4. VIII. morgens Temperatur 38,5, Puls 144, deutlich fühlbar. Intravenöse Kochsalzinfusion. Ernährungsklistiere.

Vormittags Erbrechen.

Am medialen Wundrand blaue Verfärbung der Haut. Wasserstoffsuperoxyd in die Bauchwunde. Halbfeuchter Verband.

Mittags wieder Erbrechen, jetzt schwarzbraun.

4 Uhr Temperatur 39,5, Puls 148 . Kochsalzinfusion.

Abends Verbandwechsel, blaue Verfärbung hat sich handgroh bis zum Nabel ausgedehnt. Exstirpation desselben. $\mathrm{H}_{2} \mathrm{O}_{2}$-Injektion. Intravenöse Kochsalz-Infusion. 0,0001 Digalen.

Um Nitternacht sehr unruhig.

5. VIIl. morgens 1 Uhr Exitus letalis.

Autopsie: Operativer Defekt eines groBen Dünndarmteils von der lleocöcalklappe an. $1,30 \mathrm{~m}$ Jejunum noch vorhanden. Janchige Peritonitis. Frische fibrinöse Peritonitis am Magen. Ektasie des Magens, blasses derbes Panlireas. Trübung und Hyperämie der Nieren. Frische Schwellung der Mesenterialdrüsen.

Aspiration von Mageninhalt.

10. J.-Y. 835/1900. W., 16 Jahre, Knecht. Aufnahme 6. IX. 1900, gestorben 6. IX. 1900. Volvulus des Kökum und Col. ascendens. Detorsion.

Anamnese: 31. VIII. 1900 diffuse Schmerzen im Leib. Am Morgen desselben Tages noch normaler Stuhlgang. Dann kein Stuhlgang. Am 3. IX. 1900 nach Klysma nur kleiner Kotballen entleert. Am 3. IX. 1900 Erbrechen. 5. IX. 1900 Koterbrechen. Druckempfindlichkeit nahm zu, kein Stuhlgang, keine Wintle. 
Status: Schwerkranker Junge. Puls klein, frequent (120 in der Minute.) Leib trommelförmig aufgetrieben. Schall tympanitisch. Druckempfindlich. Kotiges Erbrechen. Kein Stuhl. Keine Winde. Keine Hernie. Über der Symphyse und in den abhängigen seitlichen Partieen gedämpfter Schall.

6. IX. 1900. Operation in Chloroform Narkose. Med. Längsschnitt, serös-blutiges Exsudat in reichlicher Menge in der Bauchhöhle. Kolossal aufgeblähte Dünndarmschlingen. Serosa stark gerötet. Keine Peritonitis. Wunde bis zur Symphyse und Proc. xiph. erweitert. Eventeration des Dünndarms: $30 \mathrm{~cm}$ lange, kollosal aufgetriebene Dickdarmschlinge, welche die ganze linke Seite des Bauches und das Lipigastr. ausfüllt. Aussehen schwarzgrün nicht mehr spiegelnd, prall gefüllt, Scheitel der Schlinge liegt im linken Epigastrium, dort mit Netz und Bauchwand entzündlich verklebt. Cöcum und Col. ascendens um $360^{\circ}$ gedreht. Dickdarm unterhalb leer. Achsendrehung beseitigt. Größter Teil der gangränösen Darmschlinge auBerhalb der Bauchhöhle gelagert (Mesocolon sehr lang). Darm reponiert, Cöcum entleert. Durch Troikartwunde Darmrohr durch die Valvula ileocoecalis in den Dünndarm. Bauchsituationsnähte. Während der Operation Kampfer-Kochsalzinfusion. Nach der Operation Pat. wieder bei BewuBtsein. Aber Puls sehr schlecht. $4^{1 / 2}$ Uhr 3 Stunden post operat. Exitus.

Autopsie: Der gedreht gewesene Darm war gangränös.

11. J.-N. 1292/1903. L., C., 42 Jahr, Arbeitsmann aus W. Volrulus flexurae sigmoideae. Laparotomie. Lösung der Verschlingung. Vorlagerung. Aufnahme 25. XI. 1903, gestorben 28. XI. 1903.

Anamnese: Schon früher häufig Kolikschmerzen. Am 20. XI. 1903 Kolik, initiales Erbrechen. Einlauf, reichlicher Stuhl, heiße Umschläge, galliger Massen. Seitdem nicht wieder erbrochen, keine Neigung zu Übelkeit. Aber kein Stuhlgang, keine Winde. Meteorismus nahm zu, gestern abend Stuhldrang, blutiger Schleim. Rechts von der Mittellinie im Epigastrium stärkere Auftreibung, die an GröBe zunahm.

In den ersten Tagen Temperatur $38,8-39,0$, in den letzten Tagen $38,0-38,2$.

Status: Etwas magerer, krank aussehender Mann mit fieberhaft geröteten Wangen.

Zunge trocken, mit dunklen Borken bedeckt.

Puls 96.

Leib sehr stark aufgetrieben, gespannt, hoch tympanitisch. Unter den stark gespannten Bauchdecken lassen sich Konturen des darunter liegenden Darms erkennen. Eine stärkere Vorwölbung in der Pylorusgegend, eine andere solche in der linken Iliacalgegend. Der Leib ist im ganzen stark druckempfindlich, besonders in der linken Seite weniger als in der rechten.

Leberdämpfung vollkommen verschwunden.

Abends: Sofortige Operation. Sauerstoff Chloroform Narkose: Dr. Göbell. Schnitt in die Mittellinie vom Nabel bis zur Symphyse. Nach Eröffnung des Peritoneums wölbt sich eine fast oberschenkeldicke Dickdarmschlinge vor, die so erweitert ist, daB sie erst aus der Wunde heraus, 
gewälzt werden kann, nachdem diese bis zum Proc. xiphoideus erweitert ist. Schlinge: Flexura sigmoidea, stark blau verfärbt, von Gas aufgebläht, enthält ganz wenig Flüssigkeit. Die Spannung ist eine so pralle, trommelartige, daß der Darm bei Berührungen Töne wie ein Instrument von sich gibt. An 3 Stellen ist die Serosa ein wenig eingerissen. Die Flexur ist um ihr sehr langes Mesosigmoideum 1/1/2 mal gedreht. Nachdem die Drehung beseitigt, ist der Darm frei. Es erfolgt Stuhlgang und Winde. Darmschlinge weniger prall gespannt. Auch oberhalb der Flex. ist das Colon descend. transvers. ad maximum gedehnt, aber nicht cyanotisch, Col. ascendens nicht übermäßig gedehnt. Cöcum Appendix unverändert. Schlundsonde per rectum bis in die Flexur. Winde entweichen unter hörbarem Geräusch, auch dünner Stuhl. Flexur kollabiert, ebenso der Dickdarm. Dünndarm sieht auch verdächtig blaurot an einigen Stellen aus. Mesosignoideum ist so lang, daB die vorgelagerte Schlinge bis zur Mitte des Oberschenkels reicht, stark verdickt, schwielige alte Narben. Dabei auch frische peritonit. Auflagerungen. An seiner Wurzel ist es sehr schmal, so daB ab- und zuführender Schenkel sehr dicht nebeneinander liegen. An der Ansatzstelle des Mesosigmoid. eine Dünndarmschlinge durch Adhäsionen angeklebt.

Kochsalzspülungen der ganzen Bauchhöhle und des herausgelagerten Darms. Naht der Bauchwunde bis auf ihren unteren Teil, aus welchem die Flexura sigmoidea herausgeleitet wird. Schlinge eröffnet und so gelagert, daß die Wunde nicht beschmutzt werden kann. Verband.

26. IX. Winde und Stuhl gehen reichlich ab. Der gröBte Teil per anum, wenig durch die Fistel. Pat, fühlt große Erleichterung. Puls jedoch sehr klein, unregelmäßig. Kochsalzinfussion. Kampfer. Temperatur 38,8.

27. IX. Kollapstemperatur. Exitus.

Autopsie: Keine allgem. Peritonitis, weder Exsudat noch Auflagerungen. Die vorgelagerte Flex. sigm. ist weit und kollabiert, an 2 Stellen über handgroße gangränöse Partieen. Das Mesoigmoideum ist stark verdickt mit dicken alten weißlichen Schwielen durchzogen und von frischen periton. Auflagerungen bedeckt. Seine Wurzel setzt sich ganz nahe an der Stelle an, wo auch das Mesenterium des Dünndarms entspringt, so daß es fast den Anschein hat, als ob ein Mesent. comm. bestände. Von seinem Ansatz zieht ein fester starker Strang zur Flex, duodeno-jejunalis hinüber an der Stelle, wo diese hinter dem Mesent. des Dünndarms hervortritt. Der Strang vereinigt sich mit dem Mesent. des Dünndarms und zicht mit ihm zusammen vor dem Duodenum hinweg. $\mathrm{Es}$ ist dies die Stelle, von der bei der Operation angenommen wurde, daB hier eine Adhäsion zwischen Mesosigmoideum und Dänndarm vorläge.

Das Mesosigmoideum ist an seiner Wurzel sehr schmal, nicht breiter als $5 \mathrm{~cm}$. Fs liegen infolgedessen der ab- und zuführende Schenkel sehr nahe beieinander. Die ganze Flexur ist sehr beweglich und leicht zu drehen.

12. J.-N. 204/1905. Kr., K., 47 Jahr, Frau aus K. Aufnahme 13.IV. 1905, gestorben 14. IV. 1905. Volvulus der Flexura sigmoidea. Laparotomie. Darmvorlagerung. Anus praeternaturalis.

Anamnese: Früher gesund, niemals Bauchbeschwerden, aber stets Stuhlverstopfung. Seit etwa einer Woche Schmerzen in der linken Bauch- 
seite. 12. IV. 1905 nachmittags Schmerzen sehr intensiv. Winde gingen nicht mehr ab. Erbrechen! Heute morgen schwoll der Leib enorm an. Gestern früh zum letzten Male Stuhlgang. Heute nachmittag wird Pat. auf Veranlassung des Arztes in die Klinik gesandt.

Status: Magere, sehr blasse Frau mit cyanot. Lippen. Haut ganz leicht ikterisch gefärbt. Puls 96 , kaum fühlbar. Temperatur $35,5^{\circ}$. Sensorium frei, aber sehr apathisch. - Leib enorm aufgetrieben, an einzelnen Stellen Konturen aufgeblähter Darmschlingen zu erkennen. Keine peristalt. Bewegungen. Über dem ganzen Abdomen mäBige Druckempfindlichkeit. Nirgends Resistenz. Keine Dämpfung in den abhängigen Partien. Während der Untersuchung Erbrechen galliger Massen. Die Leberdämpfung bis 3 fingerbreit unter dem Rippenbogen. Milzdämpfung nicht vergrößert.

Sofortige Operation im I. Ätherrausch Dr. Baum.

Medianer Bauchschnitt ober- und unterhalb des Nabels. Nach Eröffnung des Peritoneums quellen unter enormem Druck über zweifaustdicke, enorm geblähte dannwandige Dickdarmschlingen hervor. Serosa glatt und glänzend. Achsendrehung der Flexura sigmoidea rechts herum um $360^{\circ}$. An der Kuppe der gedrehten Schlinge talergroße, grünverfärbte, stinkende Stelle. Oberhalb dieser Stelle Darm eröffnet. Ströme flüssigen Kots unter hohem Druck entleert. Dickes Drain eingenäht. Schlinge vorgelagert, übriger Teil der Wunde durch Knopfnähte geschlossen. 2000 Kocksalzinfusion. Kampfer.

14. IV. 1900. Heute morgen 6 Uhr Exitus.

A u top sie: Starke ektasierte Flex. sigm. Starke Ektasie des sehr langen Dickdarms mit Blutungen in der Schleimhaut. Hyperämie der schlaffen Lungen und Emphysem der vorderen Partien. Fleckung des Herzmuskels.

13. J.-N.782/1905. S., G., 30 Jahre, Knecht aus B. Aufnahme 10. VIII. 1905, gestorben 19. IX. 1905. Volvulus flexurae sigmoideae. Peritonitis acuta. Laparotomie. Vorlagerung der Flexur. Med. Laparotomie. Resektion der Flexur. Darmnaht.

Anamnese: Erkrankte vor 2 Tagen mit ziehenden Schmerzen im Unterleib, die sich hauptsächlich in der linken Seite lokalisierten und nach der Magengegend ausstrahlten. Appetit und Verdauung waren zunächst noch normal. Erst gestern Übelkeit und Erbrechen. Der Stuhl war dünnflüssig. Seitdem keine Winde, keine Stuhlentleerung. Arzt sandte Pat. sofort zur Klinik.

Status: Mittelgroßer, dürftig genährter, etwas cyanotisch aussehender Mann. Herz und Lungen ohne Befund, Zunge belegt, trocken. Pat. klagt über heftige Schmerzen im ganzen Abdomen.

Abdomen aufgetrieben, besonders das Hypogastrium. Bauchdecken prall gespannt. Starke Druckempfindlichkeit unterhalb und beiderseits rom Nabel, desgleichen in der Ileokökalgegend. Nirgends jedoch eine abnorme Resistenz nachweisbar.

AufstoBen, frequenter kleiner Puls.

Sofortige Laparotomie: Dr. NöBke.

Schrägschnitt in der Regio ileocoecalis. Cöcum. Appendix normal. Weiter medianwärts beim Hervorziehen der Därme kommt die sehr bewegliche 
enorm erweiterte Flexura sigmoidea zum Vorschein, welche stark dunkelrot injiziert und mit fibrinös-eitrigen Auflagerungen bedeckt ist. Flexur ist gedreht, aber so, daß das Mesenterium selbst fast gar nicht verändert erscheint. Im kleinen Becken reichlich dünnflüssiges, trübes, serös-bräunliches Exudat. Auftupfen. Die stark erweiterte Flexur wird ca. $30 \mathrm{~cm}$ lang herausgelagert. Jodoformtamponade. Drainage des kleinen Beckens. Subkutane Ernährung, stündlich Kampfer.

12. VIII. fieberfreier Verlauf.

Spontane Entleerung von dünnflüssigem, übelriechendem Kot. Reichlicher Abgang von Winden.

15. VIII. Verband Wechsel. Kein eitriges Sekret, frischrote Granulationen. Gute Verklebung der vorgelagerten, bereits etwas geschrumpften Flexur.

23. VIII. Operation: Morphium-Chloroform-Narkose. Med. Laparotomie: Dr. Nößke. Aufsuchen der beiden zu der vorgelagerten Schlinge führenden Darmenden. Abklemmung derselben. Provisorische Einstülpung der Flexurstümpfe. Vernähung des zu- und abführenden Darmendes end to end. 3 fache Naht. Exstirpation der vorgelagerten Schlinge durch queren Schnitt durch den rechten Rektus. Etagennaht der med. Wunde. Tamp. der rechtsseitigen Bauchwunde. Opium, Kampfer. Sublut. Ernährung.

27. VIII. reichlich Stuhlentleerung.

1. IX. Darmnaht hat nicht gehalten. Darmfistel.

2. IX. Heute morgen Erbrechen von $1500 \mathrm{ccm}$ schwarzer, kaffeesatzartiger Flüssigkeit (Blut.)

9. IX. Blutung nicht wieder aufgetreten.

In der Bauchwunde andauernd sehr viel schwarzer Kot.

13. IX. Jejunostomie, kräftige Ernährung durch die Fistel.

15. 1X. Wieder starkes Blutbrechen etwa $1500 \mathrm{ccm}$.

19. IX. Exitus. Autopsie: Großes, rundes Geschwür an der kleinen Kurvatur mit Durchbruch durch die hintere Magenwand in die freie Bauchhöhle. Reichliche, kotige Flüssigkeit. Querverlaufende Naht im oberen Rektum.

14.J.-N.1376/1905. W., G., 14 Jahre. Schulknabe aus G. Aufn.7.XII.1905. Ent 2. II. 1906. Volvulus flexurae sigmoideae. Resectio flexurae sigmoideae.

Auamnese: cf. S. 438. Am 20. XI. 1905 kolikartige Schmerzen, geringes initiales Erbrechen. Kein Stuhlgang. Abführmittel ohne Erfolg.

Am 24. XI. 1905. Leib aufgetrieben, starkes Kollern im Leib, alle 5-10-15 Minuten sichtbare Darmauftreibung unter heftigen Schmerzen. Keine Hernie. Kökum frei. Kein Fieber. Kein freier ErguB. Keine Druckempfindlichkeit. Nach Klysmata Stuhlgang und Flatus. Vom 27. XI. bis 2. XII. leidliches Befinden. Meteorismus noch vorhanden, in groBen Intervallen Kolikschmerzen. Erhebliche Erleichterang, wenn Flatus abgingen.

In der Nacht vom 3. zum 4. XII. spontan Stuhlgang. 4. XII. plötzliche Verschlimmerung, heftige, sich häufig wiederholende Schmerzanfälle. $1 \%$ Liter Klysma mehrfach ohne Wirkung, kein Stuhlgang, Flatus seltener, 
kein Erbrechen, aber AufstoBen. Kein Fieber. 1/4 mgr Atropin subkutan ohne Erfolg.

Status: Schwer leidend aussehender Knabe mit eingefallenen Gesichtszügen, sehr reduziertem Ernährungs- und Kräftezustand. Pupillen weit, mit geringer Reaktion (Atropin!) Puls 120, klein. Zunge feucht nicht belegt. Abdomen sehr stark aufgetrieben, trommelartig gespannt. Umfang in Nabelhöhe $86 \mathrm{~cm}$. Alle 3-5 Minuten unter heftigem Schmerz lautes Kollern, zugleich links zwischen Nabel und Sp. a. s. eine von 2 Einziehungen begrenzte, längsverlaufende, wallartig auftretende Vorwölbung. Im Rektum fühIt man 3 Ringe, die sich spastisch um den Finger herumlegen, neben dem Finger stürzt dünnflüssiger Stuhl mit Winden hervor. Versuch, mit Darmrohr und hohem Klistier Entleerung zu erzielen, mißlingt.

Behandlung: Subkutane Kochsalzinfusion, $1 \mathrm{~L}$.

8 Uhr p. m. Operation, Dr. Göbell. Äther-Tropfnarkose: Mediane Laparotomie eröfnet das Abdomen von der Symphyse bis oberhalb des Nabels: Sofort stellt sich in der Wunde eine kolossal geblähte Darmschlinge ein, die ohne große Mühe geboren werden kann. Es ist die sehr große, fast mannsoberschenkeldicke Flexura sigmoidea, gespannt wie eine Trommel, aber noch mit normaler Serosa bedeckt. Achsendrehung links herum 11/2 mal. Detorsion. Entleerung vom Rektum aus. Flexur fast $60 \mathrm{~cm}$ lang. Mesosigmoideum sehr lang, drüsen- und gefäBreich, FuBpunkte $6-8 \mathrm{~cm}$ voneinander entfernt. Wand ohne Kontraktionsfähigkeit. Resektion der Flexur. AbschluB der Enden. Anastomose side to side, aber Längsöffnung im zuführenden, quere öffnung im abführenden Teil. Jodoformgazestreifen, Drain. Dünndarm zeigt ausgezeichnete Peristaltik, deshalb nicht entleert. SchluB der Bauchwunde durch Etagennähte. Dauer 2 Stunden. Puls beschleunigt. Kampfer. Intravenöse Kochsalzinfusion.

Verlauf nicht günstig. Am 2. Tag post op. Temp. 39,8, Puls 152, am 3. Tag mittags 40,0 , Puls 140. Temperatur fällt nach Lockerung der Tamponade und Einlegen eines stärkeren Drains, aber Erbrechen. Stuhlgang durch Klistiere reichlich erzielt. Subkutane Kochsalzinfusionen. Digalen. Am 4. Tag morgens fäkulentes Erbrechen. Magenspülung. $20 \mathrm{~cm}$ langer Spulwurm. Durch Darmrohr reichliche Stuhlentleerung und Winde. Subkutane und intravenöse Kochsalzinfusion. Am 5. Tag post op. 37,8, Puls 116. Kein Erbrechen mehr. Allgemein Befinden besser. Stuhlgang nur, wenn der Spasmus im untern Rektum durch Darmrohr überwunden, reichlich dünnflüssig. Am 6 . Tag immer noch dünnflüssige Stühle. Tannigen. Am 7. Tag starker Kräfteverfall. Temperatur fast normal. Subkutane Kochsalzinfusion, am 8. Tag immer noch Schmerzen und Koliken, am 12. Tag entleert sich aus der Wunde etwas Kot.

Erst am 22. Tag p. op. breiige Stuhlentleerung, aber dieselbe immer durch den Krampf des Sphincter tertius erschwert, immer nur nach Dehnung mit den Fingern und Einschieben eines Darmrohrs.

Am 25. Tag p. op. Dehnung der Spinkter in Narkose. Einlegen eines dicken Stopfrohrs. Seitdem schlieBt sich die Wunde. Stuhl dickbreiig. 
Ein Beitrag zur Pathologie und Therapie des inneren Darmverschlusses.

Am 2. II. 1906 Gewichtszunahme 7 Pfund. Stuhlentleerung normal. Geheilt entlassen.1)

\section{Innere Einklemmung.}

15. J.-N. 601/1901. Sch. A., 45 J., Maurergeselle aus K. Aufn. 26. VI. 1901. Innere Einklemmung durch Netzadhäsion, gestorben 30. VI. 1901. Laparotomie. Lösung der Adhäsion. Drainage.

Anamnese: 26.27. VI. 19012 Uhr plötzlich an heftigen Leibschmerzen erkrankt, ohne daß eine heftige Bewegung vorangegangen war. Unter warmen Umschlägen Linderung. Schmerzen in der rechten Unterbauchgegend gleich heftig. Etwas Stuhl, kein Erbrechen, 28./29. VI. starke Verschlimmerung. Kein Stuhl. Keine Winde. Häufiges Aufstoßen. Hände kalt und blau.

29. VI. mittags 2 Uhr hierher verlegt.

Status: Mittelgroßer kräftig gebauter Mann, stark verfallen. Zunge stark belegt, trocken. Fieberhaft gerötete Wangen. Starker Foeltor ex ore. Häufiges Aufstoßen. Leib stark aufgetrieben. Bauchdecken leicht ödematös. In der rechten Seite gleichmäBige Auftreibung, línks noch Peristaltik zu erkennen. In der rechten Ileocöcalgegend Dämpfung bis 2querfingerbreit rom Nabel. Starke Druckempfindlichkeit, welche nach links hin abklingt. Rechtes Bein flektiert. Dämpfungszone in der Ileocöcalgegend wechselt bei Lagewechsel.

Keine Hernien. Puls 126, klein, regelmäBig.

Diagnose: Perityphlitis mit freiem, eitrigem Ergu日.

Behandlung: Sofortige Operation. Dr. Sick. Äthernarkose. Schräger Schnitt in die Ileokökalgegend eröffnet das Peritoneum. Stark geblähte, blauschwarze noch mit spiegelndem Peritoneum bedeckte Dünndarmschlingen. Mesenterium stark verdickt, zum Teil infarciert, zum Teil mit Blutextravasaten durchsetzt. In der Bauchhöhle blutigseröse Flüssigkeit (Bakteriolog. steril). Ca. $80 \mathrm{~cm}$ Dünndarm sind hinter einen derben Adhäsionsfaden geschlüpft, welcher vom Netz zu einem Haustrum des Colon ascendens zieht. Dieser derbe Faden wird durchrissen. Darm ist frei. Schnürfurchen sehen etwas verdächtig aus. Einzelne Dünndarmschlingen des eingeklemmt gewesenen Teils etwas brüchig. Exsudat ausgetupft. Große Glasdrains eingelegt. Reposition der Därme. Situationsnaht. Darmrohr.

Abends wenig blutiger, übelriechender Kot entleert.

30. VI. nachts unter Kampfer und Morphin leidlich. Temperatur morgens 38. Puls 120, klein. Kein Erbrechen. Durch das Darmrohr reichliche Kotmassen entleert.

Im Laufe des Tages verfällt Patient immer mehr.

Exitus letalis.

Autopsie: Infarkt des Mesenterium mit Nekrose von $80 \mathrm{~cm}$ Dünndarm. Peritonitis.

16. J.-N. 585/1904. S. J., 33 J., Landmann aus N. Aufnahme

1) Anm. Am 11. V. 1906 völliges Wohlbefinden, Stuhlentleerung normal. Man fühlt noch die Muskelringe, aber sie sind nicht mehr im Zustand dauernder Koutraktion. 
2. VII. 1904, gestorben 8. VII. 1904 . Innere Einklemmung einer lleumschlinge in einem Mesenterialschlitz. Adhäsionen. Tuberkulöse Mesenterialdrüsen. Wirbelkaries.

\begin{tabular}{|c|c|c|c|c|c|c|}
\hline $\mathrm{Nr}$. & Name & $\begin{array}{l}\dot{\Phi} \\
\dot{L}\end{array}$ & 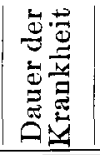 & Diagnose & Befund & $\begin{array}{c}\text { Operations- } \\
\text { verfahren }\end{array}$ \\
\hline 15 & Sch. A., & $\mid \begin{array}{c}45 \mathrm{~J} . \\
\mathrm{m} .\end{array}$ & 3 Tage & $\begin{array}{l}\text { Perityphlitis mit } \\
\text { freiem eitrigem } \\
\text { Erguß. }\end{array}$ & $\begin{array}{l}\text { Innere Einklem- } \\
\text { mungvon } 80 \mathrm{~cm} \\
\text { Dünndarm zw. } \\
\text { Netzadhäsion } \\
\text { u. Col. ascen- } \\
\text { dens. }\end{array}$ & $\begin{array}{l}\text { Trennung der } \\
\text { Adhäsion. }\end{array}$ \\
\hline 16 & S. J., & $\begin{array}{c}33 \mathrm{~J} \\
\mathrm{~m} .\end{array}$ & $\mid \begin{array}{l}4 \text { Tage } \\
\text { abso- } \\
\text { luter } \\
\text { Ver } \\
\text { schlu } \beta\end{array}$ & $\begin{array}{ll}\text { Dünndarmver- } \\
\text { schluß durch } \\
\text { Tub. }\end{array}$ & $\begin{array}{l}\text { Adhäsionen. } \\
\text { Dicht oberhalb } \\
\text { d. Valvula ileo- } \\
\text { coecalis: Ein- } \\
\text { klemmung des } \\
\text { Ileum i. e. Me- } \\
\text { senterialschlitz. }\end{array}$ & $\begin{array}{l}\text { Einklemmuog be- } \\
\text { seitigt. Lücke } \\
\text { vernäht. }\end{array}$ \\
\hline 17 & $\begin{array}{l}\text { B. Th., } \\
1017 / 1903\end{array}$ & $\begin{array}{c}23 \mathrm{~J} \\
\mathrm{~m} .\end{array}$ & 2 Tage & $\begin{array}{l}\text { Darmverschluß } \\
\text { in Verb. mit } \\
\text { früherer Ap- } \\
\text { pendizitis? }\end{array}$ & $\begin{array}{l}\text { Innere Einklem- } \\
\text { mung zw. Ad- } \\
\text { häsion u. Me- } \\
\text { senteriumeiner } \\
\text { Darmschlinge } \\
\text { (alter Bruch- } \\
\text { darm). }\end{array}$ & $\begin{array}{l}\text { Einklemmung be- } \\
\text { seitigt. Resek- } \\
\text { tion } 25 \text { cm. }\end{array}$ \\
\hline 18 & $\begin{array}{l}\text { W. M. } \\
1201 / 1904\end{array}$ & $\begin{array}{c}35 \mathrm{~J} \\
\mathrm{w} .\end{array}$ & 7 Tage & $\begin{array}{c}\text { Darmverschluß } \\
\text { nach Myomope- } \\
\text { ration (keine } \\
\text { Strangulation). }\end{array}$ & $\begin{array}{l}\text { Innere Einklem- } \\
\text { mung zw. Ad- } \\
\text { häsion u. Peri- } \\
\text { ton. parietale. }\end{array}$ & $\begin{array}{l}\text { Trennung der Ad- } \\
\text { häsion. Darm- } \\
\text { resektion. }\end{array}$ \\
\hline 19 & Sch. R., & $\begin{array}{c}38 \mathrm{~J} . \\
\mathrm{m} .\end{array}$ & 4 Tage & $\begin{array}{l}\text { Dünndarmver- } \\
\text { schluß. }\end{array}$ & $\begin{array}{l}\text { Abtrennung der } \\
\text { obersten Jeju- } \\
\text { numschlinge } \\
\text { durch Adhäsio- } \\
\text { nen.Zahlr. Ad- } \\
\text { häsionen. Tub. } \\
\text { Mesenterial- } \\
\text { drüsen. }\end{array}$ & $\begin{array}{l}\text { Lösung der Um. } \\
\text { schnürung und } \\
\text { Adhäsionen. }\end{array}$ \\
\hline 20 & Frau M. & $\begin{array}{c}36 \mathrm{~J} . \\
\mathbf{w} .\end{array}$ & 8 T'age & $\begin{array}{l}\text { Dünndarmver- } \\
\text { schluß nach Ap- } \\
\text { pendizitis. }\end{array}$ & $\begin{array}{l}\text { Mehrmalige } \\
\text { Knickung des } \\
\text { Dünndarms } \\
\text { durch Adhäsio- } \\
\text { nen u.Umschnü- } \\
\text { rung e. Dünn- } \\
\text { darmschlinge. }\end{array}$ & $\begin{array}{l}\text { Lösung u.Durch- } \\
\text { trennung der } \\
\text { Adhäsionen. } \\
\text { Enteroplastik. }\end{array}$ \\
\hline
\end{tabular}


Ein Beitrag zur Pathologie und Therapie des inneren Darmverschlusses. 473

Anamnese: Sonst gesund. Früher als Schlächter oft perisüchtiges Vieh geschlachtet und gegessen. Vor 3-4 Jahren Drüsen am Halse. In Winter 1903/1904 Beschwerden im Leib. Fieberte längere Zeit, starke

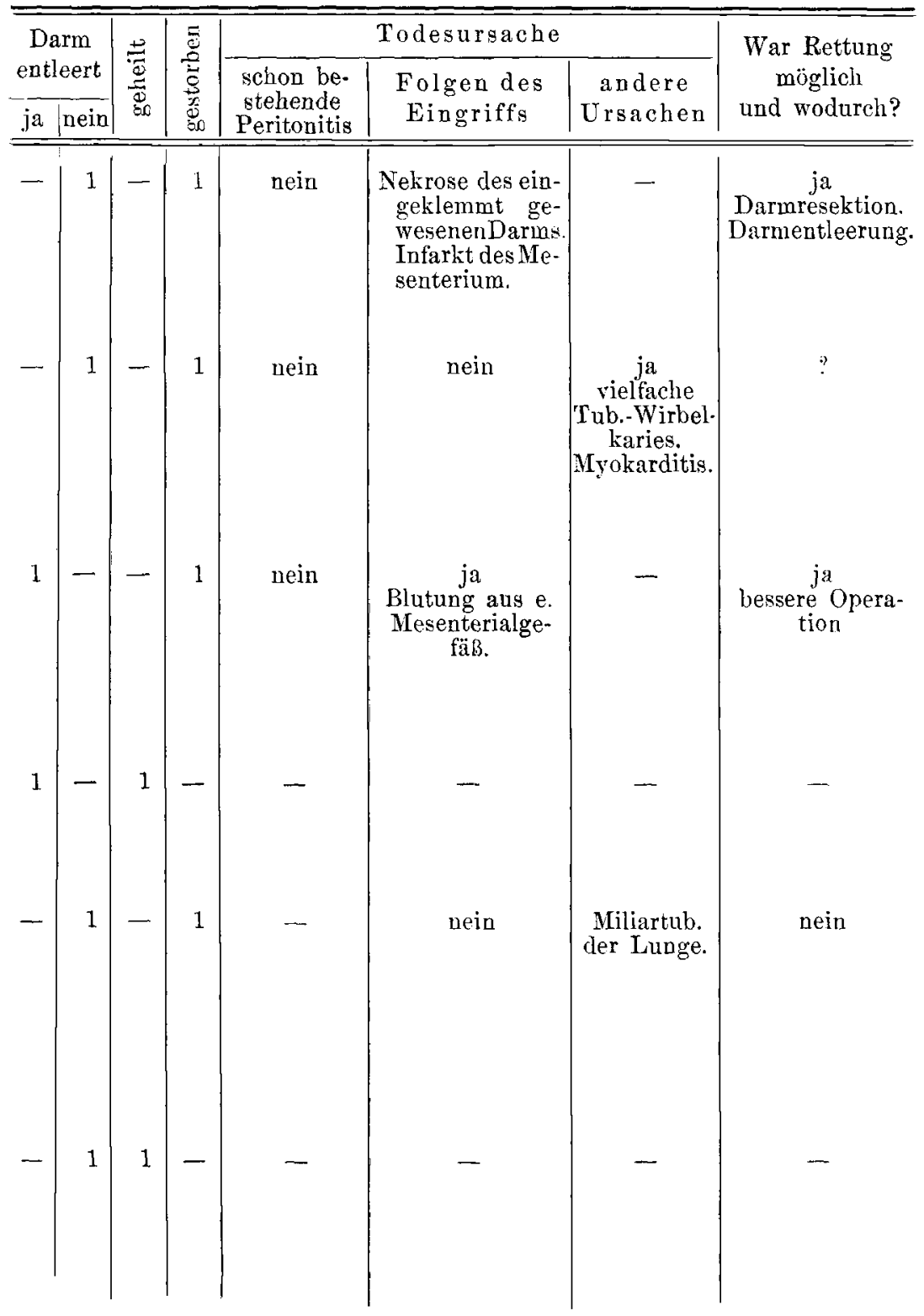




\begin{tabular}{|c|c|c|c|c|c|c|}
\hline $\mathrm{Nr}$. & Name & $\stackrel{\stackrel{H}{0}}{\stackrel{4}{4}}$ & 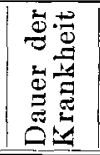 & Diagnose & Befund & $\begin{array}{c}\text { Operations- } \\
\text { verfahren }\end{array}$ \\
\hline 21 & $\begin{array}{l}\mathbf{F r}, \mathbf{J} . \\
435 / 1905\end{array}$ & $\begin{array}{c}48 J \\
\mathrm{~m} .\end{array}$ & $17 \mathrm{Std}$ & $\begin{array}{l}\text { Dünndarmver- } \\
\text { schluß. Stran- } \\
\text { gulation durch } \\
\text { Adhäsionen. } \\
\text { 2. Rezidiv. }\end{array}$ & $\begin{array}{l}2 \text { bindfadenför- } \\
\text { mige Stränge } \\
\text { umschnüren d. } \\
\text { Dünndarm- } \\
\text { Knickung des } \\
\text { Dünndarms } \\
\text { durch Adhä- } \\
\text { sionen. }\end{array}$ & $\begin{array}{l}\text { Durchtrennung } \\
\text { derStränge. Lö- } \\
\text { sung der Ad- } \\
\text { häsionen. }\end{array}$ \\
\hline 29 & B., J. & $\begin{array}{l}29 \mathrm{~J} . \\
\mathbf{m} .\end{array}$ & 2Tage & $\begin{array}{l}\text { Peritonitis (Ap- } \\
\text { pendizitis?). }\end{array}$ & $\begin{array}{l}\text { Peritonitis. Gan- } \\
\text { grän eines } \\
\text { Meckelschen } \\
\text { Divertikels. Ein- } \\
\text { klemmung der } \\
\text { nächstgelege- } \\
\text { nenDünndarm- } \\
\text { schlinge. }\end{array}$ & Darmresektion. \\
\hline
\end{tabular}

Nachtschweiße. Im März erhebliche Steigerung der Beschwerden, bis plötzlich Erscheinungen völligen Darmverschlusses auftraten. 11 Tage danach Allgemeinbefinden besser, aber Kolikschmerzen verschwanden nicht ganz und Stuhlgang dünnflüssig. Seit 4 Tagen kein Stuhlgang, häufiges Aufstoßen. Gestern zum erstenmal Erbrechen. Das Erbrochene sauer, nicht kotig. Einläufe ohne Erfolg, keine Winde. Appetit z. Z. vorhanden. Schlaf durch Morph. reichlich. Gegenwärtige Beschwerden Spannung und Gurren im Leib.

Status: Kräftig gebauter Mann mit etwas schlaffer Muskulatur, Schwund des Fettpolsters. Wangen und Schleimhäute gut gefärbt. Temperatur normal. Puls 96, voll und weich. An den Lungen keine krankhaften Veränderungen. Am Hals, Rücken, Brust und Bauch zahlreiche Tb.-Narben. $\mathrm{Zu}$ beiden Seiten der Lendenwirbelsäule je eine flache, kleine, handtellergroße, fluktuierende Geschwulst. Fluktuation von einer in die andere. W. S. ohne Veränderungen.

Leib etwas aufgetrieben. Bauchdecken mäBig gespannt. In den abhängigen Partieen 3 fingerbreite, tympanitische Dämpfung, die sich bei Lagewechsel aufhellt. Betastung nicht schmerzhaft. Tumor nicht nachweisbar. Leber unterer Rand $6 \mathrm{~cm}$ oberhalb des Rippenbogens. Urin klar, eiweiBfrei.

Behandlung: Flüssige Diät, hohe Einläufe. Nährklistiere. Infusionen. Abends etwas brauner, tonfarbener Stuhl mit einigen Bröckeln in dem braungefärbten Einlauf. Erbrechen sauer, nicht kotig. Winde sind abgegangen.

5. VII. 1904. Seit dem 3. VII. morgens kein Stuhlgang. Trotz hoher Einläufe keine Winde. Flüssige Nahrung wird erbrochen.

Chlorof.-Nark. Op.: G. H. Helf erich. Großer Medianschnitt mit Exzision des Nabels. Bei Eröffnung der Bauchhöhle geringe Menge klaren gelblichen 


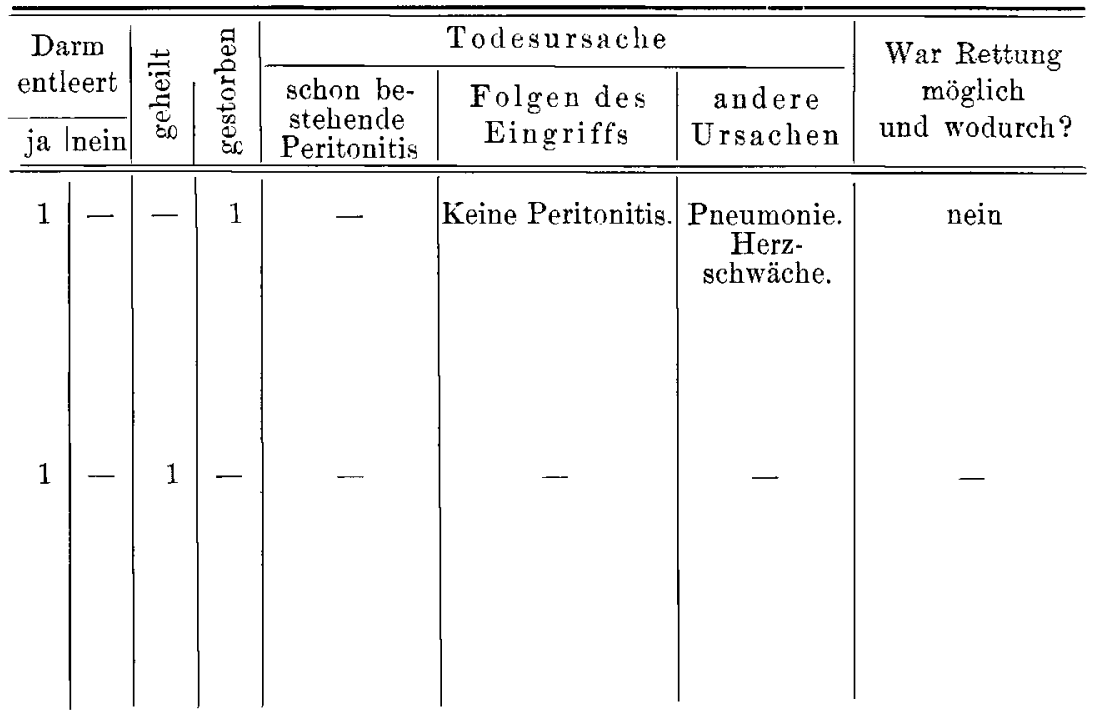

Ergusses entleert. Düundarmschlingen liegen gebläht vor. Dickdarm leer. Beim Aufsuchen des Passagehindernisses werden vielfache Verklebungen des Darms sichtbar. An einer Stelle liegen zwei Schlingen in talergroßer Ausdehnung mit breiter Fläche aneinander. Die Umgebung ist kallös verdickt (perfor. Ulceration?). Im Mesenterium zahlreiche bis kleinwalnu8große Lymphdrüsen. Das Passagehindernis liegt oberhalb der Bauhinschen Klappe. Hier liegt eine Spange geschrumpften fibrösen Gewebes in der Wurzel des Mesenteriums der letzten Dünndarmschlinge und hat zu einer erheblichen Annäherung der Ursprungsstellen dieser Schlinge geführt. Durchtrennung der Spange nach doppelter Ligatur. Jetzt sieht man, daB eine Drehung dieser Schlinge stattgefunden hat and auBerdem die Schlinge durch einen Mesenterialschlitz hindurchgetreten ist. Abwärts liegender Dünndarmteil und Dickdarm leer. Zurückziehen der Schlinge aus dem Loch, welches vernäht wirl. Reposition. SchluB der Wunde durch tiefgreifende Knopfnähte.

6. VII. Patient hat gut geschlafen. Fühlt sich gut. Puls 100, ziemlich kräftig. Zunge feucht. Kein AufstoBen. Winde abgegangen. Nachmittags Ölspritze.

7. VII. Kein Stuhlgang, doch reichlich Winde. Abends etwas apathisch.

7.18. VII. Nachts sehr unruhig, inmer mehr benommen. Puls sehr frequent und klein.

8. VII. Patient völlig benommen. Puls 108, klein. Augen geöffnet. Pupillen weit, absolut starr. Beide Bulbi gleichmäßig und dauernd nach links abgelenkt. Ausgesprochene Nackenstarre und Steifigkeit in den Gelenken des linken Arms. Rechter Arm und beide Beine weich. CheyneStockessches Atmen.

Abends Exitus. 
Autopsie: Multiple Wirbelkaries an der seitlichen Außenfläche mehrerer Wirbelkörper und käsige Erweichung der benachbarten Weichteile. Starke Hyperämie des Schädelinhalts. Vielfache tuberkulöse Veränderungen der inneren Organe.

1\%. J.-N. 1017/1903. T. B., 23 J., Mechaniker aus D. Innere Einklemmung zwischen den verwachsenen Schenkeln eines Bruchdarms. Darmresektion. Aufnahme 28. IX. 1903, gestorben 30. IX. 1903.

Anamnese: Als Kind einmal Blinddarmentzündung. Vor Eintritt beim Militär angeblich Blutarmut. Irgendwelche Störung der Magen-Darmfunktion niemals vorhanden gewesen. Kein Bluterbrechen. Am 26. d. M. mit Schmerzen in der Magengegend und initialem Erbrechen erkrankt. Seitdem kein Stuhlgang, keine Winde.

27. IX. Sekundäres Erbrechen. Schmerzen anfallsweise, kolikartig.

Status: Kräftig gebaut, gesund aussehend. Züge nicht verfallen. Zunge feucht, wenig belegt. Temperatur 37.8 .

Leib im ganzen mäßig aufgetrieben, überall ziemlich weich und nicht besonders druckempfindlich. Nur in der Medianlinie oberhalb der Blase bis an den Nabel hin leichter Druckschmerz. Resistenz nirgends fühlbar. Reichlicher freier FlüssigkeitserguB. In der Ileocöcalgegend etwas intensivere Dämpfung, hellt sich bei Beckenhochlagerung auf. Vom Rektum aus Douglas: angefüllt. Bruchpforten frei. Bei den anfallsweise auftretenden Schmerzen keine Peristaltik sichtbar. Gleichzeitig stets Aufstoßen von fäkulentem Geruch. Tonische Krämpfe im Gebiet beider Nervi ulnares.

Puls 80 , regelmäBig, kräftig.

Herztöne rein.

Sofortige Operation in gemischter Chloroform-Äthernarkose: Dr. Göbell. Langer rechtsseitiger Schrägschnitt eröffnet das Abdomen. Stark geblähte Dünndarmschlingen, Serosa derselben stark injiziert, aber spiegelnd. Reichliche ziemlich klare, seröse Flüssigkeit. Cöcum und Appendix normal. Im kleinen Becken ein Packet miteinander verschlungener Ileumschlingen. Alte Adhäsionen verbinden die beiden Schenkel einer Ileumschlinge und bilden einen Ring, durch den unter gleichzeitiger Drehung um seine Längsachse eine zweite Darmschlinge mit seinem Mesenerium durchgeschlüpft und eingeklemmt ist. Am Mesenterium der 1. Schlinge narbige Veränderungen. Resektion der Darmpartieen $(25 \mathrm{~cm})$, Vereinigung der Enden mit Murphyknopf, nachdem vorher aus dem zuführenden Ende reichliche Mengen Inhalt entleert. SchluB der Bauchwunde mit durchgreifenden Nähten. Tampons nach außen. Erbricht während der Operation Kot. Kochsalzinfusion.

29. IX. Temperatur 39,2. Puls 140, klein. Patient sieht verfallen aus. Kein Erbrechen. Leib nicht stärker aufgetrieben, aber überall ziemlich druckempfindlich. Keine Winde. Abends Temperatur 40,6. Puls 150! 30. IX. 1 Uhr morgens gestorben.

A u top si e: Ausgedehnte Blutungen aus Operationsnaht am Mesenterium! Linksseitiger Schenkelbruch.

18. J.-N. 1201/1904. W., M. 35 J., Arbeiterin aus H. 6. XI. 1904 bis 9. II. 1905. Innere Einklemmung des Dünndarms zwischen Adhäsionsstrang und Kleinbeckenwand. Darmresektion. 
Ein Beitrag zur Pathologie und Therapie des inneren Darmversehlnsses.

Anamnese: Vor 9 Jahren zum ersten Male subseröse Myome des Uterus in der hiesigen Frauenklinik per laparotomiam entfernt.

Vor 5 Jahren zum zweiten Male in derselben Klinik wegen Myomen operiert. Verlauf jedes Mal ungestört. Bei der zweiten Operation musten vicle Athäsionen gelöst werden. Seitden gosund.

Am 27. X. 1904 Leibschmerzen, initiales Erbrechen. Kein Stuhlsang. Keine Winde. Anfangs Erbrechen gallig. Darm wühlte im Leibe. Patientin merkte, wie es rurch den Leib nach unten rechts hinzog, dort Halt machte und bald darauf Erbrechen auftrat. Am 2. XI. 1904 Schmerzen etwas geringer, aber keine Winde und kein Stuhl. Seit dem 4. XI. Erhrechen deutlich kotig. Feute morgen Aufnahme.

Status: Blasse, leidlich genährte, elend aussehende Frau mit starken, übelriechenden Ruktus, erbricht dümnflüssige kotige Massen. Zunge stark schmutzig belegt, Haut trocken. Abdomen aufgetrieben. \%wischen Nabel und Symphyse zwei dicht nebeneinander liegende breite Laparotomienarben. Von Zeit zu Zeit tritt links vom Nabel und im linken Hypogastrium eine Darmschlinge in lebhafterer Bewegung deutlich hervor, wälirend rechts und im linken Hypogastrium die Wölbung eine gleichmäBige bleibt und keine Peristaltik zu konstatieren ist. Keine abnorme Dämpfung, kein freier ErguB. Leber in Kantenstellung. Rechts von der rechten Narbe oberhalb des Tuberculum pub. etwas Druckempfindlichkeit. Untersuchung der Genitalien (Geh. Rat Werth) ergibt nichts Besonderes. Puls mittelkräftig, regelmäBig, 110 , etwas weich.

Diagnose: Obturationsileus mit starker Paralyse des Darms oberhalb des Hindernisses.

Behandlung: Magenausspülung befördert sehr reichliche Mengen kotigen Inhalts zutage.

$121 / 2 \mathrm{~h} \mathrm{p.m.} \mathrm{Operation} \mathrm{in} \mathrm{Sauerstoff-Chloroformnarkose.} \mathrm{(Dr.} \mathrm{Göbell.)}$ Medianer Laparotomieschnitt links vom Nabel eröffnet das ganze Abdomen. Netz liegt über geblähten Dänndarmschlingen und ist an der Laparotomienarbe (links) adhärent. Es wird gelöst. Eventeration. Dünndarm stark erweitert, blaurot, noch spiegelnd. Nur im kleinen Becken mit geringen Fibrinbeschlägen versehen. Vom Uterus zu einer Appendix epiploica der Flexura sigmoidea zieht ein Strang. Ligatur an beiden Enden, Exstirpation. Die geblähten Dünndarmschlingen führen zum Hindernis im kleinen Becken: Eine Adhäsion zieht ron den Genitalien zum Mesenterium des unteren Ileum und bewirlit dadurch einen DarmverschluB, daB es, ohne die Blutzufuhr der Darmschlinge zu beeinträchtigen, den zu- und abführenden Schenkel komprimiert. Am abführenten ist eine tiefe Rinne (Dekubitus), an zuführenden Schenkel ein gangränöser Ring mit Perforation vorhanden, welche eben im Augenblick der Lösung entstanden ist. Zu- und abführender Schenkel sind an der Stelle der Schnürung (Kompression) miteinander verkleht und können leicht grelöst werden. Darmschlinge zwischen den Furchen gut ermährt. Die befreite Darmpartie wird in Mull eingeschlagen. Oberhalb Ileum mit dickstem Troikart punktiert und eine sehr reichliche Entleerung des Dünndarms bewirkt $(4-5$ Liter dünnflüssiger Kot). Der Dünndarm oberhalb des oberen Schnürrings ist nach der Entleerung ganz schlaff und welk, paralytisch mit blauschwarzen Partieen durchsetzt. Serosa spiegelt nicht mehr. Deshalb $1 \mathrm{~m}$ Ileum reseziert. Unteres abführendes 
Ileumende mit Tabaksbeutelnaht eingestülpt. Oberes Ende auch geschlossen, an das Cöcum an die vordere Fläche seitlich angelagert (Ileocolostomie). Dünndarm noch sehr morsch, so daß die Nähte durchschneiden und die Naht durch viele Knopfnähte gesichert werden muß. Jodoformstreifen zum unteren Winkel der Bauchwunde herausgeleitet. Kochsalzberieselung. Entfernung der abschlieBenden Mullkompressen. Reposition des Darms. Netzversorgung. Etagennaht der Bauchwunde. Verband.

7. XI. Allgemeinbefinden gut, wenig AufstoBen, kein Erbrechen. Puls 110, mittelkräftig, regelmälig. 0-Diät, täglich 2 Infusionen à 800,0 mit Traubenzucker.

Abends sind reichliche Winde abgegangen.

11. XI. Allgemeinbefinden unverändert gut. AnfstoBen seit dem 2. Tage nach der Operation verschwunden. Heute auf Glyzerineinlauf reichlicher Stuhlgang. Flüssige Diät.

15. XI. Ernährung gut im Gange. Wunde reizlos, Entfernung der Nähte. Lockerung der Tampons.

20. XI. Tampon entfernt. Drain $5 \mathrm{~cm}$ tief eingelegt. Weiterer Verlauf durch einen phlegmonösen Dekubitus am Kreuzbein kompliziert, der nach ausgiebiger Incision bald eine gut granulierende Wunde bildet. Am 12. XII. 1904 hat sich eine Thrombose des linken Beins entwickelt, die am 1. I. 1905 zurückgegangen ist. Am 11. I. 1905 wird die granulierende Fläche am Kreuzbein durch Lappenplastik gedeckt.

Am 9. II. mit geheilter Bauchwunde, geheilter Zirkulationsstörung des linken Beins und fast völlig geheilter Wunde am Kreuzbein entlassen.

19. J.-N. 307/1904. Schr. R., 38 J., Gärtner aus R. Aufn. 7. V. 1904, gestorben 22. V. 1904. Strangulation der obersten Jejunumschlinge und Knickung des Dünndarms durch Adhäsionen. Befreiung der Schlinge, Lösung der Adhäsionen. Miliartuberkulose der rechten Lunge.

Anamnese: Seit einem Jahr geringer Husten und Auswurf, einige Male mit Blut. Wegen rechtsseitigen Lungenspitzenkatarrhs in ärztlicher Behandlung, aber bis zum 3. V. 1904 arbeitsfähig.

In der Nacht vom 3. zum 4. V. starke Schmerzen in der Nabelgegend. Am Morgen Zunehmen der Schmerzen. Erbrechen. Stuhlgang in geringer Menge. Dann weder Stuhl noch Winde, auch auf Rheuminfusion und Einläufe nicht. Schmerzen und Erbrechen bestanden fort.

S tatus: Grazil gebauter Mann in mäBigem Ernährungszustande. Hautfarbe blaß. Wangen eingefallen. Temperatur 38,8, Puls 136, regelmäBig. Über der rechten Lungenspitze leicht verkürzter Schall. Verstärktes Vesikuläratmen, namentlich Exspirium - ohne Rasselgeräusche. Leib wenig aufgetrieben, etwas gespannt. Gegend links unterhalb des Nabels etwas vorgetrieben. Hier schmerzhafte Resistenz. Bei Perkussion leerer Schall, Dämpfung reicht bis zum Ansatz der 10. Rippe, nach rechts bis zur Mittellinie, nach abwärts bis zum Lig. inguinale. Keine Fluktuation; kein freier Ergub. Per rectum: Douglas vorgewölbt, sonst nichts Abnormes.

Behandlung: Feuchter Umschlag. Tet. Op. $3 \times 15$ Tr. Nachts Morph. 0,01 .

8. V. Angeblich gestern abend Winde abgegangen. Allgemeinzustand gebessert. Kein Erbrechen. Puls langsamer, kräftiger. 
Ein Beitrag zur Pathologie und Therapie des inneren Darmverschlusses. 479

9. V. Nachts starke Schmerzen in der Nabelgegend. Kein Stuhlgang, keine Winde. Dämpfung jetzt nur in den abhängigen Partien, verschwindet bei Lagewechsel. Vorwölbung mehr umschrieben (sich vorwölbende Darmschlinge).

Chlorof.-N. Operation (G. R. Helferich). Laparotomie: Armdicke, blaurote Darmschlinge sichtbar. Mäßige Menge rötlich-brauner trüber Flüssigkeit. Oberste Jejunumschlinge dicht unterhalb der Plica duodeno jejunalis abgeschnürt durch peritonitische Adhäsionen, von denen sich Hunderte im ganzen Verlauf des Darms in Form von mehr oder weniger festen Anhängseln, Strängen, Falten usw. vorfinden. Kein einziger Teil des Darms ist frei von solchen Adhäsionen. Das Mesenterium ist durch solche Stränge verschiedentlich erheblich verkürzt. Im Mesenterium zahlreiche bis haselnuBgroBe Lymphdrüsen. Der Rest des Dünndarms und der Dickdarm leer und kontrahiert. Nach Lősung der schnürenden Stränge tritt der Darminhalt der geschnürten Sehlinge in die unteren Darmteile. Auch hier werden noch mehrere Stränge nach doppelter Unterbindung durchtrennt. Keine Nekrose der geschnürten Darmteile. Bauchnaht. Infusionen mit Traubenzucker.

11. V. Nach Einlauf Winde.

13. V. Mit Vin. Rhei und Einläufen ist mehrfach Stuhlgang erfolgt. Winde gehen gut ab. Keine Infusionen mehr. Flüssige Nahrung per os.

14. V. morgens. Stärkerer schleimig-eitriger Auswurf. Zeichen einer Pneumonie des rechten Unterlappens. Temperatur 39,2, Puls 100.

19. V. Dauernd hohes Fieber. Rechtsseitige Unterlappenpneumonie. Links reichliches, fein- bis mittelgroßblasiges Rasseln.

21. V. Anfall von Herzschwäche. Exitus.

Autopsie: Chronische ulceröse Phthisis des rechten Oberlappens. Miliare Tuberkulose der übrigen Lunge. Konfluierende lobuläre Pneumonie des rechten Unterlappens.

20. J.-N. 1552/1902. Fran M., 36 J., aus W. Aufn. 15. I. 1903, entlassen 24. II. 1903. Strangulation einer Ileumschlinge durch Adhäsion (nach Appendizitis). Lösung der Adhäsionen.

Anamnese: Vor 2 Jahren Blinddarmentzündung. 18. XII. 1902 wieder typischer Anfall, welcher bis zum 30. XII. 1902 abklang. Bis zum 7. I. 1903 Wohlbefinden. Am 7. I. 1903 plötzliches Erbrechen, verbunden mit heftigen Kolikschmerzen. Bis zum 13. I. Kolikanfälle ohne Erbrechen. Am 13. I. 1903 in die gynäkologische Klinik gebracht. Dort trat bald nach der Aufnahme von neuem Erbrechen auf, das sich während der Nacht häufiger wiederholte.

Am 14. I. Stuhl- und Windverhaltung, deshalb am 15. I. Aufnahme in die chirurgische Klinik.

Status: Mittelgroße magere, elend aussehende Frau mit trocknen Lippen und belegter, etwas feuchter Zunge.

Puls 80, etwas hlein, regelmäBig. Temperatur 38,2.

Brustorgane ohne besonderen Befund.

Abdomen stark aufgetrieben. Schall überall laut tympanitisch, nirgends Dämpfung. Leber aufwärts gedreht, unterer Rand am Proc. xiphoideus. Unterer Teil des Abdomens, besonders die Ileocöcalgegend stark druck-

Dentsche Zeitschrift f. Chirurgie. LXXXII. Bd. 
empfindlich. Es läßt sich indessen weder palpatorisch noch perkutorisch irgend etwas Besonderes daselbst nachweisen. Von Zeit zu Zeit sieht man die Därme sich wie dicke Schlangen aufbäumen. Dann hat die Patientin sehr starke Kolikschmerzen.

Sofortige Operation in Chloroformnarkose (Geh.Rat Helferich). Mediane Laparotomie im Hypogastrium und links vom Nabel. Es drängen sich prall gefüllte Dünndarmschlingen in die Wunde, von denen eine am stärksten gebläht und blaurot verfärbt ist, die anderen sind nur gerötet. Bei der weiteren Entwicklung des Dünndarms erweist er sich links neben dem Nabel mehrmals durch Adhäsionen geknickt: 1. zieht eine Netzadhäsion nach abwärts und knickt den Darm; 2. geht von einer Appendix epiploica des Colon ascendens eine Adhäsion zum Mesenterium der am stärksten geblähten, blauroten Dünndarmschlinge. Diese Schlinge ist am zuund abführenden Schenkel durch diese Adhäsionen ringförmig umschnürt. Der Schnürring am abführenden Ende gleicht sich rasch aus, wobei noch eine geringe Stenose zurückbleibt, an welcher die Reste der Adhäsionen haften. Diese Reste werden abgelöst. Dadurch entsteht ein Serosadefekt, der durch fortlaufende Katgutnähte übernäht wird. Die Schnürfurche am zuführenden Ende ist anfangs weiß, erholt sich aber später wieder. Es bleibt eine so enge Stelle zurück, daß sie durch $3 \frac{1}{2} \mathrm{~cm}$ langen Längsschnitt und quere Naht erweitert werden mus.

Reposition des Darms. Schluß der Bauchhöhle. Aseptischer Verband. Subkutane Kochsalzinfusion. Nachmittags Kamillenteeklistier.

16. I. morgens Temperatur 38,4, Puls 102. AufstoBen. Auf Klysma kein Stuhlgang, aber Winde. O-Diät. Ernährungsklistiere.

Abends Temperatur 38,5, Puls 100. Auf 0,0006 Physostigm. salicyl. erfolgt Stuhlgang.

18. I. Darmentleerung durch kleinste Physostigmindosen gut unterstützt. Heute Nahrung per os.

20. I. Puls und Temperatur normal. Darmfunktion gut. Ernährung macht Forschritte.

28. I. Nähte entfernt.

7. II. Heftige Kolikschmerzen in der linken Bauchseite werden durch Kataplasmen und Bauchmassage beseitigt. 24. II. Geheilt entlassen.

21. cf. Seite 498.

22. J.-N. 623/1905. B. J. 29, J., Arbeiter aus S. Aufn. 10. VII. 1905. Ileus durch Meckelsches Divertikel. Peritonitis. Laparotomie. Lösung der inneren Einklemmung. Darmresektion.

Anamnese. Im Jahre 1894 Rippenfellentzündung mit 15 Wochen langem Krankenlager. Im Dezember 1904 Gelenkrheumatismus (4 Wochen).

Seit 15 Jahren leidet Patient „am Magen", d. h. Appetitmangel. Brechdurchfall, der sich oft ohne Veranlassung einstellt, Krämpfe im Magen, die einige Tage dauern. Diese Erscheinungen stellen sich manchmal jeden Monat, zuweilen jeden zweiten Monat ein. Am 8. Juli 1905 mittags, als Patient Kaffee getrunken hatte, bekam er auf einmal das Gefühl, als ob ihm mit einem Messer quer durch den Leib geschnitten würde. Patient mußte gelbgrüne Massen erbrechen. Trotzdem konnte Patient sich nach 
Hause begeben. Der herbeigerufene Arzt ließ den Patienten möglichst viel Kaffee, Tee und Eis zu sich nelmen. Die Schmerzen nalmen jedoch zu, das Erbrechen dawerte fort. Deshalb läßt sich Patient mittelst Wagen heute hierher bringen.

Status: Mittelgroßer, kräftig gebauter Mann mit gesunder Gesichtsfarbe, trockener belegter Zunge, hat eben im Wagen erbrochen, hat seit vorgestern keine Winde, klagt über heftige Schmerzen im ganzen Leib.

Herz und Lungen ohne besonderen Befund, nur untere Grenzen etwas aufwärts gedrängt. Temperatur 37,6, Puls frequent. Abdomen aufgetrieben, Nabel verstrichen. In den abhängigen Partien Dämpfung, die bei Lagewechsel verschwindet und an der tiefliegenden Seite doppelt so breit wird. Leberdämpfung verschwunden. Über dem ganzen Abdomen Druckempfindlichkeit, am stärksten im rechten Hypogastrium. Einwärts rom Cöcum deutliche Resistenz. Douglas vorgewölbt, wenig druckempfindlich. Nirgends vermehrte Peristaltik sichtbar.

Diagnose ohne obige genaue Anamnese Peritonitis bei Appendizitis.

Behandlung: Sofortige Operation. Chloroform-Sauerstoffuarkose (Dr. Göbell): Mediane Laparotomie, zunächst im Hypogastrium eröffnet das Peritoneum. Es liegen stark geblähte, blaurote Dünndarmschlingen vor, Erweiterung des Schnitts nach aufwärts und abwärts. Es fließen sehr reichliche Mengen trübe, blutig-serösen, mit Fibrinflocken gemischten Exsudats ab. Dünndarm wird eventriert. Dünndarmschlingen mächtig gebläht, mit schmierig klebrigem Exsudat bedeckt. Kleines Becken voll von derselben Flüssigkeit wird ausgetupft. Die Ursache des Darmverschlusses findet man im untersten Teil des Ileum. Etwa $20 \mathrm{~cm}$ oberhalb der Valvula Bauhini sitzt am Dünndarm an dünnem, mehrfach gedrehtem Stiel eine hühnereigroBe gangränöse, mit eitrigem Fibrin belegte Geschwulst, die durch eine gleichfalls gedrehte Adhäsion an dem Mesenterium einer etwas oberhalb gelegenen Dünndarmschlinge fixiert ist. Zwischen dieser Geschwulst und dem Mesenterium der dicht oberhalb des Geschwulststiels gelegenen Dünndarmschlinge ist die nächsthöhere Schlinge hindurchgeschlüpft und eingeklemmt. Durch Kappen des links gelegenen Adhäsionsbandes wird die Schlinge befreit. Die ganze beteiligte Dünndarmpartie wird, nachdem der Darm gründlich entleert ist, reseziert. Vereinigung end to end mit Murphyknopf, um die Operation abzukürzen. Tampons an die Vereinigungsstelle. Reposition der Därme. Tamponade. Drainage. Situationsnähte, Verband. Intravenöse Kochsalzinfusion 1500.

11. VII. Temperatur 38,6, Puls 116, lilein, weich. Kampfer. Winde sind gegangen. 3 Ernährungsklistiere. Intravenöse Infusion 2 Liter.

Abends 38,5, Puls 108, klein. Intravenöse Infusion $600 \mathrm{ccm}$. Patient erbricht, stöBt auf.

12. VII. Keine Winde. Erbrechen. Temperatur 38,3, Puls 108, klein. 1 Liter Kochsalzklistier. Kampfer.

Subkutane Infusion mit Traubenzucker.

Nachmittags Anlegen einer Darmfistel am freiliegenden unteren Dünndarm. Es entleert sich sehr reichlicher Dünndarminhalt.

Abends Darmrohr ins Rektum. Nach Spülung des Rektum, Stuhlgang.

13. VII. Temperatur 37,8, Puls 100. Nachts Stuhlgang. 
Intravenöse Kochsalzinfusion 1000.

Abends Temperatur 37,5, Puls 94. Kein Erbrechen mehr. Täglich V. W. $\mathrm{H}_{2} \mathrm{O}_{2}$-Spülung der Wunde.

14. VII. Auf Klistier erfolgt Stuhl. Aus der Darmfistel entleert sich nicht viel Sekret. Drain aus dem Darm entfernt. Auswurf.

16. VII. Abends 39,3, Puls 120. Husten, reichlich schleimig-eitriger

Kampfer. Expectorans, Prießnitz.

17. VII. Fieberfrei.

21. VII. Normale Temperatur. Puls 80. Husten nur noch gering. Tampons sind alle entfernt. Wunde granuliert gut, d. h. in ihr liegen die mit Granulationen bedeckten Därme frei. Stuhlgang erfolgt spontan.

Im Urin kein Eiweiß, kein Zucker.

28. VII. Darmschlingen nicht mehr zu unterscheiden. Nach der Ileocöcalgegend hin führt ein $5 \mathrm{~cm}$ tiefer Gang. Eröffneter Darm zeigt einen ganz kleinen Schleimhautknopf. Allgemeinbefinden gut. Murphyknopf noch nicht gefunden.

10. VIII. Wunde hat sich etwas verkleinert. Gang noch $2 \mathrm{~cm}$ tief. Zusammenziehen durch Heftpflaster. Die kleine Darmfistel ist noch offen.

9. XI. Da verschiedene Versuche, die Fistel zum Schließen zu bringen, miBlingen, Chloroformnarkose, Exstirpation der Granulationen. Anfrischen der Darmfistel. Katgutnaht. Freilegen der Rektusränder. Plattennaht durch Haut und Rekti. Katgutnähte der Rekti. Drainage. Hautzwirnnaht. Verband.

30. IX. Geheilt entlassen.

Das Präparat zeigt das detorquierte an der Basis mit einem anämischen Schnürring versehene Divertikel mit schwarzverfärbter gangränöser, aber nirgends perforierter Wand.

\section{Invagination.}

23. J.-N. 1302/1901. H. A., 42 J., Schumachersfrau aus K. Aufnahme 5. XII. 1901, geheilt 30. XII. 1901. Fibroma ilei submucosum. Invaginatio ilei. Laparotomie. Hebung der Invagination. Darmresektion (Naht).

Anamnese: 30. XI. An Leibschmerzen und Mattigkeit. Sie hatte Stuhldrang, aber keine Entleerung. Nach einem Klysma Erleichterung. Es entleerten sich einige feste Kotmassen. Am folgenden Tage Schmerzen, Übelkeit, Erbrechen. Schmerzen saßen hauptsächlich um den Nabel herum und links von demselben. Seitdem täglich Schmerzen und Erbrechen. Kein Stuhlgang. Das Erbrochene grünlich und sehr übelriechend.

5. XII. Status: Kleine, grazile, magere Frau mit leidendem Gesichtsausdruck, normaler Haut, blabrosa Schleimhäuten, belegter, feuchter Zunge, geringem Foetor ex ore. Brustorgane ohne besonderen Befund. Puls 78, mittelkräftig, regelmäBig. Urin kein Eiweiß.

Menses mäBig. Uterus hinten oben, retrovertiert. Abdomen leicht aufgetrieben, alte Striae. Rektusdiastase von 2 Fingerbreite. Kleine paraumbilikale Hernie oberhalb des Nabels. Sonst keine Hernien. BauchoberHäche unregelmäBig hügelig. Vermehrte Peristaltik. Schall überall tympanitisch. Kein nachweisbarer freier Ascites. Unterer Leberrand schneidet 
den Rippenbogen in der Parasternallinie. Abdomen überall weich, nirgends besonders druckempfindlich. In der Blase normaler Urin, geringe Menge. Im Magen wenig grünlicher Mageninhalt, nicht făkulent riechend. Einige Winde gehen ab. Auf $1 \frac{1}{2}$ Liter lohes Klistier kein Stuhl. Öfters Aufstoßen, Würgen, aber kein Erbrechen.

Behandlung: Hohe Masseneinläufe. Magenspülung. Kein Stuhlgang. 0,005 Atropin.

6. XII. Keine Besserung.

Chloroform-Äther-Tr.-Narkose (Geh. Rat Helferich): Mediane Laparotomie. Nabel exstirpiert. Stark geblähte Dünndarmschlingen. Kolon leer, auch Cöcum. Invagination ron $15 \mathrm{~cm}$ Länge im unteren Ileum. Zuführende Darmschlingen prall gefüllt, abführende leer. Am Ende des invaginierten Teiles fester, rundlicher, walnuBgroBer Tumor. Invagination gehoben. Im Mesenterium geschwollene Drüse in dem dem Tumor entsprechenden Sektor. Darmresektion. End to end-Vereinigung. Bauchwunde, Etage nnaht.

Präparat: Gegenüber dem Mesenterialansatz liegt ein länglich runder, $5 \mathrm{~cm}$ langer, $4 \mathrm{~cm}$ dicker und hoher, von glatter Schleimhaut überzogener Tumor, breitbasig aufsitzend.

Im Mesenterium erbsengroße, harte, geschwollene Drüse.

Mikroskopisch: Fibroma ilei.

In den ersten Tagen nach der Operation Winde nur durch Einlauf. Am 11. XII. Reichlicher Stuhlgang.

Wunde heilt glatt.

30. XII. Geheilt entlassen.

J.-N. 855/1902. G., K. 18 J., Schiffszimmerlehrling aus K. 20. VIII. bis 17. IX. 1902, geheilt. Darminvagination (Ileum). Darmresektion.

Anamnese: Im allgemeinen stets gesund, aber schon längere Zeit an vorübergehenden Leibschmerzen gelitten. Am 17. VIII genoB P. morgens Stachelbeeren und dann Bier. Nach ungefähr einer Stunde bekam P. so heftige Leibschmerzen, daß er zu Bett gehen muBte. Seitdem keine Winde, kein Stuhl. In den folgenden Nächten mehrere Male dünnflüssige, gelbliche, übelriechende Massen erbrochen.

20. VIII. Status: Mittelgroßer kräftig gebauter Mann mit blaßrosa Schleimhäuten und stark belegter Zunge, klagt über verhaltenen Stuhl, verhaltene Winde. Erbrechen. Leibschmerzen. Brustorgane ohne besonderen Befund. Puls 104, klein, regelmäBig.

Abdomen leicht aufgetrieben, mäßige Kantenstellung der Leber. Schall überall tympanitisch. Kein freier ErguB und keine Dämpfung. Leib überall nur wenig druckempfindlich. Nirgends eine besondere empfindliche Partie. Untersuchung per rectum ergibt: Das Rektum fast leer. Douglas leicht druckempfindlich. Keine besondere Resistenz. Urin kein Eiweib, kein Zucker. Nachts Erbrechen von übelriechenden Massen, fast $3 / 4$ Liter. Hohes Klistier ohne Erfolg.

21. VIII. Operation (Geh. Rat Helferich): Medianer Laparotomieschnitt. Sofort fallen stark geblähte, livide verfärbte Dünndarmschlingen vor. Flex. sigmoid. stark mit Gas gefüllt, im oberen Rektum nur Kybala. Im kleinen Becken nahe dem Cöcum liegt ein großes Darmkonvolut. Es 


\begin{tabular}{|c|c|c|c|c|c|c|}
\hline Nr. & Name & $\stackrel{+}{ \pm}$ & 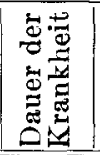 & Diagnose & Befund & $\begin{array}{l}\text { Operations- } \\
\text { verfahren }\end{array}$ \\
\hline 23 & H., A. & $\begin{array}{c}42 \mathrm{~J} \\
\mathrm{w} .\end{array}$ & 6 Tage & $\begin{array}{l}\text { Dünndarmver- } \\
\text { schluß. Obtura- } \\
\text { tions-Ileus. }\end{array}$ & $\begin{array}{l}15 \mathrm{~cm} \text { lange In- } \\
\text { vagination im } \\
\text { unteren Ileum } \\
\text { (Fibroma ilei } \\
\text { submucosum). }\end{array}$ & $\begin{array}{l}\text { Desinvagination. } \\
\text { Resektion. }\end{array}$ \\
\hline 24 & $\mid \begin{array}{l}\text { G., } \mathbf{K} . \\
855 / 1902\end{array}$ & $\begin{array}{c}18 \mathrm{~J} \\
\mathrm{~m}\end{array}$ & $\begin{array}{l}\left.3^{1}\right|_{2} \\
\text { Tage }\end{array}$ & Invagination. & $\begin{array}{l}\text { Invaginatio ilei } \\
(26 \mathrm{~cm}) .\end{array}$ & $\begin{array}{l}\text { Darmresektion } \\
(90 \mathrm{~cm}) .\end{array}$ \\
\hline $2 \check{5}$ & $\mid \begin{array}{l}\text { Fr., H. } \\
1598 / 1903\end{array}$ & $\begin{array}{c}10 \\
\text { Mon. } \\
\text { m. }\end{array}$ & $\begin{array}{c}10 \\
\text { Tage }\end{array}$ & $\begin{array}{l}\text { Invagination des } \\
\text { Colon. }\end{array}$ & $\begin{array}{c}\text { Aufsteigende In- } \\
\text { vagination der } \\
\text { Flexur in das } \\
\text { Col. descendens. }\end{array}$ & $\begin{array}{l}\text { Desinvagination. } \\
\text { Kolostomie. }\end{array}$ \\
\hline 26 & St., F. & $\begin{array}{l}8 \mathrm{~J} . \\
\text { w. }\end{array}$ & 7 Tage & $\begin{array}{l}\text { Dünndarmver- } \\
\text { schluß. }\end{array}$ & Invaginatio ilei. & Resektion. \\
\hline 27 & $\mid$\begin{tabular}{|l} 
Sch., E. \\
$343 / 1906$
\end{tabular} & $\begin{array}{l}7 \mathrm{~J} . \\
\mathrm{w} .\end{array}$ & 9 Tage & $\begin{array}{l}\text { Darminvagina- } \\
\text { tion. }\end{array}$ & $\begin{array}{l}\text { Invaginatio ileo- } \\
\text { coecalis. }\end{array}$ & $\begin{array}{l}\text { Resektion. Anus } \\
\text { praeteruatura- } \\
\text { lis. }\end{array}$ \\
\hline 28 & $\mid$\begin{tabular}{|l|} 
Gl., W. \\
$1328 / 1905$
\end{tabular} & $\begin{array}{l}7 \mathrm{~J} . \\
\mathrm{m} .\end{array}$ & ó Tage & $\begin{array}{l}\text { Darminvagina- } \\
\text { tion. }\end{array}$ & Invaginatio ilei. & Resektion. \\
\hline
\end{tabular}

zeigt sich, daß $26 \mathrm{~cm}$ Dünndarm invaginiert sind. An der Grenze des stark geblähten zuführenden Dünndarms und des Intussuszeptum Darm weißlich verfärbt (Schnürring) und nahe der Perforation unterhalb der Invagination Darm leer. In der Bauchhöhle ganz geringer seröser ErguB. mit einzelnen Fibrinfäden. Nach Versorgung und AbschluB der Bauchhöhle Resektion: $26 \mathrm{~cm}$ oberhalb, $10 \mathrm{~cm}$ unterhalb durchtrennt $(80$ bis $90 \mathrm{~cm}$ ). $\mathrm{Zu}-$ und abführendes Ende miteinander vereinigt (Nah.). Bauchwunde durch durchgreifende Zwirnknopfnähte geschlossen. Kochsalzinfusion. Abends gehen Winde.

Glatter Verlauf.

17. IX. Geheilt entlassen.

25. J.-N. 1598/1903. F. H., 10 Monate alt. Aufn. 3. II. 1904, gestorben 4. II. 1904. Invagination der Flexura sigmoidea in das Col. desc. Hebung der Invagination.

Seit $7^{1 / 2}$ Wochen krank. Erkrankung begann mit Darmblutungen und Schleimabgang aus dem Rektum. Seit 10 Tagen eigentlich kein Stuhl, nur weiBlicher Schleim. Zu gleicher Zeit Erbrechen, letztes Erbrechen heute morgen gegen $4 \mathrm{Uhr}$, auch Flatus seit den letzten 10 Tagen nicht mehr abgegangen.

Status: Hochgradig anämisches, aber kräftig gebautes Kind, sehr apathisch. Erheblicher Erschöpfungszustand. Puls 150 in der Minute, regelmäßig, ziemlich kräftig. Abdomen mäßig aufgetrieben, meteoristisch, 


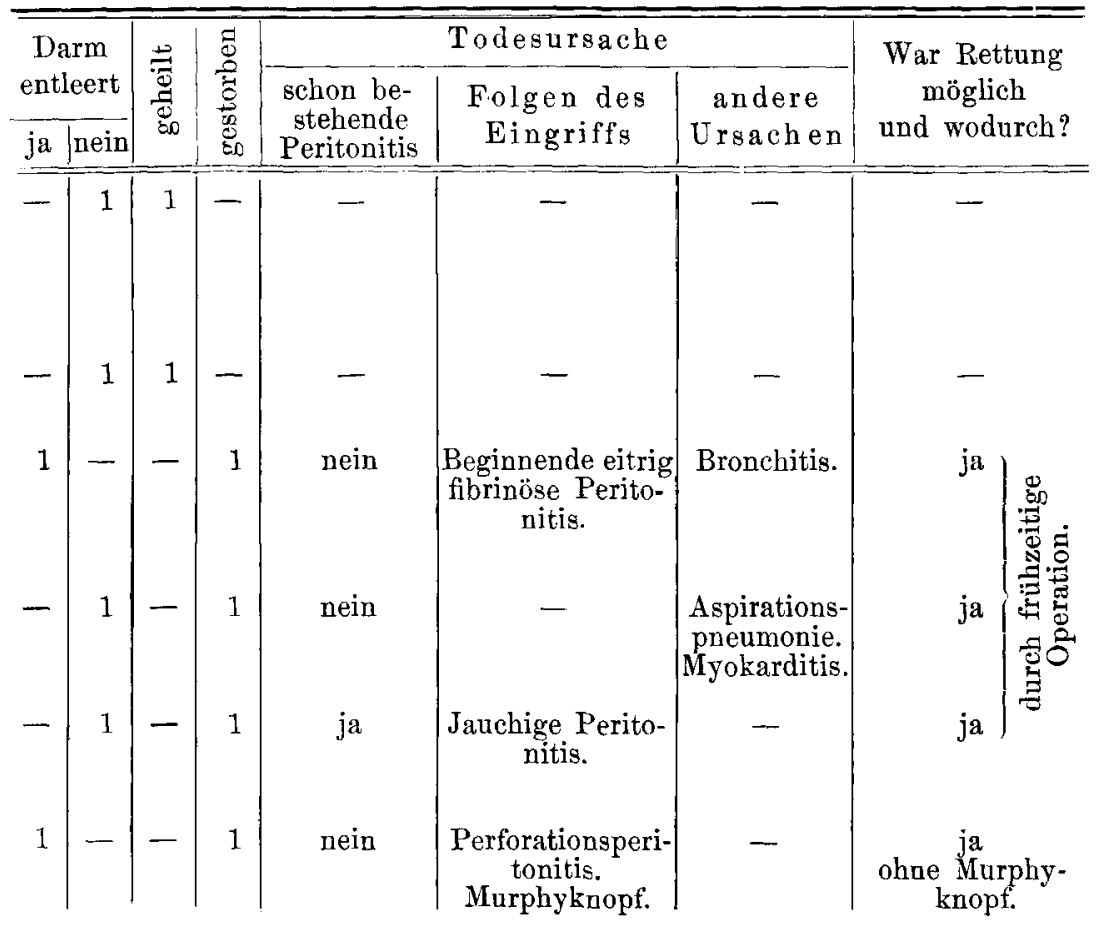

namentlich im Verlauf des Colon ascendens und transversum. Darmschall überschreitet den rechten Rippenbogen nach oben um 2 Finger breit. Leber in Kantenstellung. Leib ziemlich weich. Der Flexura sigmoidea entsprechend fühlt man im linken Hypogastrium eine Resistenz, die sich von auBen-oben nach unten-innen gegen die Symphyse hinzieht und sich zwischen dem palpierenden Finger von vorn nach hinten verschieben läBt. Der Perkussionsschall über der Resistenz gedämpft tympanitisch, über dem übrigen Abdomen überall Darmschall. Zeitweise sieht man starke peristaltische Bewegungen, welche namentlich das Colon ascendens und transversum betreffen und in der Gegend der Flexura coli sin. aufhören, auch an den Dünndärmen sind solche zu erkennen. Das sonst völlig apathische Kind schreit dabei bisweilen auf. Vom Rektum im linken Cavum Douglasii gleichfalls Resistenz. Herz und Lungen intakt.

Sofortige Operation in leichter Äther-Tr.-Narkose (Geh. Rat Helferich): Langer Medianschnitt. Bei Eröffnung des Peritoneums quellen geblähte Dünndarmschlingen hervor. Untersuchung nach Eventeration des Dünndarms. Kolon mäBig beweglich. Flexura und Kolon nicht zu unterscheiden. Blutiger Darminhalt durchschimmernd. Im unteren Teil des Kolon findet sich eine Invagination und zwar ist der untere Darmteil in den oberen invaginiert, etwa $15 \mathrm{~cm}$. Durch Streichen von unten nach oben gelingt es verhältnismäBig leicht, den invaginierten Teil zu entwickeln. An der Stelle, an welcher der invaginierte Teil in den ihn aufnehmenden umbiegt, 
Darmwand in einer Ausdehnung von ca. $5 \mathrm{~cm}$ starr, infiltriert, anämisch. Anlegen einer seitlichen Öffnung oberhalb und parallel des Lig. Poupartii, durch welchen ein Teil der Flexura nach auRen gelagert und mit Seidennähten an der Haut fixiert wird. Reposition des Dünndarms. Naht der medianen Wunde, durchgreifende Nähte. Mit dem Paquelin vorgelagerter Darm quer eröffnet, in größerer Menge breiiger Kot und geronnenes Blut.

Abends Temperatur 41,5, Puls 176, Kochsalzinfusion.

3 Uhr morgens Exitus.

Autopsie: Beginnende eitrig-fibrinöse Peritonitis. Bronchitis. Gemeinsames Lig. ileocolicum commune. Sehr langes Mesosigmoideum. Starke Wandverdickung und GefäBektasien des Cöcum und aufsteigenden Kolon. Frische Rötung und Wandverdickung der Flexura sigmoidea.

26. J.-N. 749/1904. St., F., 8 J., Arbeiterstochter aus K. Aufn. 1. VIII. 1904, gestorben 2. VIII. 1904. Ileus durch Invaginatio ilei. Darmresektion.

Anamnese: Fruher gesund. Am 26. VII. plötzlich mit Schmerzen in der rechten Unterbauchgegend erkrankt. Winde sind seitdem nicht mehr abgegangen. Stuhlgang in geringer Menge auf Einlauf; Erbrechen in den ersten Tagen wenig, erst in den letzten beiden Tagen reichlich fäkulent.

Status: Blasses, mageres, grazil gebautes Mädchen. Abdomen gleichmäßig aufgetrieben, starke, peristaltische Bewegungen, vorwiegend oberhalb des Nabels und an der rechten Seite. Links keine deutliche Peristaltik. In der Ileocöcalgegend sehr prall gespannte elastische Resistenz, bewegliche Darmschlingen, tympanitischer Schall. Kein freies Exsudat. Druckschmerz nicht sehr ausgesprochen, nur in der ileocöcalen Gegend etwas stärker. Leber in Kantenstellung. Bruchpforten frei. Puls 120, kräftig, ziemlich regelmäßig. Herz und Lunge ohne wesentlichen Befund. Zunge stark belegt. Temperatur 37,9. Beim Spülen des Magens reichliche Mengen fäkulent riechender Flüssigkeit.

1. VIII. 1904. Sofortige Operation (Dr. Sick): Chloroformnarkose. Schnitt unterhalb des Nabels. Eröffnung des Peritoneums, kaum getrübtes Exsudat. Stark geblähte Dünndarmschlingen mit injizierter aber spiegelnder Serosa. Cöcum noch gefüllt. Am Proc. verm. keine Entzündungserscheinungen. Die in das Cöcum übergehende Dünndarmschlinge ist sehr rigid. Untersuchung ergibt, daß sie gegen das Cöcum hin invaginiert ist. An einer umschriebenen Stelle ist Gangrän der Darmwand eingetreten. Es entleeren sich beim Bewegen des Darms nekrotische Fetzen. Die ganze von der Invagination betroffene Darmpartie zeigt auBerdem eine Drehung des Mesenterium um etwa $90^{\circ}$. Der Darmteil, welcher in den Beginn des invaginierten Stückes übergeht, ist zu einem kaum fingerdicken Strang ausgezogen. - Reselition der ganzen Darmpartie. Enden eingestülpt, übernäht. Seitliche Einpflanzung des Ileum ins Cöcum. Tamponade. Drainage. Etagennaht der Bauchwunde.

2. VIII. Hohe Temperatur. Nachts geschlafen. Kein Erbrechen, frequenter kleiner Puls. Abdomen nicht erheblich gespannt. Druckschmerz beiderseits in der Unterbauchgegend. Spontane Urinentleerung. Kein Abgang von Winden. Verfallenes Aussehen. Kalte Extremitäten. 
Ein Beitrag zur Pathologie und Therapie des inneren Darmverschlusses.

Nachmittags nicht erbrochen, verfällt zusehends.

Abends Bauchwunde eröffnet. Trübes Fxsudat aus der Gegend des kleinen Beckens. Hervorquellende Darmschlingen, hier fibrinös belegt.

$1 / 212$ Uhr Exitus.

Autopsie: Leicht lösbare peritonitische Verklebungen der Darmschlingen im Becken. Vernähung des unteren Ileumendes mit dem Cöcum. Ganz geringer blutig-seröser ErguB im Becken. Aspiration in den Lungen. Sehr blasses, fettig degeneriertes Herz.

27. J.-N. 343/1905. Sch., E., 7 J., Vogtstochter aus St. Aufn. 9. V. 1905, gestorben 10. V. 1905. Invaginatio ileocoecalis. Darmresektion.

Anamnese: Früher gesund. Am 1. Mai Bronchitis, Leibschmerzen. Am 3. Mai Wasserklistier, ergiebige Entleerung. Schmerzen bestanden fort, in der Unterbauchgegend rechts unten vom Nabel lokalisiert. Wassereinläufe kamen an den folgenden Tagen mehr oder weniger schokoladenfarbig mit krümeligen Fäces vermischt zurück. Es trat Meteorismus und Erbrechen auf. Deshalb zur Klinik.

Status: Grazil gebautes, mittelkräftiges Mädchen. Beiderseits über den Lungen Schnurreil. Temperatur 37,8, Puls frequent, aber liräftig. Abdomen meteoristisch. Leber reicht bis zum Rippenbogen. Bei jeder Berührung starke Spannung der Bauchdecken. Ganzes Abdomen druckempfindlich, Keine Resistenz in der Ileocöcalgegend. Bei längerer Betrachtung des Abdomens von Zeit zu Zeit auftretende starke peristaltische Bewegungen, hauptsächlich um den Nabel herum.

Untersuchung per rectum: elastische Vorwölbung der vorderen Wand. Flüssige, stinkende Kotmassen. Ob Winde abgehen, läBt sich nicht feststellen. Einlauf liommt kotig gefärbt zurück.

10. V. Kind hat nachts nur wenig geschlafen.

Temperatur morgens 37,6. Kein Erbrechen.

Operation in Chloroformnarkose (Dr. Sick): Mediane Laparotomie. Stark erweiterte, blaurot verfärbte, hypertrophische Dünndarmschlingen. Eventeration, in der Tiefe links ganz dünne kontrahierte Darmschlingen, Vom Mesenterialansatz fliebt Eiter nach abwärts. Nach dem Eiterherd hin Appendix und ein Netzzipfel, der sich leicht ablösen läBt. Appendix wird abgetragen. Bei der Besichtigung des Cöcum fällt seine pralle Füllung auf. Man erkennt jetzt, daß es sich um eine Invaginatio ileocoecalis handelt. Diese läBt sich teilweise lösen. Ileum an einer Stelle gangränös. Resektion der erkrankten Darmpartie. Verschluß des Kolon. Einpflanzen des Ileum durch einen rechts gelegten Schnitt. Tamponade. Kochsalzinfusion.

Temperatur abends 39,8, Puls nicht zählbar. Kochsalzinfusion.

Kein AufstoBen. Kein Erbrechen. Abends 9 Uhr Exitus.

Autopsie: Janchige Peritonitis. Resektion des unteren Ileum und des Proc. vermiformis. Anus praeternat. der rechten Leistengegend. Tuberkulose der Mesenterialdrüsen. Starke Bronchitis. Schwellung der Bronchialdrüsen. Starke Trübung der Leber und Nieren. Geringe Milzschwellung. Anämie des Pankreas.

28. J.-N. 1328/1905. G., W., 7 J. Aufn. 28. XI. 1905, gestorben 3. XII. 1905. Invaginatio ilei. Darmresektion. 
Anamnese: Bis vor 5 Tagen gesund. Nach einem FuBtritt vor den Unterleib Leibschmerzen in der Nabelgegend. Stuhldrang, aber kein Stuhlgang und keine Winde. Aufnahme in die Klinik von den Eltern abgelehnt Schmerzen nahmen zu. Leib aufgetrieben, häufiges Erbrechen, am 27. XI. in die medizinischen Klinik und am 28. XI. in die chirurgischen Klinik.

Status: Schwerkranker, schlecht genährter, blasser Junge, Falten zwischen den Augenbrauen und an den Mundwinkeln. Temperatur 37,6, Puls 140, klein. Kolikartige Schmerzen rechts vom Nabel, gleichzeitig deutliche Darmperistaltik. Leib stark aufgetrieben. Bauchdecken gespannt, freier ErguB nicht nachzuweisen. Druckempfindlichleit nicht so stark, als der Schmerz bei Auftreten der Darmperistaltik. Vom Rektum aus nichts Besonderes.

$12 \frac{1}{2}$ Uhr p. m. Sofort Operation (Dr. Göbell): Mediane Laparotomie. Stark geblähte Dünndarmschlingen quellen ziemlich stürmisch hervor. Kein freier Erguß. Keine stärkeren Entzundungserscheinungen. Invagination im untersten Ileum ca. $12 \mathrm{~cm}$. Das unterste Ende der Invagination noch $20 \mathrm{~cm}$ von der Ileocöcalklappe entfernt. Intussuszipiens an mehreren Stellen gangränös. Unterstes Ileum vollkommen leer. - Resektion der ganzen Darmpartie ca $35 \mathrm{~cm}$. Entleerung des zuführenden Darms durch Punktion. Side to side Anastomose mit Murphyknopf, weil Puls an der Radialis nicht mehr zu fühlen. Naht des Mesenterialschlitzes, Reposition der Därme. Schluß der Bauchwunde mittelst durchgreifender Zwirnknopfnähte. Verband.

Intravenöse Kochsalzinfusion $(750 \mathrm{ccm})$. Puls kehrt an der Radialis wieder, 160, von leidlicher Fülle. Warmes Wasserkissen. Glühweinklistier. Kampfer.

Nachmittags Aussehen besser. Temperatur 37,6, Puls 152. Auf zwei Einläufe zweimal reichlicher Stuhlgang.

28.209. XI. nachts 2 Uhr. Puls läßt nach. Radialpuls kaum fühlbar, ca. 180 Schläge, verschwindet während der Präparation der Vena saph. zur intravenösen Infusion völlig. Augen starr, Patient reagiert nicht auf Anruf noch bei der Incision, erscheint moribund. Trotzdem Infusion $(750 \mathrm{ccm})$ zu Ende geführt. Gegen Erwarten gegen Ende der Infusion Radialpuls wieder fühlbar. In weiteren Verlauf der Nacht erholt sich Patient weiter. Stündlich Kampfer. Kaffee und Wein erbrochen, Noch zweimal reichlich spontan Stuhl, dünn, braun.

29. XI. Allgemeinbefinden besser. Schmerzen im Leib geringer. Aber Erbrechen. Nichts per os. Sublutane Infusionen. Hohe Einläufe, reichlicher Stuhl und Winde.

Nachts 29./30. Puls lä8t wieder nach. Digalen, subkutane Infusion.

30. XI. Leibscbmerzen lassen nach. Subjektiv leidliches Befinden. Leib weich und unempfindlich. Kein Erbrechen. Puls 140. Zweimal subkutane Infusion. Kampfer.

1. XII. Subjektives Wohlbefinden. Flüssige Nahrung (Milch, Schleimsuppen) gut vertragen. Viermal flüssiger Stuhl und Winde. Viel Schlaf. Temperatur normal. Puls 128.

2. XII. Nach leidlicher Nacht Klagen über Leibschmerzen. Leib gespannt. Temperatur 39,1, abends 40,1. Starkes Erbrechen. Allgemein starke Spannung des Leibes. 
Ein Beitrag zur Pathologie und Therapie des inneren Darmverschlnsses.

3. XII. Ausgesprochenes Bild der diffusen Peritonitis. Exitus.

Autopsie: Perforationsperitonitis: gegenüber dem Murphyknopf im zuführenden Darm Perforation: Dehnungs- oder Druckgeschwür?

\section{Torsion und Knickung.}

29. J.-N. 1559/1899. D., E., Witwe, 55 Jahre, aus B. Aufgenommen 21. II. 1900, entlassen 20. III. 1900.

Peritoneale Darmverwachsungen nach Appendizitis.

Geringe Ileuserscheinungen.

Lösung der Adhäsionen.

Rezidiv nach $4^{1 / 2}$ Jahren. Ileokolostomie.

Anamnese: 6. III. bis 7. IV, 1899 in der Kieler chirurgischen Klinik wegen Appendizitis behandelt. Es blieb eine Kotfistel zurück, welche sich zu Hause nach einigen Wfederaufbrüchen vor vielen Wochen definitiv schloß. Seitdem viele Schmerzen, oft Übelkeit, viel Unruhe im Darm und das Gefühl, daß sowohl Winde, wie Kot sich in der rechten Unterbauchgegend fangen und nicht leicht durchkommen. Die starken Beschwerden veranlassen die Patientin, sich zu einer Operation zu entschlieBen.

Status: Magere, aber sonst gesunde Frau.

Abdomen: In der Mittellinie zwischen Symphyse und Nabel eine Längsnarbe gut verheilt. Rechts von der Mittellinie dicht über dem Lig. ing. eine breite strahlige längliche schräggestellte $8 \mathrm{~cm}$ lange Operationsnarbe. Geringe Verdickungen und Verwachsungen $\mathrm{zu}$ fühlen, sonst alles weich, keine Resistenz. - Uterus retroflektiert, beweglich. An der rechten Beckenwand festsitzend eine halbhühnereigroße, halbweiche, nicht entzündliche Resistenz. Adnexe nicht zu fühlen.

Stuhlentleerung auf Klistiere ungenügend, nach 01 . Ricini unter vielen Beschwerden reichlich.

Behandlung: 26. II. 1900. Operation in Chloroform-Narkose (Geh. Rat Helferich): Schrägschnitt in der rechten Unterbauchgegend. Eröffnung des Peritoneum. Dünndarm breit mit der Bauch- und Beckenwand verwachsen. Adhäsionen fest fibrös, müssen scharf durchtrennt werden. Verschiedene Darmschlingen gelöst, Cöcum freiprapariert. Auch an der rechten Beckenwand Schlingen breit fixiert. Ablösung derselben. Darm nunmehr frei. Reposition des Darms. Schluß der Bauchhöhle durch Etagennaht. Verband.

Verlauf ohne Störung.

20. III. 1900. Völlig beschwerdefrei, auch beim Umhergehen.

Geheilt entlassen.

Bis Winter 1903/04 völlig gesund, dann wieder Schmerzen in der Ileocöcalgegend. Schwerer Stuhlgang mit heftigen Schmerzen, zuweilen von Ohnmacht begleitet. Im Sommer 1904 Kur in Kissingen ohne Erfolg, im Gegenteil Verschlimmerung. Ohne Abführmittel kein Stuhlgang, selbst ganz dünner Stuhl nur mit großer Anstrengung entleert.

23. IX. 1904 Wiederaufnahne in die Klinik (996/1904.)

Status: Pat. immer noch leidlich genährt. Herz: 2. Aortenton accentuiert. Geringe Arteriosklerose. Pulmonens ohne besonderen Befund. 
Abdomen ein wenig aufgetrieben, im rechten Hypogastrium stärker. Im Hypogastrium die 3 alten Narben. Nur die von der ersten Operation

\begin{tabular}{|c|c|c|c|c|c|c|}
\hline $\mathrm{Nr}$. & Name & 离 & 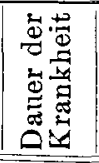 & Diagnose & Befund & $\begin{array}{l}\text { Operations- } \\
\text { verfahren }\end{array}$ \\
\hline 29 & $\begin{array}{l}\text { D. E. } \\
1559 / 1899\end{array}$ & $\begin{array}{c}61 \mathrm{~J} . \\
\text { w. }\end{array}$ & - & $\begin{array}{l}\text { Beginnender } \\
\text { Darmverschluß } \\
\text { durch Adhäsio- } \\
\text { nen nach Ap- } \\
\text { pendicitis. }\end{array}$ & $\begin{array}{l}\text { Vielfache Knick- } \\
\text { ungen des un- } \\
\text { teren Ileum } \\
\text { durch Adhäsio- } \\
\text { nen. }\end{array}$ & $\begin{array}{l}\text { Lösung der Ad- } \\
\text { häsionen. }\end{array}$ \\
\hline 30 & J. & $\begin{array}{c}59 \mathrm{~J} \\
\text { w. }\end{array}$ & - & $\begin{array}{l}\text { Dünndarmver- } \\
\text { schluß durch } \\
\text { Adhäsionen } \\
\text { nach Appendi- } \\
\text { citis. }\end{array}$ & $\begin{array}{l}\text { Netzstränge. Ad. } \\
\text { hägionen im kl. } \\
\text { Becken. }\end{array}$ & $\begin{array}{l}\text { Lösung der Ad- } \\
\text { häsionen. }\end{array}$ \\
\hline 31 & $\begin{array}{l}\text { P. A. } \\
1430 / 1900\end{array}$ & $\begin{array}{c}40 \mathrm{~J} \\
\mathrm{~m} .\end{array}$ & 3 Tage & $\begin{array}{l}\text { Darmverschluß } \\
\text { durch Obtura. } \\
\text { tion. }\end{array}$ & $\begin{array}{l}\text { Adhäsion quer } \\
\text { über das Colon } \\
\text { asc. gespannt. }\end{array}$ & $\begin{array}{l}\text { Durchtrenuung } \\
\text { der Adhäsionen. }\end{array}$ \\
\hline 32 & Tr. J. & $\begin{array}{c}\bar{\rho} 3 \mathrm{~J} . \\
\mathrm{m} .\end{array}$ & - & $\begin{array}{l}\text { Darmverschluß } \\
\text { durch Adhäsio- } \\
\text { nen nach Ap- } \\
\text { pendicitis. }\end{array}$ & $\begin{array}{l}2 \text { Dünndarmbal- } \\
\text { len durch Ad- } \\
\text { bäsionen ent- } \\
\text { standen. Un- } \\
\text { teres Ileum leer. }\end{array}$ & $\begin{array}{l}\text { Enteroanasto. } \\
\text { mosis. }\end{array}$ \\
\hline 33 & N. M. & $\begin{array}{c}76 \mathrm{~J} \\
\mathrm{w}\end{array}$ & 4 Tage & $\begin{array}{l}\text { Dünndarmver- } \\
\text { schluß. }\end{array}$ & $\begin{array}{l}\text { Winklige Knick- } \\
\text { ung des Ileum } \\
\text { durch Adhä- } \\
\text { sionen am Cö- } \\
\text { cum. }\end{array}$ & $\begin{array}{l}\text { Exstirpation der } \\
\text { Appendix. Lö- } \\
\text { sung der Adhä- } \\
\text { sionen. }\end{array}$ \\
\hline 34 & $\begin{array}{l}\text { Fr. J. } \\
261 / 1904\end{array}$ & $\begin{array}{c}47 \mathrm{~J} \\
\mathrm{~m} .\end{array}$ & 4 Tage & $\begin{array}{l}\text { Dünndarmver- } \\
\text { schluß. }\end{array}$ & $\begin{array}{l}\text { Torsion u. Ver- } \\
\text { engerung des } \\
\text { untersten Ileum } \\
\text { durch retrope- } \\
\text { ritonealen Ver- } \\
\text { lauf. }\end{array}$ & $\begin{array}{l}\text { Peritonealplastik. } \\
\text { Ileocolostomie. }\end{array}$ \\
\hline 35 & Fr. J. & $\left|\begin{array}{c}47 \mathrm{~J} \\
\mathrm{~m} .\end{array}\right|$ & 9 Std. & $\begin{array}{l}\text { Dünndarmver- } \\
\text { schluß. }\end{array}$ & $\begin{array}{c}\text { Zahlr. Adhäsio- } \\
\text { nen. Knickung } \\
\text { des Darms. }\end{array}$ & $\begin{array}{l}\text { Lösung u. Durch- } \\
\text { trennung der } \\
\text { Adhäsionen. }\end{array}$ \\
\hline 36 & $\begin{array}{l}\text { M. } \\
1806 / 1904\end{array}$ & $\begin{array}{l}42 \mathrm{~J} \\
\text { w. }\end{array}$ & 3 Tage & $\begin{array}{l}\text { Dickdarmver- } \\
\text { schluß durch } \\
\text { Uterusverlage- } \\
\text { rung. }\end{array}$ & $\begin{array}{l}\text { Knickung } \\
\text { des Dünndarms } \\
\text { durch viele Ad- } \\
\text { häsionen im kl. } \\
\text { Becken. }\end{array}$ & $\begin{array}{l}\text { Lösung der Ad- } \\
\text { häsionen. } \\
\text { Darmresektion. }\end{array}$ \\
\hline 37 & L. L. & $66 \mathrm{~J}$. & 12 Std. & $\begin{array}{l}\text { Dünndarmver. } \\
\text { schluß. }\end{array}$ & $\begin{array}{l}\text { Kuppe einer } \\
\text { Ileumschlinge } \\
\text { am Mesosig- } \\
\text { moideum breit } \\
\text { fixiert. Oberes } \\
\text { Ileum unter } \\
\text { dieser Schlinge } \\
\text { durchgeschlüpft. }\end{array}$ & $\begin{array}{l}\text { Lösung der Ad- } \\
\text { häsionen, }\end{array}$ \\
\hline
\end{tabular}


Ein Beitrag zur Pathologie und Therapie des inneren Darmverschlusses, 491 herrührende, zeigt einen Bauchbruch: Narbengewebe unmittelbar über dem Intestinum, aber nicht mit ihm verwachsen. Im rechten Hypogastrium deut-

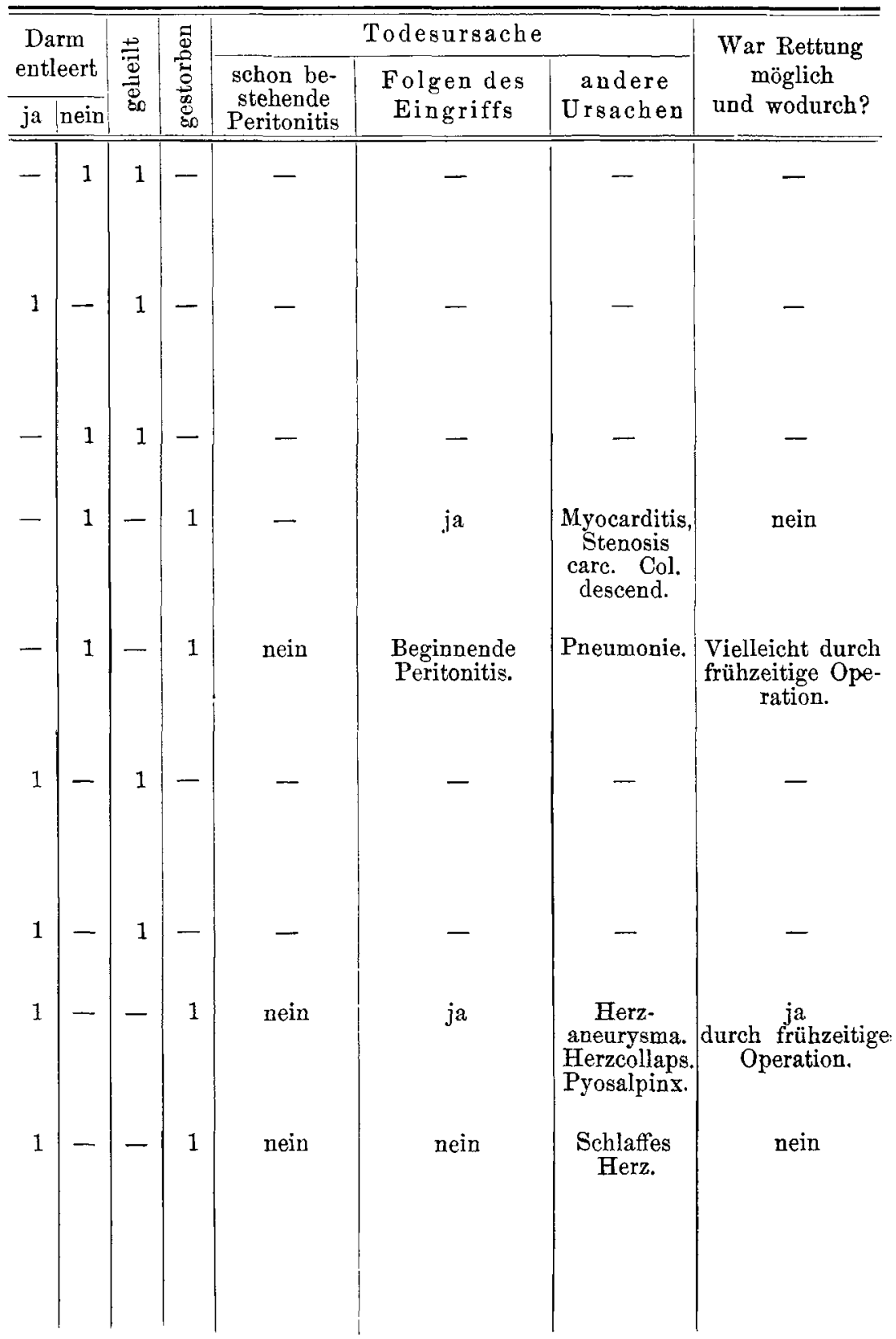




\begin{tabular}{|c|c|c|c|c|c|c|}
\hline $\mathrm{Nr}$. & Name & $\stackrel{\substack{D \\
\pm}}{4}$ & 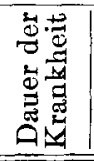 & Diagnose & Befund & $\begin{array}{c}\text { Operations - } \\
\text { verfahren }\end{array}$ \\
\hline 38 & $\begin{array}{l}\text { W. O. } \\
1036 / 1901\end{array}$ & $\begin{array}{l}6 \mathrm{~J} . \\
\mathrm{m} .\end{array}$ & 48Std. & $\begin{array}{l}\text { Dünndarmver- } \\
\text { schlu } \beta .\end{array}$ & $\begin{array}{l}\text { Tub. Mesenterial- } \\
\text { drüsen. Perito- } \\
\text { nitis tub. Knick- } \\
\text { ung des Ileum } \\
\text { durch Adhäsio- } \\
\text { nen. }\end{array}$ & $\begin{array}{l}\text { Exstirpation der } \\
\text { Mesenterial- } \\
\text { drüsen. Lösung } \\
\text { der Adhäsio- } \\
\text { nen. }\end{array}$ \\
\hline 39 & N. O. & $\begin{array}{c}26 \mathrm{~J} \\
\mathrm{~m} .\end{array}$ & 9 Tage & $\begin{array}{l}\text { Dünndarmver- } \\
\text { schluß. }\end{array}$ & $\begin{array}{l}\text { Dünndarm durch } \\
\text { Verwachsungen } \\
\text { geknickt. }\end{array}$ & $\begin{array}{l}\text { Lösung der Ad- } \\
\text { häsionen. }\end{array}$ \\
\hline 40 & $\begin{array}{l}\text { Kr. J. } \\
1444 / 1904\end{array}$ & $\begin{array}{c}47 \mathrm{~J} \\
\mathrm{~m} .\end{array}$ & 4 Tage & $\begin{array}{l}\text { Dickdarmver- } \\
\text { schluß. }\end{array}$ & $\begin{array}{l}\text { Sigmoiditis. Bei } \\
\text { der 3.Op.Knick- } \\
\text { ung der Flexur } \\
\text { durch tub. Ad- } \\
\text { häsionen am } \\
\text { unteren Ileum. }\end{array}$ & $\begin{array}{l}\text { 1. Probelaparo- } \\
\text { tomie. } \\
\text { 2. Kolostomie. } \\
\text { 3. Peritonealpla- } \\
\text { stik. }\end{array}$ \\
\hline 41 & $\begin{array}{l}\text { N.'M. } \\
1774 / 1905\end{array}$ & $\begin{array}{c}58 \mathrm{~J} . \\
\mathbf{w} .\end{array}$ & 4 Tage & $\begin{array}{l}\text { Dickdarmver- } \\
\text { schluß. }\end{array}$ & $\begin{array}{c}\text { Knickung der Fle- } \\
\text { xura sigmoidea } \\
\text { durch Adhäsion } \\
\text { der Kuppe am } \\
\text { l. Tubenwinkel. }\end{array}$ & $\begin{array}{l}\text { Lösung der Ad- } \\
\text { häsionen. Ap- } \\
\text { pendicostomie. }\end{array}$ \\
\hline
\end{tabular}

liche Peristaltik sichtbar. Man fühlt zwischen Nabel und Spina oss. il. a. s. eine geblähte Darmschlinge, die nach dem Kökum hin druckempfindlich ist. Von Zeit zu Zeit Gurren. Kökum fast leer. Uterus nach links und hinten verdrängt, retrovertiert. Keine abnorme Resistenz im kleinen Becken.

24. IX. 1905. Behandlung: Sauerstoff-Chloroform-Narkose: (Operation: Geh. Rat. Helferich.) Pararektaler, etwas schräger Schnitt, trifft die mittlere Narbe in der Mitte, welche in ihrer Längsrichtung durchtrennt wird. Man gelangt gleich auf den von Adhäsionen umgebenen Darm, welcher mühsam isoliert wird. Netz ist adhärent wird gelöst. Das Ileum ist in seinen untersten $40-50 \mathrm{~cm}$ mehrfach an der Bauchwand und mit sich selbst verwachsen, so daB es nur einer sehr sorgfältigen Präparation gelingt, den Darm freizumachen. Eine eigentliche Striktur nicht nachweisbar, die vielfachen Knickungen erklären leicht die ileusartigen $\mathrm{Zu}$ stände.

Da die Adhäsionen sich sicher wieder bilden werden, wird das ganze untere Ileum und Colon ascendens ausgeschaltet. Ileokolostomie zwischen von Adbäsionen freiem Ileum und Colon transversum (dreifache Nahtreihe, Verengerung des abführenden Ileum und des zuführenden Colon transversum). Peritoneale Katgutnaht. Durchgreifende Zwirnknopfnähte, fortlaufende Hautzwirnnaht. Verband. lassen.

5. X. Glatter Verlauf. Heilung p. pr., in ambulante Behandlung ent- 
Ein Beitrag zur Pathologie und Therapie des inneren Darmverschlusses. 493



31. J.-N. 1430/1900. P. A., 40 Jahre, Arbeiter aus K. Aufgenommen 29. I. 1901, entlassen 23. II. 1901.

Ileus. Knickung des Col. ascendens durch Adhäsion.

Lösung der Aủhäsion.

Seit 3 Tagen heftiges Schneiden im Leib und andauernd Erbrechen. Stuhlgang und Winde seit dem 26. I. 1901 nicht abgegangen. Früher hatte P. nach schwerer Arbeit öfters Schmerzen in der rechten Bauchseite. Stuhlgang sonst bisher immer regelmäBig.

Status: Mittelgroßer, liräftiger, wohlgenährter Mann, Zunge stark belegt, trocken. Puls: mittelkräftig 96 .

Temperatur 36,4. Brustorgane ohne Befund.

Abdomen stark aufgetrieben, Venen erweitert. Haut in der rechten Unterbauchgegend leicht gerötet, daselbst mäßiges Oddem. Schall über dem Abdomen tympanitisch, nur links ein wenig gedämpft. Leber in Kantenstellung. Das ganze Abdomen druckempfindlich, besonders in der Ileocöcalgegend und von hier aufwärts bis zum Rippenbogen. Von Zeit zu Zeit sieht man die stark geblähten Dünndarmschlingen deutlich in Bewegung. Im Rektum Kotballen. Magenspülung entleert reichliche kotige Massen.

Operation: 29. I. 3 Uhr nachmittags. Operation: Dr. Sictä, Chloroform-Narkose. Medianer Schnitt eröffnet das Peritoneum. Aus der Wunde drängen sich sofort geblähte hyperämische Dünndarmschlingen hervor. Am Dünndarm kein VerschluB zu finden. Unteres Ileum sehr stark gebläht 
und bläulich-rot verfärbt. Herauslagerung des Dünndarms. Proc. vermiformis ohne pathologische Veränderung. Colon transversum leer und dünn. Netz nach der Flexura coli dextra hin verzogen. Am Colon ascendens ist der VerschluB dadurch zustande gekommen, daB sich eine bindegewebige Adhäsion quer über das Colon gespannt und dasselbe auf diese Weise komprimiert und geknickt hat. Flexura coli dextra füllt sich ebenso wie das Colon transversum nach Durchtrennung der Adhäsion. Eine andere Ursache für den DarmverschluB ist nicht zu finden. Reposition des Dünndarms. Schluß der Bauchhöhle. Steriler Verband.

Abends Klysma, wenig Stuhl und Winde.

Heilung ohne Zwischenfall. 23. II. 1901 geheilt entlassen.

32. J.-N. 1551/1899. Tr. J., 53 Jahre, Arbeiter aus K. Aufgenommen 20. II. 1900, gestorben 24. II. 1900 .

Chronischer Ileus bei Peritonitis adhaesiva.

Enteroanastomose.

Anamnese: Pat. hat sehr viel an Stuhlverstopfung gelitten und trat am 1. XII. 1899 nach 4 tägiger Stuhlverhaltung in die Klinik ein. Durch Einläufe und Ol. Ricini wurde damals reichliche Stuhlentleerung erzielt. Es blieb in der Ileocöcalregion eine etwa hühnereigroße, druckempfindliche Resistenz zurück. Deshalb wurde am 6. XII. 1899 das Cöcum und die Appendix freigelegt. Man fand zahlreiche Adhäsionen, eine eigentümliche Starrheit der Cöcalwand. Der Proc. vermiformis war in der Mitte verdickt und hart. Er wurde exstirpiert. Nach glatter Heilung wurde Pat. entlassen. Ende Januar 1900 angeblich nach einem Diätfehler Auftreibung tes Leibes und Schmerzen im Leib. Auftreibung verschwand, Schmerzen blieben bestehen. Appetitmangel. 12., 13., 14. II. 1900 Erbrechen bei aufgetriebenem Leib. In den letzten Tagen Stuhlverhaltung, Winde nur sehr vereinzelt. Kein Erbrechen, aber Aufstoßen.

Status: Blasser, etwas verfallen aussehender Mann, in schlechtem Ernährungszustand. Herz und Lungen ohne besonderen Befund. Abdomen stark aufgetrieben, Bauchdecken stark gespannt. Lebergrenzen nach oben etwas verschoben. Starke Peristaltik der Därme. Starkes Gurren im Leib, weithin hörbar. Operationsnarbe fest und gut. Keine Dämpfung. Rektale Untersuchung: Douglas vorgewölbt. Kein Erbrechen, aber Aufstoßen, ganz selten Winde. Puls klein 96.

Behandlung: Klysmata. Pechartiger, stark stinkender Stuhl.

Am 22. II. Stuhlgang auf Klistier, dunkelbraun gefärbt.

24. II. Leib stark aufgetrieben. Keine Winde. Allgemeinbefinden schlecht. Puls 112, klein.

Deshalb Operation: Äther-Narkose. Mediane Laparotomie im Hypogastr. (Geh. Rat Helferich), später Verlängerung bis zum Proc. xiphoid. Geringer seröser Erguß. Dünndarm durch Adhäsionen zu zwei Ballen zusammen gebacken, die vom ersten zum zweiten Ballen führende Dünndarmschlinge weit und gebläht. Die vom zweiten Ballen abführende Dünndarmscblinge ist leer. Um den Ballen zeigt sich das Peritoneum mit zahlreichen Knötchen besetzt. Cöcum von gleicher Beschaffenheit wie bei der ersten Operation. Enteroanastomose zwischen der geblähten Verbindungsschlinge und dem leeren Dünndarm (durch Naht). VerschluB der Bauchböhle durch 
Etagennaht. Verband. 15 Minuten post operationem Exitus. Keine Störung der Narkose.

Autopsie: Sehr starkes Lungenemphysem und -ödem. Zahlreiche kleine myokarditische Schwielen. Leichte Verdickung der Mitralis. Geringe chronische Endarteritis und fettige Fleckung der Aorta. Trübung und Induration der Leber, sehr kleiner linker Leberlappen. Geringe Milzschwellung. Ǩleines, stenosierendes Krebsgeschwür des Colon descendens. Verwachsung zweier Darmpakete mit starken Knickungen. Tiefe rechtsseitige Leistenhernie mit stark schwieligen Verdickungen des Peritoneums. Geringe rechtsseitige Hydrocele.

33. J.-N. 1904/242. N. M., 76 Jahre, Witwe aus K. Aufgenommen 23. 1V. 1904, gestorben 26. IV. 1904.

Dünndarmverschluß durch Adhäsionen (nach Appendizitis.)

Lösung der Adhäsionen. Exstirpatio appendicis.

Anamnese: Wegen rechtsseitiger Hemiplegie im städtischen Krankenhaus. Seit dem 19. dieses Monats Darmverschluß. Am 19. dieses Monats noch Stuhlgang. Seitdem nicht wieder, trotz täglicher hoher Einläufe von Wasser und 01 Ricini. Erbrechen von sauren, nicht fäkulent riechenden Massen. Starke meteoristische Auftreibung des Abdomens. Schmerzen seit dem 22. IV. in der rechten Hälfte des Abdomens lokalisiert. Ructus und Singultus nur ganz vereinzelt. Am 22. kein Erbrechen. Am 22. werden durch Magenspülung braune, nicht übelriechende Massen entleert. Am 23. morgens Erbrechen ähnlicher, etwas übelriechender Massen.

Status: Magere, für ihr Alter aber in leidlicher Verfassung sich befindende Frau. Rechtsseitige Hemiparese. Starke Arteriosklerose. Herztöne rein. Puls 102, dann und wann aussetzend, ziemlich kräftig. Abdomen mäßig aufgetrieben, aber ziemlich weich. Cöcalgegend druckempfindlich, keine Resistenz, kein freies Exsudat. Leber in Kantenstellung. Stark vermehrte Peristaltik. Die dabei sich abzeichnenden Darmschlingen gehören dem Dünndarm an, während am Dickdarm keine Peristaltik sichtbar ist. Keine Rektumstenose, keine Brucheinklemmung. Pat. erbricht massenhafte, stark fäkulent riechende Flüssigkeit. Zunge belegt.

Behandlung: Magenspülung. Äther-Tr.-Narkose. Operation Dr. Baum. Medianschnitt links vom Nabel. Nach Eröffnung des Peritoneum quellen stark geblähte Dünndarmschlingen hervor. Die Untersuchung zeigt rechts im Becken stark kontrahierte Dünndarmschlingen. Beim Hervorziehen des Darms wird eine rechts am Cöcum gelcgene Dünndarmschlinge gelöst, die leichte Verwachsungen zeigt, die offenbar mit gleichen Verwachsungen am Cöcum in Zusammenhang gestanden haben. Die Dünndarmschlinge ist dadurch an das Cöcum herangezogen und winklig geknickt, zeigt hämorrhagische Infiltration der Wand und leichte Trübung der Serosa. Am Cöcum finden sich noch weitere flächen- und strangförmige Verwachsungen mit der seitlichen Beckenwand. Die Appendix zieht nach unten und ist an dem Rand einer peritonealen Ausstülpung am Schenkelkanal verwachsen. Es wird hier gelöst und in üblicher Weise exstirpiert. (App. ist obliteriert.) Rechts große Ovarialcyste.

Jodoformstreifen (an die Stelle des Appendixstumpfes) wird durch Deutsche Zeitschrift f. Chirurgie. LXXXII. Bd. 
eine seitliche Inzision herausgeleitet. Reposition der Darmschlingen. Durchgreifende Zwirnnähte.

26. IV. $1 \mathrm{Uhr}$ nachts. Keine Symptome einer allgemeinen Peritonitis. Exitus unter dem Zeichen der Darmlähmung.

A u topsie: Laparotomie-Wunde, Defect des Proc. vermiformis. Kleine rechtsseitige Schenkelhernie. Rötung und Fibrinbelag einer Dünndarmschlinge. Ganz geringe beginnende fibrinöse Peritonitis. Alte Verwachsung des Netzes mit dem S-förmig geschlungenen Colon transversum. Starkes Lungenödem. Mehrere kleine pneumon. Infiltrate des rechten Oberlappens. Beiderseits Pleura-Spitzen-Schwiele. Starke Residuen beiderseitiger Pleuritis. Hypertrophie des linken Ventrikels. Kalkherde in den Papillarmuskeln. Verdickung der Mitralsegel. Fettige Fleckung des Endokards. Starke chronische Endarteriitis. Bronchitis.

34. J.-N. 261/1904. J. Fr., 47 Jahre, Arbeiter aus K. Aufnahme 20. IV. 1904, geheilt 21. V. 1904.

Darmverschlu $B$ durch Torsion am unteren Ileumende.

Ileocöcostomie.

Anamnese: Bis zum 25. dieses Monats vollkommen gesund, starke Schmerzen im Leib, brettharte Spannung der Bauchdecken, bald darauf Erbrechen, welches erst am 29. fäkulent. Puls stets kräftig, frequent, kein Stuhl, keine Winde.

Status: Sehr kräftig gebauter Mann. Puls 108, voll, regelmäBig. Zunge kaum belegt, feucht. Leib sehr stark aufgetrieben. Auftreibung überall gleichmäBig. Sichtbare Peristaltik vorhanden, aber wenig ausgesprochen, dagegen häufig laute, spritzende Darmgeräusche hörbar. Peryussionsschall überall laut tympanitisch. In den abhängigen Partien schmale Zone gedämpft tympan. Schalls, die sich bei Lagewechsel deutlich aufhellt. Untere Grenze der Leberdämpfung handbreit über den Rippenbogen. Bei Betastung nirgends Resistenz, Geringe Druckempfindlichkeit der Gegend zwischen Nabel und linken Rippenbogen.

Behandlung: Operation in Chloroform-Narkose. Mediane Laparotomie (Dr. Göbell) stark geblähte etwas livide Dünndarmschlingen, Serosa spiegelnd. Mäßige Mengen frisch serösen Ergusses. Eventeration. Hindernis für die Passage sitzt am unteren Ileum und ist bedingt durch eine Drehung und Verengerung des Darms. Ursache: starke, nur wenig narbig aussehende, im Mesenterium des unteren Ileum liegende Stränge, welche das Mesenterium stark verkürzen und vom Mesocöcum in radiärer Ordnung in das Mesenterium hineinziehen, und die durch verschieden starken Zug eine Drehung des Darms um seine Längsachse bewirkt haben. Darm ist zwischen den Ansatzstellen dieser Stränge verengert. Zunächst durch quere Schnitte und Längsnaht Peritonealplastik. Ileum beweglicher, aber noch nicht ausreichend, zwar stellt sich die Passage wieder her, aber die Drehung und Verengung des Darms bleibt bestehen. Es wird darauf zur vollkommenen Herstellung der Darmpassage eine Anastomose zwischen Ileum und Cöcum angelegt ( 3 fache Naht). Vorher Darm mit dickem Troikart entleert. Peripher der Anastomosenstelle Ileum durch raffende Nähte verengert. Jodoformstreifen bis an die Ileocöcalgegend. Naht der Bauchwunde. Kochsalzinfusion. 
1. V. Winde und Stuhlgang abgegangen. Kein Erbrechen, kein Aufstoßen.

2. V. Delirium alcohol.

21. V. Geheilt entlassen.

35. J.-N. 540/1904. Derselbe. Aufn. 22. VI. 1904, geheilt 19. VII. 1904.

Akuter Ileus, infolge Abknickung durch peritonitische Adhäsionen. Laparotomie. Lösung der Adhäsionen. Bauchnaht.

Anamnese: Pat. am 12. V. entlassen. Sehr gutes Befinden. Appetit reichlich. Stuhlgang täglich, meist dünnbreiig. Er hat bereits 8 Tage ohne Beschwerden gearbeitet. Nach Angabe seiner Frau soll er jedoch an den letzten 2-3 Tagen nicht mehr ganz so munter gewesen sein. Appetit und Stublgang regelrecht. Heute morgens $3 \mathrm{Uhr}$ erwachte er vor Schmerzen im ganzen Leib, dabei Stuhldrang. Nach ziemlich reichlichem Stuhl keine Erleichterung. Schmerzen so heftig, daB er nicht arbeiten konnte. SchweiBausbruch. Schwächegefühl. Keine Besserung. Aufnahme in die Klinik.

Status: Kräftig gebauter, etwas blasser und krank aussehender Mann in hinreichendem Ernährungszustande. Leichte Cyanose der Lippen. Zunge leicht belegt. Aufstoßen. Lungen und Herz ohne Befund. Puls 132, klein sehr leicht unterdrückbar. Leib aufgetrieben. Bauchdecken etwas gespannt. Keine Dämpfung in den abhängigen Partien. Keine sichtbare Peristaltik. In der Medianlinie etwa $25 \mathrm{~cm}$ lange feste Narbe. Betastung des Leibes überall in mäBigem Grade schmerzhaft, keine lokalisierte Druckempfindlichkeit. Vom Rektum aus nichts Besonderes.

Bei der Magenspülung große Mengen braungelber Flüssigkeit von leicht fäkulentem Geruch entleert. Ausspülung. Hoher Einlauf. Keine Winde.

Eine Stunde nach der Magenspülung Erbrechen von intensiv fäkulent riechenden Massen. Deshalb sogleich Operation in Chloroform-Narkose (Dr. Göbell.) Medianschnitt durch die alte Narbe eröffnet die Bauchhöhle. Mit der Narbe fest verwachsen ist das Netz und eine Dünndarmschlinge, welche nur unter Ablösung der Serosa befreit werden kann. Zwischen den übrigen Dünndarmschlingen sind zahlreiche membranöse und ligamentöse Adhäsionen vorhanden, ebenso zwischen einzelnen Dünndarmschlingen und dem Mesenterium der nächstliegenden Schlinge. Durch stumpfes Präparieren, unterstützt durch Ligieren und Durchtrennen der bandartigen Adhäsionen gelingt es, den ganzen Dünndarm zu befreien. Die untersten $20 \mathrm{~cm}$ des oberhalb der Anastomose gelegenen Ileum sind leer. Die Anastomose ist durchgängig. Hindernis für die Passage besteht in einer Abknickung durch Adhäsionen. Nach Lösung der letzteren wird die Passage frei und es gelingt, den Inhall des Dünndarms zum gröBten Teil in den Darm zu streichen. Wenn auch der absolute Verschlus $20 \mathrm{~cm}$ oberhalb der Anastomose gelegen war, so wirkten doch auch alle sonstigen Adhäsionen mit, durch Erschwerung der Passage den Ileus herbeizuführen. Schluß der Bauchhöhle durch Knopfnähte.

Nach der Operation Glyzerinspritze. Einführen eines Darmrohres. Zwei Kochsalzinfusionen täglich. Kampfer nach Bedarf.

23. VI. Subjektives Wohlbefinden, guter Schlaf. Kein AufstoBen. Puls 104, kräftiger, Zunge feucht. Reichlicher Stuhlgang und Winde. 
Flüssigkeit per os. Daneben täglich 2 Löffel Rhabarberwein und eine Glyzerinspritze.

26. VI. Wohlbefinden häIt an. Reichlicher Stuhlgang. Da über $2000 \mathrm{ccm}$ Flüssigkeit per os genommen werden, keine Infusionen mehr. Entfernung einzelner Nähte.

6. VII. Einzelne Stichkanäle secernieren noch. Sonst ist die Wunde verheilt. Ernährung reichlich. Stuhlgang täglich 1-2 mal. Pat. ist nachm. auBer Bette.

19. VII. Allgemeinbefinden vorzüglich. Noch 1 kleine pfennigstückgroße, granulierende Wunde nahe dem Nabel.

Pat. in die ambulante Behandlung entlassen.

21. J.-N. 435/1905; vgl. Nr. 34 und 35. Fr. J., 47 Jahre, Arbeiter aus K. Aufnahme 1. VI. 1905, gestorben 6. VI. 1905.

Strangulationsileus durch Adhäsionen nach früheren Laparotomien.

1. VI. 1905. Pat. ist eine Zeit lang nach seiner Entlassung im vorigen Jahre mit Thiosinamininjektion und Bauchmassage behandelt worden. Dann hat er sich ganz wohl gefühlt und ist voll arbeitsfähig gewesen.

Vor 2-3 Tagen bemerkte Pat., daB ihm der Leib anschwoll. Gestern traten heftige Leibschmerzen auf, Erbrechen gelber, mit Speiseresten vermischter Flüssigkeit. Starker Schweiß wechselte mit Frostgefühl ab. Auch traten schmerzhafte Krämpfe in den Beinen und Händen auf. Deshalb 11 Uhr abends hier eingeliefert.

Status: Magerer, aber muskelstarker Mann, nur wenig krank aussehend. Zunge belegt, feucht, stöBt übelriechend auf, hat auf der Fahrt hierher reichlich erbrochen. Puls 120, kräftig, regelmäBig. Herz normale Grenzen, Töne leise, dumpf. Wadenkrämpfe. Abdomen kaum aufgetrieben. In der Mitte links vom Nabel, von der Mitte des Epigastr. bis zur Symphyse eine $6 \mathrm{~cm}$ breite Laparotomienarbe, ebenso breite Rektusdiastase. Unter der dunnen Bauchwand Darm in lebhafter Bewegung. Er ist, wie scheint, mit der Narbe nur wenig verwachsen, dieselbe läBt sich auch überall von der Unterlage abheben. Von Zeit zu Zeit tritt am rechten Rippenbogen medial von der Mittellinie eine zirkumskripte mit Schmerzen verbundene Darmsteifung auf, die ohne nachfolgendes Stenosengeräusch verschwindet. Magenspülung (ca. 10 Liter) entleert sehr reichliche, bereits fäkulent riechende Flüssigkeit. Klistier von 4 Litern bewirkt Abgang von sehr reichlichem dünnflüssigem Stuhl und Winden. Es bleiben aber die sich steifende Darmschlinge am rechten Rippenbogen und die paralytisch plätschernden Darmschlingen zwischen den Rekti bestehen. In der Hoffnung, daB sich nach dieser sehr reichlichen Darmentleerung nach oben und unten, die Darmpassage wieder herstellt, Pat. ins Bett. Morphium 0,01. Warmer Umschlag um den Leib.

2. VI. Pat. hat heute morgen fade, riechende, bräunlich-grünlich-gelbliche Flüssigkeit erbrochen. Kalter SchweiB, Puls 124 klein, weich.

Abdomen: Zwischen den Rekti die Darmschlingen in vermehrter Peristaltik. Schlinge am rechten Rippenbogen immer noch prall. Keine Winde. Magenspülung entleert reichlich fäkulente Flüssigkeit. Kochsalzinfusion, Kochsalzklistier.

Chloroform, dann Äther-Tropf-Narkose. Laparotomie (Dr. Göbell) im 
Epigastrium oberhalb der Narbe legt den Magen frei, von da aus kann ohne große Schwierigkeit entlang dem linken Rand der Narbe das übrige Abdomen eröffnet werden. Netzadhäsionen werden rasch beseitigt. Untere Hälfte des Dünndarms leer, die obere stark gefüllt. Für die Passage ein 3 faches Hindernis vorhanden: 1. 2 bindfadenförmige Stränge, die den Dünndarm umschnüren, aber ohne schwere Strangulation, dann Adhäsionen an der Flex. col. d., die eine völlige Knickung bewirkt haben. Nach Durchtrennung der Stränge und nach Lösung der Adhäsionen wird die Passage wieder frei. Darm punktiert, entleert. Punktionsöflnung durch zweifache Nahtreihe geschlossen. Nach der Ileocöcalgegend hin und oberhalb der Blase viele Adhäsionen, von denen einige gelöst werden. Reposition der Därme, 2 Liter Kochsalzlösung in die Bauchhöhle. Schlußs der Bauchhöhle durch Etagennaht. Kampfer. Ein Klysma.

3. VI. Winde sind abgegangen, Pat. sieht besser aus. Temperatur abends 38,2, Puls 108. Kochsalzinfusion mit Traubenzucker.

4. VT. Temperatur normal, Puls 80 . Winde gehen auf Glyzerinklystier ab. Leidliches Befinden. Etwas frequente Atmung.

5. VI. Puls 78, Temperatur 36,9. Gegen Mittag starker Meteorismus. Pat. kalt, mit SchweiB bedeckt, keine Winde. Deshalb Eröffnung des oberen Teils der Wunde und Punktion der hervorquellenden, stark geblähten Schlingen. Cöcostomie.

Zunehmende Atembeschwerden, blutig-schaumiges Sputum.

6. VI. früh $1 / 2$ Uhr Exitus.

Autopsie: Starke Verwachsungen der Darmschlingen untereinander mit stellenweiser starker Staunngshyperämie. Starker Meteorismus des ektatischen Dünndarms. Dünner Kot im Magen. Derbe pneum. Infiltrate im rechten 0.-L. und linken 0.-L. Ödem und Emphysem der übrigen Lungenlappen. Bronchitis. Tracheitis, etwas schlaffes, fettdurchwachsenes Herz. Ganz frische Entzündung am Aortensegel der Mitralis, Verwachsung und Hinabrückung zweier Aortenklappen. Chronischer Magenkatarrh. Fettdurchwachsung des Pankreas. Stellenweise Hyperämie des Darms. Geschrumpfte, etwas weiche Milz. Indurierte Leber. Indurierte blasse Nieren mit chronischer parenchymatöser Entzündung. Etwas derbe, große, blasse Nebennieren.

36. J.-N. 1806/1904. Frau M., 42 J., aus E. Aufgenommen 25. III. 1905, gestorben 26. III. 1905 .

Chronischer Ileus, durch schrumpfendes parametritisches Exsudat und perimetritische Adhäsionen.

Laparotomie, Lösung von Adhäsionen.

Darmresektion. Ileokolostomie Tamponade. Mykocarditis chron. Aneurysma verum cordis. Endocarditis valvulae mitralis. Nephritis chron. parenchymatosa.

Anamnese: Seit 6 Monaten in ärztlicher Behandlung wegen eines großen, linksseitigen, parametritischen Exsudats, das in der ersten Zeit von hohem Fieber begleitet war. Im Verlauf der Erkrankung mehrfach vorübergehende Anfälle von Erbrechen und Stuhlverhaltung. Vorübergehende Anfälle von Herzschwäche. Seit 4 Wochen wieder Erbrechen und schwere Verstopfung. Seit 3 Tagen Verschlimmerung. Kein Stuhl, keine Flatus. 
Alles Genossene erbrochen. Puls zunehmend beschleunigt und irregulär. Heute fäkulentes Erbrechen, endlich Operation eingewilligt.

Status: Grazil gebaute, dürftig genährte, blaß und krank aussehende Frau. Sensorium frei. Temperatur $38,2^{\circ}$. Puls extrem irregulär, im ganzen beschleunigt, schwach and weich. Herzdämpfung nicht vergrößert, bei der äuBerst unregelmäBigen Herzaktion nur ab und zu ein dumpfer Ton hörbar, in verschiedener Stärke und unrein, kein deutliches Geräusch.

Zunge wenig belegt. Lippen trocken. Leib stark aufgetrieben. Bauchdecken mäßig stark gespannt. Spannung und Druckempfindlichkeit überall gleichmäBig. Kein freier ErguB. $A b$ und zu peristaltische Bewegungen im unteren Teil des Bauchs. Per vaginam kleines Becken ganz von Exsudatmassen ausgefüllt. Uterus nach hinten verlagert und retroflektiert, völlig fixiert. Per rectum fühlt man den Uterus das Rektum verlegen und verschließen.

Magenspülung: gelbbraune, farle riechende Massen entleert. Einführung einer Schlundsonde ins Rektum gelingt nicht. Infusion Kampfer.

In der Nacht einmal Erbrechen, deutlich fäkulent.

26. III. 1905. Op.: Chloroform-Äther-Narkose. Dr. Göbell.

Medianschnitt zwischen Schwertfortsatz und Symphyse. Bei Eröffnung der Peritonealhöhle geblähte, gerötete hypertrophische Darmschlingen sichtbar. Ein Teil des Dünndarms ins kleine Beeken hinabgezogen und hier zu einem festen Konglomerat mit den Genitalien und Seitenwänden des Beckens verbacken. Hier mannigfache Abknickungen. Dünndarmschlingen gelöst, erst glatt, dann mit großer Mühe in der Gegend der linken Adnexe Abszeßhöhle eröffnet. Tief im kleinen Becken ist eine Dünndarmschlinge an der hinteren Wand adhärent, starke Knickung, Lösung. Darmlumen eröffnet, herausgelagert. Darm durch diese öffnung entleert.

Kochsalzspülung, Resektion des ganzen Dünndarmpakets. Side to side Anastomose der Enden. Während der Reselition Zustand verschlechtert. Bauchhöhle tamponiert. Situationsnähte.

Patientin erholt sich weder durch Kampfer noch durch intravenöse Infusion aus ihrem Kollaps.

Autopsie: Operativer Defekt eines großen Teils des Ileum oberhalb der Valvula Bauhini.

Eitrige linksseitige Salpingitis mit starken peri- und parametritischen Verwachsungen. Vereinzelte kleine Abszesse im Cav. vesico-uterinum.

Starke Stenose der Mitralis mit vollständigem Schwund der Sehnenfäden. Geringe Verdickung einer Aortenklappe, Aneurysma an der Herzspitze mit organisiertem Thrombus. Glottisödem. Zähe kleine Milz. Induration und zahlreiche Narben der Niere. Starke Trübung der Nieren mit beginnender fettiger Degeneration. Meningeal- und Hirnödem.

37. J.-N. 1355/1908. L. L., 66 J., Kätnersfrau aus Pr. Aufgenommen 10. XII. 1903, gestorben 20. XII. 1903.

Carcinoma linguae.

Ausräumung der Submaxillargrube. Exstirpation des Carcinoms.

Ileus durch Torsion einer adhärenten Ileumschlinge. Laparotomie: Lösung der Schlinge.

A namnese: Vor 11 Jahren in der hiesigen Frauenklinik wegen eines Gebärmuttergewächses operiert. 
Ein Beitrag zur Pathologie und Therapie des inneren Darmverschlusses, 501

Status: Kleines, mageres Mütterchen. Abdomen aufgetrieben, vermehrte Peristaltik. Med. Laparotomienarbe im Hypogastrium. Stuhl and Winde gehen. An der Zunge rechts hinten großes Carcinom.

Behandlung: Ausräumung der rechten Submaxillargrube. Unterbindung der $A$. lingualis.

12. XII. 1903. Fxstirpation des Carcinoms.

In den ersten Tagen nach der Operation: L. H. Bronchopneunomie mit hohem Fieber.

16. XII. 1903. Leibschmerzen. - Nach Ol. Ricini Stuhl und Winde.

18. XII. 1903. Normale Temperatur. Nach Klistier und Ol. Ricini 2 mal Stuhlgang.

19. XII. 1903. Wieder Rasseln, l. H. unten. - Abdomen etwas aufgetrieben. Stuhlgang und Winde auf Klistier.

20. XII. 1903. Keine Winde, auch nicht auf Klysma. Patientin verfallen. Im Rektum kein Hindernis. Kein ErguB. I. H. u. Rasseln. Puls kaum fühlbar.

Op. (Dr. Göbell): Unteres Ileum leer. Kuppe einer Schlinge des mittleren Ileum am Mesosigmoidum bereits fixiert, Schlingenschenkel durch Adhäsionen vereinigt. Oberes Ileum unter dieser adhärenten Schlinge durchgeschlüpft. Durch den starken Zug an der adhärenten Schlinge Darmpassage unmöglich. Keine Achsendrehung, keine Einklemmung. Lösung der Adhäsionen, Entleerung des Darms. Reposition. Etagennaht.

Abends 10 Uhr Exitus. Autopsie: Keine Peritonitis. Schlaffes Herz.

38. J.-N. 1636/1901. W. 0., 6 J. Ileus. Peritonis tub. Lösung der Adhäsionen. Aufgenommen 20. II. 1902, entlassen 21. III. 1902.

Anamnese: Eltern gesund. Im Frühjahr 1901 krank, seitdem eine Geschwulst (?) im 'Leibe. Seit einigen Tagen heftige, noch jetzt bestehende Leibschmerzen. Stuhlgang früher immer regelmäßig, seit gestern ausgeblieben. Klistiere ohne Wirkung. Keine Winde. Kein Erbrechen.

Status: Für sein Alter mittelgroßer, gut genährter Knabe. Lippen trocken, Zunge belegt.

20. II. abends Puls mä8ig kräftig, Temp. 35,5. Brustorgane ohne besondern Befund.

Abdomen aufgetrieben. Nabel verstrichen. Die Gegend um den Nabel herum und links von demselben am stärksten vorgewölbt. Die Därme in der Umgebung zeigen deutlich vermehrte peristaltische Bewegungen. Zeitweise hört man Gurren. Unterer Leberrand aufwärts verschoben. In der Umgebung des Nabels gedämpfte, tympanitische Zone; eine Dämpfung in der rechten Unterbauchgegend hellt sich bei linker Seitenlage auf.

Man fühlt von der rechten Sp. il. a. s. nach dem Nabel und über diesen hinaus nach links und oben sich erstreckend einen rundlichen, unregelmäBigen, prall elastischen, nicht fluktuierenden Tumor, der aus einzelnen Protuberanzen besteht und nach dem Magen hin in eine derbere Partie übergeht.

21. II. Stuhl- und Windverhaltung trotz Klistieren bestehen fort. Erbrechen von verkäster Milch und kotigen Massen. Temperatur $39,0^{\circ}$, Puls 120, klein.

Vormittags Chloroformnarkose: Mediane Laparotomie, (Geh. Rat Helferich). Durch ödematöses Bauchfell gelangt man auf einen mit dem Peritoneum 
parietale verklebten, sehr stark geblähten und mit dünnen Membranen bedeckten Dünndarmteil. Nach Erweiterung des Schnittes gelingt es, zwischen den verklebten, durch Spangen- und Membranbildung zum Teil verwachsenen Dünndarmschlingen zum Mesenterium vorzudringen. Letzteres zeigt an mehreren Stellen gelbe, verkäste Massen, welche ausgeschält werden. Nach weiterer Lösung von Dünudarmschlingen kommt man an einen mit zahlreichen Tuberkeln besetzten Darmteil. Das Netz bildet einen 2 fingerdicken, quer verlaufenden, gelblichen, anscheinend in Verkäsung begriffenen Strang. Dieser wird ausgelöst. Damit ist so viel Raum gewonnen, daß eine genaue Orientierung möglich ist. Es stellt sich nun heraus, daß der Dünndarm dicht oberhalb der Ileocöcalklappe durch eine Adhäsion geknickt ist. Unterhalb dieser Stelle ist er völlig leer, füllt sich aber nach Lösung der Verwachsungen von selbst. Reposition des Darms. SchluB der Bauchhöhle. Verband.

21. II. abends Temperatur $39,2^{\circ}$, Puls 160 . Es sind Winde abgegangen. Stuhl erfolgt auf Klysma.

22. II. Temperatur $37,8^{0}$, Puls 134. Kein Erbrechen. Stublgang.

23. II.-20. III. Heilung verläuft glatt.

21. III. Bauchwunde gut geheilt. Kein Erguß in der Bauchhöhle. Gewichtszunahme von $2 \mathrm{~kg}$. Darmfunktion gut. Entlassung.

39. J.-N. 41/1905. Otto N., 20 J., aus W. Aufn. 22. II. 1905, geheilt entl. 27. V. 1905.

Akuter Ileus durch tuberkulöse Dünndarmadhäsionen.

Laparotomie. Lösung der Adhäsionen. Darmübernähung. Tamponade. Akute Peritonitis, Enterostomie.

Anamnese: Am 10. II. ${ }^{1 / 2}$ Stunde nach dem Essen heftige Leibschmerzen, die bis zum 13. II. an Heftigkeit zunahmen. Kein Erbrechen. Stuhlverstopfung. Am 13. II. Rizinus. Appetit war vorhanden, aber Patient konnte nichts bei sich behalten. Das Erbrochene, Speisereste, Schleim, Rizinusöl. Bis zum 18. II. täglich Karlsbader Salz ohne Erfolg. Am 19. II. starke Leibschmerzen. Morphin bewirkt Nachlassen der Beschwerden. Am 20. II. ohne Schmerzen. Aber Erbrechen. Am 21. II. wieder starke Leibschmerzen, viel Aufstoßen. In die medizinische Klinik gebracht. Hier wird konstatiert: Starker Meteorismus. Umfang des Leibes $79 \mathrm{~cm}$. Deutlich peristaltisch geblähte Darmschlingen. Dauerndes AufstoBen. Durch Darmrohr und hoher Einlauf kleine Besserung. Sehr heftige Leibschmerzen. Atropin 0,003 bewirkt Erleichterung bis 5 Uhr morgens. 22. II. 7 Uhr Verlegen nach der chirurgischen Klinik.

22. II. Status: Hochgradiger Meteorismus. Geblähte Darmschlingen wölben sich unter den dünnen Bauchdecken vor. Kleiner frequenter Puls. Lebhaftes AufstoBen. Erbrechen gallig gefärbter Schleimmassen. In der Umgebung des Nabels stärkere Druckempfindlichkeit. Übrigens Abdomen nicht schmerzhaft. Magenspülung: Entleerung masziger Mengen übelriechenden gallig-schleimigen Inhalts.

Mediane Laparotomie: Geh. Rat Helferich. Stark geblăhte Dünndarmschlingen wölben sich vor. Gleichzeitig fließt ca. $3 / 4$ Liter trübseröser Flüssigkeit ab (steril), Serosa glatt und glänzend. Dünndarm geknickt durch feste Verwachsung mit dem entzündlich veränderten und geschrumpften Mesenterium. 
Ein Beitrag zur Pathologie und Therapie des inneren Darmverschlusses. 503

Zwischen Nabel und Symphyse Konvolut von Dünndarmschlingen zusammen gebacken. Beim Ablösen reißt der Darm ein. Kotentleerung in die Bauchhöhle, Kochsalzspülung. Vernähung der Öfnung, - Zweite ähnliche Verwachsung des Dünndarms mit dem Mesenterium ebenfalls gelöst. Einriß im Darm wird genăht. Kochsalzspülung. Tamponade (Jodoformgaze). Situtionsnähte. Kampfer. Subkutane Ernährung. Phys. Kochsalzlösung und $2 \frac{1}{2}$ Proz. Traubenzucker und 1 Proz. Kognak.

23. II. Hohes Fieber 39,8, Puls 140, klein. Quälendes Aufstoßen, hochgradiger Meteorismus, sichtlicher Verfall.

Abends Temperatur 41,2, Puls 140, sehr klein. Kalte Extremitäten. Viel Aufstoßen, hochgradiger Meteorismus. Starke Atemnot.

Magenspülung: reichliche, übelriechende, gallig gefärbte Flüssigkeit. Duodenalinbalt. 1/2 Stunde später Punktion der obersten sich in der Wunde einstellenden Darmschlinge mit feiner Kanüle, da sich dieselbe verstopft, stärkere Kanüle. Es entleeren sich Gase und flüssiger Darminhalt. Gummidrain $10 \mathrm{~cm}$ tief in den Darm eingeführt. In kurzen Zwischenräumen entleert sich Gas und Darminhalt.

24. II. Temperatur wesentlich gesunken. Peritonitische Erscheinungen erheblich geringer. Nur noch reichliches Aufstoßen. Übler Geschmack in Nunde. Nochmalige Magenspülung: Dabei werden wieder übelriechende Massen aus dem Magen entleert. Aus dem Darmschlauch hat sich reichlich galliges Sekret entleert. Meteorismus bedeutend geringer. Kampfer. AusschlieBlich subkutane Ernährung.

27. II. Allgemeiner Zustand wesentlich günstiger, Puls kräftiger. Nur noch selten AufstoBen. Noch keine Blähungen. Reichliche Gasentleerung aus dem Schlauch, auch Abfub von Darminhalt (ca. $200 \mathrm{ccm}$ ). Ausschließlich subkutane Ernährung.

28. II. Geringe Entleerung dünnbreiigen Stuhls aus dem After.

1. III. Erster Verbandwechsel. Mäßig eitrige Sekretion.

2. III. Entfernung des Darmschlauchs. Übernähung der Darmfistel mit feiner Seide.

5. III. Beginn mit flüssiger Ernährung per os.

10. III. Gutes Allgemeinbefinden. Darmnaht hält. Abgang von Winden per anum.

18. III. Gute Wundverhältnisse. Lebhafte Granulationsbildung.

2 IV. Wundhöhle vollkommen flach. Breite, lebhaft granulierende Wundfäche. Allgemeines Befinden sehr gut. Verdauung normal.

19. IV. Langsame Überhäutung vom Rande.

27. V. Bis auf 3 kleine flache Defekte Wunde überhäutet. Wunde derb, doch nicht starr. Entlassen.

40. J.-N. 1444/1904. J. Kr., 47 J., Schmiedemeister aus 0. Aufgenommen am 11. I. 1905, entlassen am 12. III. 1905.

lleus. Knickung der Flex. sigmoid. durch Adhäsionen. Peritonitis tub. ilei. Kolostomie. Lösung der Adhäsionen. Peritonealplastik.

Anamnese: Seit langer Zeit magenleidend. Stets vorsichtig beim Essen. Viel saures AufstoBen, auch gelegentlich Erbrechen. Schon sehr lange leidet Patient an Stuhlverstopfung.

7. I. 1905. morgens 6 Uhr kolikartige Schmerzen im Leib und Er- 
brechen. Klistier bewirkte um 9 Uhr Diarrhoe. Winde gingen ab. Am 8. I. 1905 abends und 9. I. 1905 morgens Klistier. Blut, aber keine Winde. Bis heute keine Winde, kein Erbrechen, vom Arzt hierher geschickt.

Status: Mittelgroßer, kräftig gebauter, leidlich genährter Mann mit blasser Haut, blaBrosa Schleimhäuten, etwas trockner belegter Zunge.

Brustorgane: Lungen ohne Befund. Herz an der Pulmonalis Diastolisches Geräusch, sonst nihil. Puls 96, mittelkräftig, regelmäßig.

Abdomen: Leicht anfgetrieben, Schall tympanitisch. ÄuBerlich die Konturen des geblähten Colon zu erkennen, keine vermehrte Peristaltik sichtbar. Leber, unterer Rand schneidet den rechten Rippenbogen in der Parasternallinie. Keine Hernie. Perkussion und Druck im linken Hypogastrium schmerzhaft. - Rektum enthält dünnflüssigen blutigjauchigen Inhalt, ist aber weit hinauf leer. Kein Tumor per rectum zu fühlen, nur bei bimanueller Palpation links am Eingang ins kleine Becken eine druckempfindliche Resistenz zu fühlen.

Behandlung: 12. I. Spülungen des Mastdarms. 13. I. Mediane Probelaparotomie (Geh. Rat Helferich) in Sauerstoff-Chloroform-Narkose: Flexura sigmoidea kurz, entzündlich verdickte Wand. Kein Tumor zu fühlen. An einer Stelle Netzadhäsion leicht zu lösen. Auch am Übergang zum Rektum keine Geschwulst. Mesosigmoideum kurz ohne besondere Veränderungen. Man hat den Eindruck einer zirkumskripten Entzündung der Flexur, ohne eine Ursache entdecken zu können. Zunächst SchluB der Bauchhöhle durch Etagennähte.

Am 14. I. 1905. Mehrmals Erbrechen, abends blutiger Stuhlgang und Winde.

17. I. 1905. Wohlbefinden. Stuhlgang seit 2 Tagen normal gefärbt. Winde sind täglich reichlich abgegangen. Heute keine Winde. 1 mal Erbrochen.

18. I. 1905. Auf Klysma Winde und dünner Stuhl!

23. I. 1905. Diarrhoe hat trotz Tannigen bis heute angehalten.

26. I. 1905. Heute wieder keine Stuhlentleerung. Proktoskopie: $15 \mathrm{~cm}$ hoch einige kleine Ulcera und anscheinend ein Hindernis.

27. I. 1905. Äther-Rausch. (Op. Dr. Göbell): Links Schrägschnitt. Flexur freigelegt, wieder in entzlundlichem Zustand. Anheften der Flexur, um sie später öffnen zu können.

3. II. 1905, Durch Kalomel wird reichlicher Stuhl erzielt.

11. II. 1905. Proktoskopie läßt Stenose im unteren Teil der Flexura sigmoidea als gewiB erscheinen. Deshalb wird die Flexur von der s. $Z$. angelegten Wunde aus eröffnet.

16. II. 1905. Man gelangt von der Fistel aus mit der Schlundsonde an ein Hindernis. Wasser fließt aber gut durch. Dabei wird sehr bröckliger harter Stuhl (kleine, schmale Bröckel) entleert.

20. II. 1905. Nach dem durch OI. Ricini Darm möglichst entleert und Flexur und Rektam gut durchgespült sind: III. Op. in Äther-Tropf-Narkose. Mediane Lapararotomie (Dr. Göbell) in Beckenhochlagerung und nach sorgfältigem Schutz vor Beschmutzung. Starke Adhäsionen des Dunnndarms an der Peritonealnaht. Lösung der Adhäsionen. Unteres Ileum mit vielen weißen Plaques versehen, untereinander durch alte Adhäsionen verwachsen mit zahlreichen kleinen Knötchen (Tuberkulose!). Unterstes Ileum breit mit 
Ein Beitrag zur Pathologie und Therapie des inneren Darmverschlusses. 505

dem untersten Ende der Flexura sigm. verwachsen, so daß letztere stark geknickt erscheint. Lösung der Verwachsungen. Es gelingt jedem Darmabschnitt ein neues Mesenterium resp. Mesosigmoideum zu machen. Unterstes Ende des Ileum ist durch flügelartige Falte am kleinen Beckenrand fixiert. Quere Durchtrennung der Falte, Längsnaht. Lösung der Adhäsionen am Dünndarm soweit angängig und notwendig, und Naht der Serosa an diesen Stellen. Schluß der Bauchhöhle durch Etagennähte. Xeroformpaste. Die Darmfistel wird durch Mullpelotte zugehalten. Verband.

21. II. Patient erbricht noch, Temperatur 37,6, Puls 100 . Infusionen, Kampfer.

22. 2. Erbrechen sistiert heute, aber noch keine Winde.

23. II. Nach Spülung des unteren Darmendes und Glyzerineinlauf. in das Col. descendens von der Darmfistel aus: Stuhl. Abends Winde und Stuhl nach Glyzerineinlauf. Tee per os, aber Temperatur 39,2, beiderseits Bronchopneumonie.

Puls 120.

24. II. Flüssige Kost. Schleimigeitriger Auswurf. Abends 39,8,

25. II. Stuhlgang nach Glyzerineinlauf. Temperatur fällt ab. Keine Kochsalzinfusion mehr.

26. II. Normale Temperatur.

2. III. Leib weich. Laparotomiewunde bis auf den oben offen gelassenen Wundwinkel glatt geheilt. Dünndarm und Dickdarm bis zur Fistel funktionieren gut. Dagegen läßt sich eine Entleerung nach abwärts bei verschlossener Darmfistel noch nicht erzielen.

5. III. Stuhlgang auf natürlichem Wege per anum.

11. III. Patient hat nach Glyzerinklistier täglich Stuhlgang auf natürlichem Wege gehabt. Seine Flexurafistel hat sich geschlossen, nur noch ein granulierender Knopf in der Wunde.

Mediale Laparotomiewunde geheilt.

Subjektives allgemeines Befinden gut. Patient steht mit Leibbinde auf.

Anfang September 1905. Patient hat 38 Pfund zugenommen, befindet sich sehr wohl. Stuhlgang ist regelmäBig. Schmiedet wieder. (Peroneuslähmung.)

41. J.-N. 1774/1905. N. M., 58 J., Wwe. aus K. Aufgenommen am 17. II. 1906. Dickdarmverschlu 8 durch Knickung der Flexura sigmoidea durch Adhäsionen nach früherer Myomoperation.

Lösung der Adbäsionen. Appendikostomie.

Anamnese: Vor 5 Jahren Exstirpation eines intraligament. Myoms. Zeitweise erschwerter Stuhlgang. Am 13. II. 190610 Uhr vorm. plötzlich heftige Schmerzen im Unterleib. Initiales Erbrechen. Kein Stuhlgang, keine Winde. Klysmata ohne Erfolg. Aufstoßen. Tourenweise heftige Schmerzen. Vom Arzt verabreichte hohe Klistiere ebenfalls ohne Erfolg.

Status: Mediane Laparotomienarbe im Hypogastrium.

Puls 90 , mittelkräftig regelmäßig. Abdomen aufgetrieben, mit deutlicher durch Auftreibung des Colons bedingter seitlicher Ausladung. Peristaltik sichtbar, keine Darmsteifung. Nirgends resistente unbewegliche Schlinge fühlbar, auch nicht per rectum oder vagina. Kein Rektumcarcinom. Stark ausgesprochener Ileocöcaler Meteorismus. Schallwechsel bei Seiten- 
lage täuscht freien Erguß vor. Keine Fluktuation. Uterus klein, links fixiert. Klysma von $300 \mathrm{ccm}$ sofort wieder entleert.

Diagnose: Tiefsitzender Dickdarmverschluß, wahrscheinlich im Zusammenhang mit der früheren Operation.

Behandlung: Med. Laparotomie (Dr. Göbell). Netz breit adhärent. Kuppe der Flexur durch strangartige Adhäsion mit dem linken Tubenwinkel verwachsen. Breite Adhäsion zwischen Rektum und Flexur. Rektum und unterer Teil der Flexur leer. Flexur an der Stelle der Uterusadhäsion geknickt. Durchtrennung der Adhäsionen. Flexur und

Umschnürung des Darms

\begin{tabular}{|c|c|c|c|c|c|c|}
\hline $\mathrm{Nr}$. & Name & 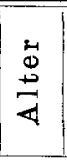 & 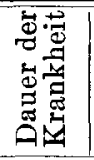 & Diagnose & Befund & $\begin{array}{l}\text { Operations } \\
\text { verfahren }\end{array}$ \\
\hline 42 & R. M. & $\begin{array}{c}6 \mathrm{~J} . \\
\text { w. }\end{array}$ & $\begin{array}{c}10 \\
\text { Tage }\end{array}$ & $\begin{array}{l}\text { Dünndarmver- } \\
\text { schluß. }\end{array}$ & $\begin{array}{l}\text { Peritonitis tub. } \\
\text { Zahlr. Adhä- } \\
\text { sionen. Um- } \\
\text { schnürung des } \\
\text { Dünndarms. }\end{array}$ & $\begin{array}{l}\text { Lösung der Ad- } \\
\text { häsionen und } \\
\text { Umschnürungen. }\end{array}$ \\
\hline 43 & $\begin{array}{l}\text { J. H. } \\
1136 / 1900\end{array}$ & $\begin{array}{c}10 \mathrm{~J} \\
\mathrm{w} .\end{array}$ & 6 Tage & $\begin{array}{l}\text { Dünndarmver- } \\
\text { schluß. (Obtu- } \\
\text { ration.) }\end{array}$ & $\begin{array}{l}\text { Proc. vermifor- } \\
\text { mis umschnürt } \\
\text { das Ileum. } \\
\text { Gangränöser } \\
\text { Schnürring. } \\
\text { Umschriebene } \\
\text { Peritonitis. }\end{array}$ & $\begin{array}{l}\text { Exstirpatio ap- } \\
\text { pendicis. } \\
\text { Darmresektion. } \\
\text { Ileokolostomie. }\end{array}$ \\
\hline 44 & K. Joh. & $\begin{array}{c}21 \mathrm{~J} \\
\mathrm{~m} .\end{array}$ & 36 Std. & $\begin{array}{l}\text { Dünndarmver- } \\
\text { schluß. }\end{array}$ & \begin{tabular}{|l|}
4 ringförmige \\
Verengerungen \\
des lleum durch \\
Mesenteriitis. \\
Adhäsionen in \\
der Ileocöcal- \\
gegend. Chron. \\
Appendizitis.
\end{tabular} & $\begin{array}{l}\text { Exstirpatio ap- } \\
\text { pendicis. } \\
\text { 4fache Entero- } \\
\text { plastik. Ileo- } \\
\text { kolostomie. }\end{array}$ \\
\hline 45 & $\begin{array}{l}\text { B. D. } \\
1112 / 1902\end{array}$ & $\begin{array}{c}25 \mathrm{~J} . \\
\mathrm{w} .\end{array}$ & 8 Tage & $\begin{array}{l}\text { Dünndarmver- } \\
\text { schluß. }\end{array}$ & $\begin{array}{l}\text { Viele Adhäsio- } \\
\text { nen. Ringför- } \\
\text { mige Stenose. } \\
30-40 \mathrm{~cm} \text { ober- } \\
\text { halb der Val- } \\
\text { vula ileocoeca- } \\
\text { lis. }\end{array}$ & $\begin{array}{l}\text { Lösung der Ad- } \\
\text { häsionen. } \\
\text { Darmplastik. }\end{array}$ \\
\hline 46 & $\begin{array}{l}\text { M. E. } \\
1664 / 1903\end{array}$ & $\begin{array}{c}11 \mathrm{~J} . \\
\mathrm{w} .\end{array}$ & 2 Tage & $\begin{array}{l}\text { Dünndarmver- } \\
\text { schluß bei Peri- } \\
\text { tonitis tub. }\end{array}$ & \begin{tabular}{|} 
Knickung des \\
Ileum nachPer- \\
foration der \\
Appendix in \\
dasselbe. Ste- \\
nose des unter- \\
sten Ileum.
\end{tabular} & $\begin{array}{l}\text { Resektion der } \\
\text { Ileocöcalpor- } \\
\text { tion. Ileokolo- } \\
\text { stomie. }\end{array}$ \\
\hline
\end{tabular}


Ein Beitrag zur Pathologie und Therapie des inneren Darmverschlusses. 507

Col. descendens per anum entleert. Ileum, Cöcum und Col. ascendens stark gefüllt. Appendikostomie. Dünndarm und Colon durch das Drain im Appendix entleert, während der Dünndarm mühevoll reponiert und die Laparotomiewunde geschlossen wird.

Im Verlauf zeigt sich die Appendikostomie sehr nützlich zur Einfuhr von Nährklistieren und entleerenden Klistieren, besonders am 5. Tage nach der Operation, an welchem sich zeigt, daß ohne Fieber eine Fascienekrose der medianen Wunde aufgetreten. Letztere eröffnet. Heilung per granulationem.

äußere und innere narbige Stemose.

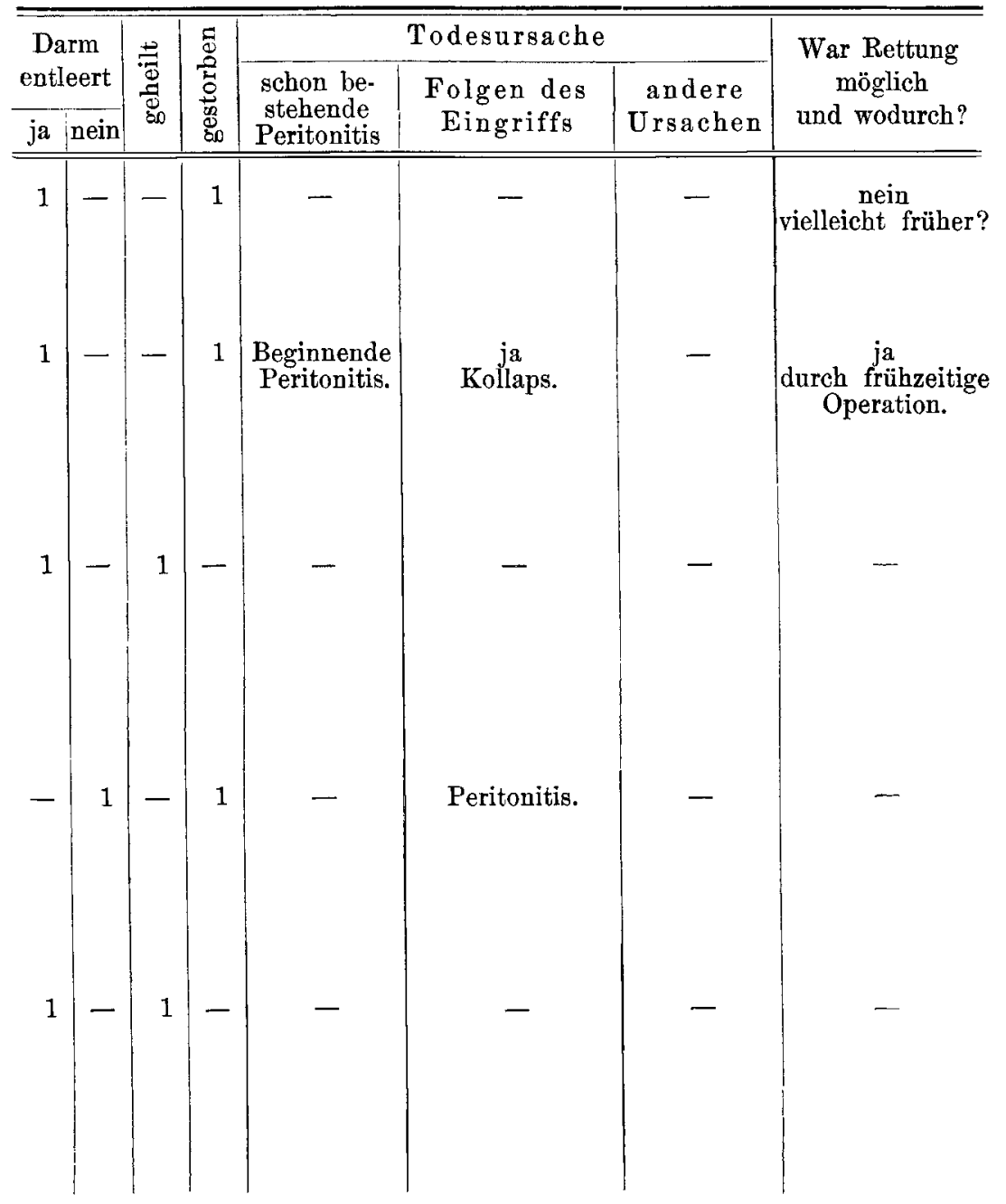


42. J.-N. 386/1904. M. R., 6 J., aus E. Aufn. 28. V. 1904, gestorben 28. V. 1904. Peritonitis tub. Ileus.

Anamnese: Seit dem 18. d. M. mit Erbrechen und Schmerzen im ganzen Leibe erkrankt. August 1903 ähnlichen Anfall. Seitdem stark abgemagert.

Status: Schwächlich gebautes, sehr mageres Kind. Haut trocken. Temperatur 38,2. Puls 154, klein, weich.

Bauch stark aufgetrieben, in den abhängigen Partien Schall abgeschwächt. Bauch überall druckempfindlich. Keine Resistenz fühlbar.

In der Unterbauchgegend zeitweise starke peristaltische Bewegungen. Bruchpforten frei. Rektaluntersuchung ohne Befund.

Sofortige Operation (Geh. Rat Helferich): Mediane Laparotomie. Peritoneum parietale durch alte Adhäsionen vielfach mit dem Dünndarm verwachsen, ebenso die Darmschlingen untereinander. Zahlreiche Tuberkel. Bei Lösung und Abbinden findet man die Ursache für den DarmverschluB: derbe, den Dünndarm abschnürende Stränge. Mesenterium verkürzt, mit verkästen Mesenterialdrüsen. Lösung der Stränge. Punktion einer stark geblähten Dünndarmschlinge, Entleerung reichlicher Menge dünnflüssigen Stuhls. Naht. Reposition, durchgreifende Knopfnähte, Verband.

Exitus. 7 Stunden post operationem.

Autopsie: Sehr starke allgemeine tuberkulöse Peritonitis mit frischen konfluierenden Tuberkeln und starke peritonitische Verwachsungen. Verkäste Tuberkulose des Uterusfundus und der Tuben. Ausgedehnte Tuberkulose des Dünndarms mit Tuberkeln, kleinere und größere Geschwüre. Vereinzelte tuberkulöse Geschwüre im .Cöcum und Colon ascendens. Zahlreiche tuberkulöse Geschwüre der $5 \mathrm{~cm}$ langen Appendix.

43. J.-N. 1136/1900. H. I., 10jährig. Mädchen. Aufgen. 15. XI. 1900, gestorben 17. XI. 1900. Darmverschluß. Umschnürung des untersten Ileum durch die Appendix. Exstirpatio appendicis.

Anamnese: Am 9. XI. nach sehr reichlichem GenuB von Schlehen Leibschmerzen und Erbrechen. Kein Stahlgang. Klistiere und Abführmittel ohne Wirkung. Dabei sollen bis heute stets Winde abgegangen sein. Anfangs tüchtiges Erbrechen. An den übrigen Tagen nur wenige Mal erbrochen, einmal Spulwürmer im Erbrochenen. Kein fäkulentes Erbrechen.

15. XI. Status: Großes, schlankes Mädchen mit frischen roten Wangen, blaßrosa Schleimhäuten, belegter feuchter Zunge. Temperatur 36,7, Puls 110, regelmäßig, kräftig. Abdomen aufgetrieben, Haut normal, nirgends besondere Druckempfindlichkeit. Klagen über Schmerzen im Leib. Man sieht deutliche Peristaltik einiger geblähter Dünndarmschlingen. Im oberen Teil und in der rechten Seite tympanitischer Schall, unterhalb des Nabels in der Ileocöcalgegend, in der linken Seite gedämpfter Schall. Ileocöcalgegend nicht druckempfindlich. Man fühlt stark gefüllte Darmschlingen. Rektum weit, soweit der Finger reicht, kein Hindernis. Urin kein Eiweiß, kein Zucker.

Behandlung: Auf großes Klysma in Knieellenbogenlage Abgang von Winden, aber kein Stuhlgang.

16. XI. Auf Klysma kein Stuhlgang. Leib weich, nirgends druckempfindlich. Nach dem Palpieren Kontraktion der Darmschlingen, welche 
Ein Beitrag zur Pathologie und Therapie des inneren Darmverschlusses. 509

sehr schön durch die Bauchdecken sichtbar sind. Bis 10 Uhr abends kein Stublgang, auch keine Winde. $10 \mathrm{Uhr}$ abends subkutane Injektion von $0,0001 \mathrm{~g}$ Atropin. $11 \mathrm{Uhr}$ abends kleiner Puls, der sich gegen 11/1/2 Uhr bessert.

17. XI. morgens Patient kollabiert. Temperatur 35,0, Puls 152, klein, nach Kampfer etwas besser. Pupillen weit, Abdomen stärker aufgetrieben. Dicht unter dem Nabel bei tiefem Druck empfindlich, sonst nirgends.

Koterbrechen. Keine Winde. Kein Stuhlgang.

11 Uhr vormittags Chloroform-Äthernarkose: Mediane Laparotomie (Geh. Rat Helferich) eröffnet in großer Ausdehnung die Bauchhöhle. In die Wunde drängen sich sofort stark geblähte, etwas hyperämische Dünndarmschlingen mit spiegelndem Peritoneum. Eventeration. Dickdarm leer. Dünndarmschlingen bis an die Valvula ileocoecalis stark gefüllt, im untersten lleumteil Schlingen sehr stark hyperämisch, leicht verklebt, an einzelnen Stellen mit Fibrin bedeckt. Bei Lösung der Verklebungen zeigt sich eine Stelle (ein kleiner querer Spalt) perforiert. Der Proc. vermiformis ist mit der Spitze an der Dünndarmschlinge verwachsen, über welcher er nahe der Ileocöcalklappe reitet. An dieser Stelle findet sich ein gangränöser Schnürring. Eröffinung des Dünndarms an mehreren Stellen. Entleerung des Dünndarminhaltes. Schluß der Öffnungen durch Darmnaht. Exstirpatio appendicis.

Abklemmung des Ileum $30 \mathrm{~cm}$ oberhalb mit großer Quetschzange, Seidenligatur und Tabaksbeutelnaht. Abquetschen des Dünndarms dicht am Cöcum. Seidenligatur und Tabaksbeutelnabt. Seitliche Enteroanastomose zwischen Iünndarm und Cöcum. Reposition des Darms. Zwirnknopfnähte. Verband. (Dauer $1 \frac{1}{4}$ Stunde.)

Nach der Operation Rotweinklistiere. Kampferinjektionen.

3 Uhr nachm. Pat. ist bei Bewußtsein. Puls etwas besser.

4 Uhr nachmittags Patientin sehr unruhig. Temperatur 39,0.

$5 \frac{1}{2}$ plötzlich Kollaps. Exitus.

Autopsie: Ausgebreitete Peritonitis. Sehr starke Erweiterung und umschriebene Hyperämie und Hämorrhagie des Dünndarms. Sehr schlaffes trübes Herz, ebenso Niere und Leber.

44. J.-N. 21/1904. J. K., 21 J., aus K. Aufn. 15. II. 1904, entlassen 25. III. 1904. Darmverschluß durch Mesenteriitis. Enteroplastik. Ileocolostomie.

Anamnese: Im Jahre 1903 im Altonaer Krankenhause wegen Gelenkrheumatismus behandelt. Wegen eines Rezidivs am 1. II. 1904 in das städtische Krankenhaus zu Kiel. 14. II. nachts plötzlich heftige Schmerzen im Unterleib, die allmählich immer stärker und krampfartig wurden. Gleichzeitig Erbrechen übelriechender Flüssigkeit. Patient verfiel sehr. Der Puls wurde frequent und klein.

Das Abdomen war meteoristisch aufgetrieben und diffus druckempfindlich, namentlich in der Cöcalgegend und um den Nabel herum. Das Erbrechen fäkulenter Massen dauerte fort. $\mathrm{Da}$ am folgenden Tag der $\mathrm{Zu}-$ stand unverändert war, gab Patient zu der Operation, die er vorher verweigert hatte, seine Einwilligung, weshalb er darauf sofort per Ambulanzwagen in die chirurgische Klinik geschafft wurde. 
Status: Mittelgroßer, schwächlicher und verfallen aussehender junger Mann. Extremitäten kühl. Puls fast nicht fühlbar, sehr frequent, Temperatursteigerung nicht vorhanden. Brustorgane ohne besondern Befund. Abdomen aufgetrieben, dur'ch die Bauchdecken hindurch sind peristaltische Bewegungen geblähter Darmschlingen sichtbar. Der Leib ist selbst bei leisester Palpation, besonders in der Ileocöcalregion schmerzempfindlich. In der Nabelgegend findet sich tympanitischer Perkussionsschall, während an den seitlichen Partien Dämpfung besteht. Fortwährend AufstoBen und Erbrechen gelblicher, flüssiger, übelriechender Massen.

Behandlung: Magenspülung. Chloroform-Sauerstoffnarkose: Mediane Laparotomie. (Geh. Rat Helferich). Geblähte Dünndarmschlingen treten hervor. Kein freier ErguB, keine Auflagerungen. Im unteren Teil des Ileum anscheinen durch Entzündungsprozesse im Mesenterium entstandene und auf die Darmserosa fortgeschrittene ringförmige Verwachsungen und Verengerungen. Im zugehörigen Mesenterium bis erbsengroße, harte Drüsen. Daneben finden sich Adhäsionen, besonders stark in der Ileocöcalgegend. Es gelingt, die nach unten-hinten liegende Appendix frei zu präparieren. In der Umgebung ihrer Spitze liegt nekrotisches Gewebe, an ihrer Basis hat sie eine kastaniengroBe, mit formbarem, härterem Inhalt gefüllte Aussackung. Unterhalb dieser wird nach Zurückpräparieren der Serosa die Ligatur angelegt und die Appendix abgetragen. Der Stumpf wird mit Serosa übernäht.

An der untersten Stenose des Ileum werden die Adbäsionen lospräpariert. Dabei wird der Darm eröffnet. Durch das so entstandene Loch wird der Darm entleert. VerschluB der Öffnung durch dreifache Naht. Ausspülung der Bauchhöhle mit steriler Kochsalzlösung. Die 3 weiter oben gelegenen engen Stellen werden durch $4-5 \mathrm{~cm}$ langen Längsschnitt und quere Naht erweitert.

Da der unterste Ileumteil durch Adhäsionen und die Naht des zur Darnentleerung benutzten Loches mehrfach geknickt und eng ist, und die Passage sich nicht recht herstellen will, wird an dem zwischen 3 . und 4 . Stenose gelegenen Ileumstück eine Anastomose mit dem Colon transversum angelegt (3fache Naht). Das abfuhrende Ileum wird durch quere Seidennähte verengert.

Spülung der Bauchhöhle mit steriler Kochsalzlösung. Reposition der Därme. Tamponade. Situationsnähte. Dauer der Operation $2 \frac{1}{2}$ Stunden.

Kochsalzinfusion $1000+20 \mathrm{ccm}$ Alkohol. Kampfer 0,1, halbstündlich subkutan.

15. II. 1904 abends. Patient hat die Operation leidlich gut überstanden. Puls 120, klein, frequent. Viel AufstoBen, Brechreiz. Extremitäten kühl.

16. II. Patient stöBt noch auf. O-Diät. Kochsalzinfusionen. Ernährungsklistiere.

17. II. Allgemeinbefinden gut. Puls kräftiger, regelmäBig.

19. II. Tamponade entfernt. Spülung mit steriler Kochsalzlösung. Tamponade erneuert.

Puls hat sich gebessert. Immer noch 0-Diät. Kochsalzinfusionen and Ernährungsklysmen. 
21. II. Flüssige Kost per os.

23. II. Patient verträgt die flüssige Kost sehr gut.

Wunde sieht gut aus, granuliert gut.

Auf Klysma Stuhlgang.

5. III. 1904. Chlorolormnarkose: Bauchwandplastik. Umschneiden der Wunde und Exstirpation der Granulationen. Präparation der vorderen Rektusscheide, des Muskels selbst und der hinteren Scheide. Etagennaht: Einige dünne Drains zwischen die Wundränder. Verband.

25. III. Glatter Verlauf. Entfernung der Nähte.

Patient kann sämtliche Speisen gut vertragen. Geheilt entlassen.

Appendix im basalen Teil bedeutend erweitert und divertikelartig ausgebuchtet. Schleimhaut atrophisch. Am Übergang der Appendix in das Cöcum nekrotische Partien. Im Innern ein etwa kastaniengrober aus formbarer Masse bestehender Kotstein.

40. J.-N. 1112/1902. D. B., 25 J., Schneidersfrau aus K. Aufn. 15. X. 1902, gestorben 18. X. 1902. Chronischer Ileus durch peritonitische Adhäsionen und narbige Darmstenose. Laparotomie. Lösung der Verwachsungen. Plastik an der Stenose.

Anamnese: Leidet an Stuhlverstopfung, solange sie denken kann. Seit voriger Woche Erbrechen, und zwar beinahe täglich, manchmal öfters am Tage. In der Nacht vom 11. zum 12. und rom 14. zum 15. sah das Erbrochene bräunlich-grünlich aus und war mehr übelriechend, (Koterbrechen heute Nacht.) Vor 7 Wochen normale Geburt. Hat das gesunde Kind selbst genährt. Im Alter von 7-8 Jahren magenkrank. Zweimal eine Krankheit mit starken Leibschmerzen und Verstopfung. Zuzeiten hatte sie Schmerzen erst unter dem rechten, dann unter dem linken Rippenbogen. Sie fühlt dann ein Gurren, worauf die Schmerzen nachlassen.

Status: Kleine, grazile, mäBig genährte Frau. Zunge feucht belegt. Mammae puerperales in Rückbildung. Kein Aufstoßen. Über der rechten Lunge etwas Giemen. Herz ohne Befund. Puls 116, etwas beschleunigt, mittelkräftig, weich, regulär. Abdomen: etwas aufgetrieben, wenig Steine, noch starke Pigmentierung des Nabels. In der rechten Seite bis zur verlängerten Mammillarlinie gedämpfter Schall. Dämpfung auch in linker Seitenlage, nur bei harter Perkussion tympanitischer Schall. Leber in Kantenstellung. In der Höhe des Nabels links eine druckempfindliche Stelle, von welcher man aus einen etwas resistenteren Darm nach rechts hinüber verfolgen kann. Rechtes Hypogastrium tympanitisch gedämpft, über dem linken Tympanie.

Uterus normal zurückgebildet, nach hinten gelagert und abwärts gedrängt.

In der Nacht vom 15. zum 16. X. Koterbrechen.

16. X. Operation: Geh. Rat Helferich. Sauerstoff-Chloroformnarkose: Medianer Laparotomieschnitt eröffnet die Bauchhöhle. In die Wunde drängen sich geblähte Darmschlingen. Zur besseren Orientierung Schnitt bis ins Epigastrium nach abwärts zur Symphyse verlängert. Jejunum durch Adhäsionen mit dem Peritonum parietale und Mesenterium verwachsen. Einzelne Adhäsionen sind strangförmig und hindern die Passage, aber nicht so stark, daB es zur Abknickung kommt. Ileum stärkere Ver-

Deatsche Zeitschrift f. Chirargie. LXXXII. Bd. 
wachsungen. An einer Stelle Darm tuberkuloseverdächtig. Das stärkste Hindernis für die Darmpassage liegt $30-40 \mathrm{~cm}$ über der Valv. Bauhini, bildet eine ringförmige Stenose. Der Zeigefinger geht zwar noch hindurch, aber der zuführende Darm wird so über die enge Stelle gestülpt (eine Art aufsteigende Invagination), daB die Passage aufgehoben wird. Um diese Klappenbildung zu vermeiden, wird das zuführende Stück so verengert, daB der Übergang von der weiten Partie zur engen allmählich erfolgt. Darminhalt entleert sich gut in dem abwärts gelegenen Teil. Darm reponiert. Bauchwand durch Etagennähte geschlossen.

16. X. nachmittags noch einmal Kot erbrochen.

0,0005 g Physostygmin subkutan.

Abends 37,5, Puls 120. Nachts erfolgt Stuhl.

17. X. morgens 37,4, Puls 118. 0,0005 Physostigmin. Kamillenklistiere. Patientin hat $2 \mathrm{mal}$ Stuhl, nimmt Nahrung, erhält im Lauf des Tages 2 mal 0,0005 Physostigmin.

Abends Temperatur 38,5, Puls 116. Große Unruhe.

Nach $5 \mathrm{ccm}$ Paraldehyd. schläft Patientin nachts ruhig, dabei Pupillen eng, bei erhaltenem Kornealreflex.

18. X. morgens 36,3, Puls 104. Patientin ist nicht klar. Pupillen sind weit, reagieren. Kochsalzinfusion 1 Liter. Ernährungsklistier. Glyzerin und Physostigmin 0,0005, Stuhl.

$11 \frac{1}{2}$ Uhr vormittags Puls stark cyanotisch. Exitus letalis.

Autopsie: MäBige Menge blutig-seröser Flüssigkeit in der Bauchhöhle. Sehr zahlreiche, meist gelöste Verwachsungen des Dünndarms. Umschriebene hämorrhagische Herde der linken Unterleibes. Zahlreiche Kollapsherde und Ödem der Lungen. Starke Bronchitis. Ecchymosen des Herzbeutels. Thrombose einzelner Pulmonalarterienäste des linken Unterlappens. Geringe fettige Fleckung der sehr engen und dünnwandigen Aorta. Starke Trübung von Herz und Nieren. Eigentümliche, teils scharfrandig, teils scharfzackig begrenzte gelbe Herde der Leber. Leichte Induration der Milz. Ecchymosierung der Uterusschleimhaut. Frische fibrinöse Verklebung der Eingeweide untereinander und mit der Bauchwunde.

Epikrise: Tod durch Atemlähmung, Muskelunruhe, enge Pupillen lieBen den Gedanken an Physostigminvergiftung aufkommen.

Es fehlten an charakteristischen Symptomen: Steigerung des Blutdrucks, Pulsverlangsamung. Vermehrte Schleim- und Speichelsekretion.

Indessen $m u B$ eine toxische Wirkung des Physostigmin als wahrscheinlich angenommen werden, die den Exitus hat herbeiführen helfen.

\section{Carcinomatöse Striktur.}

47. J.-N. 166/1902. CI. Sch., 53 Jahre, Schiffer aus L. 8. IV. bis 25. VI. 1902.

Ileus durch strikturierendes Carc. flex. sigmoid. Resectio flex. sigmoid.

Seit 13 Tagen kein Stuhlgang, in den letzten Tagen keine Winde, $13 \mathrm{mal} 0,001$ Atropin subkutan!

Status. MäBig genährter Mann. Puls 100 regelmäBig. Art. deutlich geschlängelt. - Leib sehr stark aufgetrieben. Colon transv. und Colon ascendens stark gebläht, deutlich sichtbar. Per rectum nichts zu fühlen. 
Ein Beitrag zur Pathologie und Therapie des inneren Darmverschlusses. 513

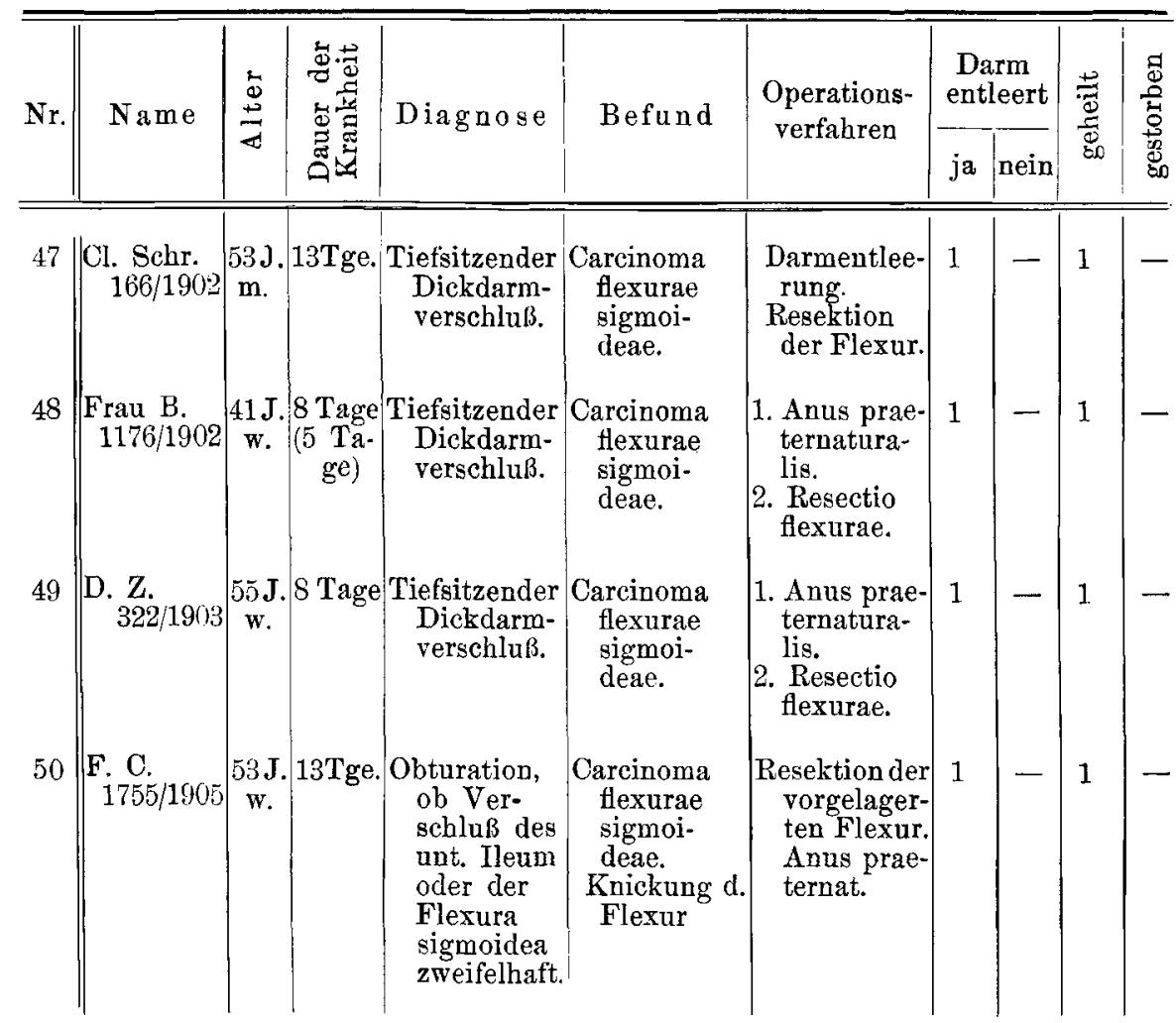

10. IV. hohe Einläufe ohne Erfolg, heute Nacht mehrfach erbrochen (nicht fäkulent).

Operation: Geh. Rat. Helferich. Chloroform Narkose. Med. Laparotomie ergibt walnußgroben, strikturierenden Tumor der unteren Flexura sigmoidea. Entleerung des Colon durch Punktion. Resektion der Flex. sig. and Vereinigung end to end.

26. VI. geheilt entlassen.

48. J.-N. 1176/1902. B., 41 Jahre, Händlersfrau. Ileus durch Carc. flex. sigmoid. Anus praeternat. Resectio flex. sigm. 24. X. 1902 bis 1. III. 1903.

Seit 3 Wochen Verstopfung. Seit 8 Tagen kein Stuhlgang, seit 5 Tagen keine Winde. Erbrechen. Kein Koterbrechen.

Status: Abdomen aufgetrieben. Von Zeit zu Zeit Darmsteifung im Colon descendens. Hinter dem Uterus höckrige Geschwulst, die etwas beweglich, die Bewegungen des Uterus nicht mitmacht. Per rectum nilil. Darmrohr am Promontorium umgeknickt.

Behandlung. 25. X. Anus praeternaturalis an der Flex. sigmoid. 
14. XI. Med. Laparotomie: Dr. Göbell. $8 \mathrm{~cm}$ oberhalb des Rektums derber, höckriger, strikturierender Tumor der Flexur: Resektion.

Fistelbildung vom oberen Rektumstumpf aus.

1. III. 1903 mit feiner Fistel entlassen.

49. J.-N. 322/1903. Z. D., 55 Jahre, Frau. Ileus durch Carc. flex. sigmoid. Anus praeternat. Resektion der Flex. sigm.

2. V. 1903 bis 27. VI. 1903.

Seit 5 Monaten heftige, anfallsweise auftretende Schmerzen im Leib. Obstipation. Seit 8 Tagen kein Stuhl, seit einigen Tagen keine Winde.

Abdomen stark aufgetrieben. In der linken Bauchseite sehr weite Schlinge ohne starke Peristaltik (Colon desc. Flexur), keine vermebrte Peristaltik. $20 \mathrm{~cm}$ oberhalb des Anus impermeables Hindernis. Kein Stuhlgang, keine Winde.

Behandlung. 3. V. 1903. Anus praeternat. in der Flex. sigmoidea.

22. V. 1903. Operation (Geh. Rat Helferich.): Resektion der Flex. sigmoid. welche ein strikt. Carc. trägt.

27. VI. 1903 geheilt entlassen.

50. J.-N. 1755/1905. F. C., 35 Jahre, Arbeiters Frau aus C. Aufnahme 13. II. 1906.

Carc. flex. sigmoideae. Darmverschlub.

Resectio flex. sigmoideae. Anus praeternat.

Anamnese: 1. II. 1906 heftiger Schmerz in der linken Bauchseite beim Wassereimerheben. Initiales Erbrechen. - (Schon einige Wochen lang schmerzhaftes Ziehen im Leib) Leib aufgetrieben, gespannt, kein Stuhlgang, keine Winde. Alle $1 / 2-1$ Stunde kolikartige Schmerzen. Erbrechen stets nach Nahrungsaufnahme, niemals kotig.

S tatus: Kleine Frau, nicht schwer krank aussehend. Puls regelmäBig von mittlerer Fülle und Spannung. Puls 112. Temperatar $38,0^{\circ}$. Abdomen stark aufgetrieben, aber keine Fafform. Leber in Kantenstellung. Stark vermehrte Peristaltik. Konfiguration des Bauches sehr wechselnd. Von Zeit zu Zeit bäumt sich im linken Hypogastrium eine von außen-oben nach innen-unten verlaufende dicke Darmschlinge mächtig auf. Auch in den übrigen Partien des Leibes lebhafte Darmbewegung. Cöcalgegend absolut ruhig. Kein cöcaler Meteorismus. Gestalt und Lage der sich steifenden Schlinge spricht für die Flexura sigmoidea. Uterus retroflektiert, links fixiert. Geringer Vaginalprolaps. Per rectum: hinter dem Corpus uteri liegt eine druckempfindlich geblähte Schlinge. Im Douglas anscheinend freier Erguß.

Diagnose: Obturationsileus, ob im unteren lleum oder der Flex. sigmoidea zweifelhaft.

Behandlung: Med. Laparotomie (Dr. Göbell). Geringes seröses Exsudat. Strikturierendes Carcinom der Flex. sigmoidea. Dasselbe liegt im kleinen Becken hinter dem retroflektierten Uterus, der nach hinten durch zahlreiche Adhäsionen fixiert ist. Carc. verschlieBt die Flexur nicht vollständig, Rektum füllt sich nach Aufheben der Knickung, folglich hat die Verlagerung des Tumors hinter das Corpus uteri mit als mechanisches 
Ein Beitrag zur Pathologie und Therapie des inneren Darmverschlusses. 515

Moment beim Herbeiführen des Darmverschlusses gewirkt. Entleerung des Dünndarms durch Punktion des Ileum. Resektion und Vorlagerung der Flex. sigmoidea durch eine zweite Wunde im linken Hypogastrium. Etagennaht der med. Wunde. -

Glatter Verlauf.

Fremdkörper.

\begin{tabular}{|c|c|c|c|c|c|c|c|c|c|c|}
\hline \multirow{2}{*}{ Nr. } & \multirow{2}{*}{ Name } & \multirow{2}{*}{$\begin{array}{l}0 \\
0 \\
\pm \\
\end{array}$} & \multirow{2}{*}{ 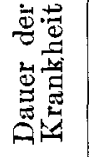 } & \multirow{2}{*}{ Diagnose } & \multirow{2}{*}{ Befund } & \multirow{2}{*}{$\begin{array}{l}\text { Operations- } \\
\text { verfahren }\end{array}$} & \multicolumn{2}{|c|}{$\begin{array}{c}\text { Darm } \\
\text { entleert }\end{array}$} & \multirow{2}{*}{$\frac{\overrightarrow{7}}{9}$} & \multirow{2}{*}{ 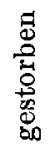 } \\
\hline & & & & & & & $\mathrm{ja}$ & nein & & \\
\hline 51 & C. K. ${ }_{1904}$ & $9 \mathrm{~J}$. & 5 Tage & $\begin{array}{l}\text { Obturations- } \\
\text { ileus des } \\
\text { Dünn- } \\
\text { darms. }\end{array}$ & $\begin{array}{l}\text { Spastische } \\
\text { Kontrak- } \\
\text { tion des } \\
\text { Dünn- } \\
\text { darms, } \\
\text { Spulwurm. }\end{array}$ & \begin{tabular}{|c|} 
Enterotomie, \\
Extraktion \\
des Spul- \\
wurms, \\
Darmnaht.
\end{tabular} & - & 1 & 1 & - \\
\hline 52 & M. L. & $\begin{array}{c}63 \mathrm{~J} . \\
\text { w. }\end{array}$ & 6 Tage & $\begin{array}{l}\text { Dünndarm- } \\
\text { verschluß. }\end{array}$ & $\begin{array}{l}\text { Gallenstein } \\
\text { im Dünn- } \\
\text { darm. }\end{array}$ & $\begin{array}{r}\text { Enterotomie, } \\
\text { Extraktion } \\
\text { des Steins, } \\
\text { Darmnaht. }\end{array}$ & - & 1 & 1 & 一 \\
\hline 53 & Fr. H. $_{1902}$ & $\begin{array}{l}32 \mathrm{~J} . \\
\text { w. }\end{array}$ & $1 \mathrm{Tag}$ & $\begin{array}{l}\text { Darmver- } \\
\text { schluß } \\
\text { durch Mur- } \\
\text { phyknopf. }\end{array}$ & $\begin{array}{l}\text { Murphy- } \\
\text { knopf im } \\
\text { Ileum. }\end{array}$ & $\begin{array}{c}\text { Enterotomie, } \\
\text { Extraktion } \\
\text { des Mur- } \\
\text { phyknopfs, } \\
\text { Darmnaht. }\end{array}$ & - & 1 & 1 & - \\
\hline
\end{tabular}

51. C. K., Schüler, 9 Jahre alt, aus N. Aufgenommen 19. VI. 04, entlassen 12. VII. 04 .

Spastischer Dünndarmverschluß (Ascaris).

Enterotomie, Extraktion des Wurms.

Anamnese: 14. VI. 04 abends Erbrechen und Leibschmerzen. Der hinzugezogene Arzt verordnete Abführmittel. Das Erbrechen und die Schmerzen nahmen zu. Erbrochen wurden immer grünliche Massen, die niemals kotig waren. Gestern abend, sowie heute vormittag wurde je ein Spulwurm erbrochen. Kein Fieber. - Vor 4 Wochen Diphtherie, seitdem dauernd kränklich; vielfach Husten.

Status: Kräftig gebauter, blasser Junge. Sensorium erhalten. Körperwärme leicht erhöht. Puls 120. Kein Aufstoßen. Etwas, nicht kotiges Erbrechen. Leib stark aufgetrieben. Leberdämpfung hochgedrängt, aber vorhanden. Das ganze Abdomen wird als druckempfindlich bezeichnet, nirgends eine besonders starke Schmerzhaftigkeit. Nirgends eine Resistenz fühlbar. In der Oberbauchgegend kann man deutlich verschiedene aufge- 
blähte Darmschlingen isoliert erkennen, zeitweise auch leichte peristaltische Bewegungen. Winde gehen nicht ab.

Sofortige Operation in Narkose: Mediane Laparotomie (Dr. Göbell). Peritoneum überall glatt und glänzend. Vorliegende Dünndarmschlingen gebläht. Nach Vorlagerung derselben sieht man sie nicht ganz scharf, sondern mehr allmählich in kollabierten Dünndarm übergehen. An der Übergangsstelle, die dem Ileum angehört, fühlt man einen gekrümmten Spulw urm im Inneren liegen. Kleine Incision und Extraktion des Wurms. Naht der Enterotomiewunde. Etagennaht.

21. VI. Temperatur gestern abend plötzlich 38,9, Puls 148. Kein Aufstoßen, kein Erbrechen. Kochsalzinfusion.

22. VI. Völliges Wohlbefinden. Puls nach kleinen Digitalisdosen wieder kräftig. Leib weich, seit gestern mittag Stuhl und reichlich Winde.

25. VI. Bis auf leichte Bronchitis Allgemeinzustand befriedigend. Pat. erholt sich zusehends, täglich normale Stuhlentleerung.

12. VII. Wunde glatt geheilt. Entlassung mit gut sitzender Bauchbinde. Pat. ist völlig beschwerdefrei.

52. J.-N. 1699/1904. M. L., Frau, 63 Jahre alt, aus K. Aufgenommen 4. III. 05, entlassen 25. III. 05. Gallensteinileus. Enterotomie. Extraktion des Steins.

An amnese: In der Jugend angeblich stets gesund. $6 \mathrm{mal}$ geboren, 3 Kinder sind erwachsen und gesund, 3 in frühester Jugend gestorben. Niemals Abort. Seit Jahren träger Stuhlgang. 27. II. 05 plötzlich heftiges reichliches Erbrechen, gleichzeitig starker Stuhldrang, den Pat. jedoch nicht befriedigen konnte, da sich in ihrer linken Bauchseite dem ein Hindernis entgegenzustellen schien. Winde gingen nicht ab. An den folgenden Tagen wiederholte sich das Erbrechen, seit vorgestern ist das Erbrochene übelriechend. Die Schmerzen zeitweise etwas stärker, aber niemals erheblich. Stuhl wurde während der ganzen Zeit nicht entleert. Früher nie Blut im Stuhl. Niemals Gelbsucht, nie Leibschmerzen oder Koliken.

Status: Kräftig gebaute ältere Frau in gutem Ernährungszustande, von guter Gesichtsfarbe. Temperatur 37,8. Puls 116, kräftig, regelmäBig. Herz ohne Befund.

Abdomen mäBig stark aufgetrieben, nirgends eine Resistenz in ihm fühlbar. Druckempfindlichkeit besteht nicht. Links unten nicht verschiebliche Dämpfung, die sonst in den abhängigen Partien nicht besteht. Leberdämpfung überragt nicht den Rippenrand, Milz nicht vergröBert. Rektalbefund negativ. Sehr häufiges fäkulentes Erbrechen.

Hoher Einlauf ohne Erfolg. Urin: Spuren von Albumen, kein Zucker.

6. III. 05 nachts und heute morgen nach der Magenspülung wiederholt kotig erbrochen.

Temperatur $37,1^{\circ}$, Puls 90.

Operation in Chloroform-Narkose. Mediane Laparotomie (Dr. Baum) umschneidet den Nabel. Dünndarmschlingen lebhaft gerötet, nur mäbig gebläht. Daneben quellen aus der Tiefe bleiche, nicht injizierte Darmschlingen von nur Kleinfingerdicke. An der Grenze zwischen weitem und engem Lumen fühlt man einen uber walnuBgroßen Tumor. Derselbe wird 
Ein Beitrag zur Pathologie und Therapie des inneren Darmverschlusses. 517

sofort als Gallenstein erkannt und durch Enterotomie entfernt. Katgutnaht der Schleimhaut, zweifache Lembert-Naht. Vernähung der Bauchwunde.

Abends Temperatur 38,8. Kotiges Erbrechen noch kurz nach der Operation, hat im Lauf des Tages völlig aufgehört. Opiumzäpfchen, Extr. Op. 0,05. Nachts Morphin 0,01.

9. III. Pat. entleert spontan normalen Stuhl. Völliges Wohlbefinden.

16. III. Entfernung der Nähte. Heilung p. p., Darmtätigkeit vollkommen normal.

25. III. Geheilt entlassen.

53. E. H., 32 Jahre, Lokomotivführers Frau in K. Aufgenommen 18. XI. 02, entlassen 21. I. 03. DarmverschluB durch Murphyknopf. Nach Gastroenterostomie. Enterotomie. Extraktion des Knopfes.

Pat. wurde wegen Ptosis und Dilatatio ventriculi am 21. XI. 02 operiert. Es wurde die Gastroenterostomia retrocolica posterior mit Murphyknopf (Dr. Göbell) ausgeführt. Am 2. XII. 02, am elften Tage nach der Operation Erbrechen, am 4. XII. 02 links Relaparotomie (Geh. Rat Helferich) wegen Circulus vitiosus. Murphyknopf verschwunden. Abführender Jejunumteil durch Adhäsion und Narbenstränge so gedreht, daBs er undurchgängig geworden war. Gegenüber der Anastomosenstelle war die Dünndarmwand narbig verändert. Eine erweiternde Plastik führte nicht zum Ziele. Am 6. XII. 02 II. Relaparotomie (Dr. Göbell) und Enteroanastomose, zwischen zu- und abführendem Darm (mit Naht). Am 26. XII. 02 Leibschmerzen, Kolik, vermehrte Peristaltik. Winde und Stuhl vorhanden. 28. XII. 02. Inmer noch derselbe Zustand. Ursache: Murphyknopf im Douglas zwischen Rektum und Vagina gut beweglich im Dünndarm liegend zu fühlen.

3. I. 03. Versuche, erst mit Physostigmin salicyl., dann mit Atropin und Abführmitteln den Knopf zu befördern, mißlingen. Kein Stuhlgang, keine Winde. Deshalb im I. Ätherrausch: Laparotomie (Geh. Rat Helferich). Im Ileum, dessen Serosa etwas injiziert, Murphyknopf, nicht fixiert. Enterotomie, Extraktion des Knopfes. Darmnaht. Etagennaht der Bauchwunde.

21. I. 03 geheilt entlassen.

54. J.-N. 1546/1905. S. Schn, 43 Jahre, Landmannsfrau aus W. Aufnalime 8. I. 06, entlassen 12. II. 06. Chronischer DarmverschluB durch Peritonitis tub. Laparotomie.

An amnese: Anfang November 1905 nachts Erbrechen, morgens Durchfälle. Seit Anfang Dezember 1905 Obstipation. Seit Anfang Januar Erbrechen, anfangs gallig, dann sehr reichlich und von fäkulentem Geruch. Dabei lieB sich durch Klysmata immer noch Stuhl erzielen, der geformt und von normaler Farbe. Urin: starker Indikangehalt.

Status: Abgemagerte Frau. Puls 120, mittelkräftig, nicht ganz regelmäBig. Abdomen aufgetrieben, Bauchdecken gespannt. Dämpfung in den abhängigen Partien, kein freier FlüssigkeitserguB. Im rechten Hypogastr. und unter dem Nabel scheibenförmiger Tnmor. Im linken Hypogastrium einzelne geblähte Darmschlingen. Uterus nach abwärts und links verlagert. Im Douglas nnd links vom Uterus Druckempfindlichkeit. Magen- 
518 XXV. GöBeLt, Ein Beitr. z. Pathol. u. Ther. d. inneren Darmversehlusses.

spülung, fäkulenter Inhalt. Auf 3 Liter Einlauf weicher Stuhl, spärliche Winde.

Behandlung: Morph.-Chloroform-Narkose. Mediane Laparotomie (Geh. Rat Helferich) legt eine intraperitoneale von Netz und Därmen gebildete, mit Knötchen versehene, breite, gleichmäßige Fläche frei. Oberhalb des Nabels kann man einzelne verklebte Dünndarmschlingen präparieren. Es wird darauf verzichtet, das Passagehindernis zu suchen, weil unmöglich. Deshalb Tamponade, Situationsnähte. Verband. Verlauf: Es gelingt, die Nachbehandlung so zu leiten, daB die Darmfunktion auch ohne Klistiere normal ist und die Nahrungsaufnahme gut vonstatten geht. Laparotomiewunde am 10. II. zum gröBten Teil geschlossen. Da der psychische $\mathrm{Zu}$ stand der Patientin zu wünschen übrig läßt, am 12. II. 06 nach Hause entlassen. 